\title{
AUTOMATED CRACK IDENTIFICATION \\ FOR CEMENT PASTE
}

\author{
by \\ Kirk W. Ketcham \\ Francisco A. Romero \\ David Darwin \\ Shanglong Gong \\ Mohamed Nagib Abou-Zeid \\ Jeffrey L. Martin
}

\section{A Report on Research Sponsored by \\ THE AIR FORCE OFFICE OF SCIENTIFIC RESEARCH Research Grant \\ AFOSR-89-0296}

SM Report No. 34

UNIVERSITY OF KANSAS

LAWRENCE, KANSAS

April 1993 


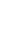




\section{REPORT DOCUMENTATION PAGE}

1a. REPORT SECURITY CLASSIFICATION

Unclassified

2a. SECURTYY CLASSIFICATION AUTHORITY

2b. DECLASSIFICATION/OOWNGRADING SCHEDULE

4. PERFORMING ORGANIZATION REPORT NUMBER(S)

SM Report No. 34

6a. NAME OF PERFORMING ORGANIZATION

University of Kansas

Center for Research, Inc.

Ec. ADDRESS (City, State, and ZIP Code)

Lawrence, KS 66045

8a. NAME OF FUNDING / SPONSORING

ORGANIZATION

8c. ADDRESS (City, State, and ZIP Code)

8b. OFFICE SYMBOL

(If applicable)

16. RESTRICIVE MARKINGS

3. DISTRIBUTION/AVAILABILITY OF REPORT

Approved for public release; distribution

is unlimited.

5. MONITORING ORGANIZATION REPORT NUMBER(S)

6b. OFFICE SYMBOL

(If applicable)

7a. NAME OF MONITORING ORGANIZATION

Air Force office of Scientific Research

7b. ADDRESS (City, State, and ZIP Code)

AFOSR/NA

Bolling Air Force Base

Washington, DC 20332

9. PROCUREMENT INSTRUMENT IDENTIFICATION NUMBER

AFOSR-89-0296

10. SOURCE OF FUNDING NUMBERS

\begin{tabular}{|l|l|l|l}
\hline $\begin{array}{l}\text { PROGRAM } \\
\text { ELEMENT NO. }\end{array}$ & $\begin{array}{l}\text { PROIECT } \\
\text { NO. }\end{array}$ & $\begin{array}{l}\text { WORK UN } \\
\text { NOCCESSION NO }\end{array}$ \\
\hline
\end{tabular}

11. TITLE (Include Security Classification)

Automated Crack Identification for Cement Paste

12. PERSONAL AUTHOR(S)

K. W. Ketcham, F. A. Romero, D. Darwin, S.-L. Gong, M. N. Abou-Zeid, and J. L. Martin

\begin{tabular}{l|l|l|l|l}
\hline 13a. TYPE OF REPORT & 13b. TIME COVERED & 930413 & DATE OF REPORT (Year, MONTh, Day) \\
\hline
\end{tabular}

16. SUPPLEMENTARY NOTATION

\begin{tabular}{|l|c|c|}
\hline 17. & \multicolumn{2}{|c|}{ COSATI CODES } \\
\hline FIELD & GROUP & SUB-GROUP \\
\hline & & \\
\hline & & \\
\hline
\end{tabular}

18. SUBJECT TERMS (Continue on reverse if necessary and identify by block number) backscattered electron imaging, backscattering coefficient, calibration, cement paste, cracking, epoxy impregnation, gray levels, hydration, image acquisition, image analysis,

19. ABSTRACT (Continue on reverse if necessary and identify by block number)

The development of an automated procedure for the identification of microcracks in cementitious materials is described. The degree and nature of microcracking is measured using backscattered electron images obtained with an integrated scanning electron microscope/image analysis system. Multiple images for specimens are analyzed using a computer program developed to identify and measure microcracks within the individual phases of cement paste. The procedure is developed to assist in the determination of the roles played by individual phases in cement paste in the formation and propagation of microcracks. Procedures for specimen testing, preparation, imaging, and crack analysis are described, along with a description of the development of the analysis program. The analysis capabilities of the program are demonstrated.

The gray level of epoxy-filled cracks in polished cement paste specimens is affected by the atomic number density of underlying and adjacent phases. As a result, cracks cannot be identified based on gray level alone. Epoxy-filled cracks in polished cement paste specimens can be identified based on local changes in gray level and the application of geometric requirements; and combined procedures that establish the floor of a crack, minimum gradient and gray level adjacent to cracks, and minimum differences in gray level between the floor of a crack and adjacent solid phases provide a reproducible and consistent technique for crack identification in cement paste.

\begin{tabular}{|c|c|c|c|}
\hline $\begin{array}{l}\text { 20. DISTRIBUTION / AVAILABILITY OF ABSTRACT } \\
\square \text { UNCLASSIFIEDUNLIMITED } \square \text { SAME AS RPT. }\end{array}$ & $\square$ DTIC USERS & \multicolumn{2}{|c|}{$\begin{array}{l}\text { 21. ABSTRACT SECURITY CLASSIFICATION } \\
\text { UnClassifed }\end{array}$} \\
\hline $\begin{array}{l}\text { 22a. NAME OF RESPONSIBLE INDIVIOUAL } \\
\text { Dr. Spencer } \mathrm{T} \text {. Wu }\end{array}$ & & $\begin{array}{l}\text { 22b. TELEPHONE (Include Area Code) } \\
\text { (202) 767-6962 }\end{array}$ & $\begin{array}{l}\text { 22C. OFFICE SYMBC } \\
\text { AFOSR /NA }\end{array}$ \\
\hline
\end{tabular}


Report Documentation Page, cont'd.

18. Subject Terms, continued:

microstructures, phases, polishing, quantitative analysis, standard, voids. 
iii

\section{ACKNOWLEDGEMENTS}

This report is based on research performed by Kirk W. Ketcham and Franciso A. Romero in partial fulfillment of the requirements for the MSCE degree from the University of Kansas.

The research was supported by the Air Force Office of Scientific Research under grant AFOSR-89-0296.

Cement was donated by Ash Grove Company. 



\section{TABLE OF CONTENTS}

Page

REPORT DOCUMENTATION PAGE $\ldots \ldots \ldots \ldots \ldots \ldots \ldots \ldots \ldots \ldots$ ii

ACKNOWLEDGEMENTS $\ldots \ldots \ldots \ldots \ldots \ldots \ldots \ldots \ldots \ldots \ldots \ldots \ldots$

LIST OF TABLES $\ldots \ldots \ldots \ldots \ldots \ldots \ldots \ldots \ldots \ldots \ldots \ldots \ldots$

LIST OF FIGURES $\ldots \ldots \ldots \ldots \ldots \ldots \ldots \ldots \ldots \ldots \ldots \ldots \ldots$

CHAPTER 1 INTRODUCTION $\ldots \ldots \ldots \ldots \ldots \ldots \ldots \ldots \ldots \ldots \ldots \ldots \ldots$

CHAPTER 2 EXPERIMENTAL PROCEDURES $\ldots \ldots \ldots \ldots \ldots \ldots \ldots$

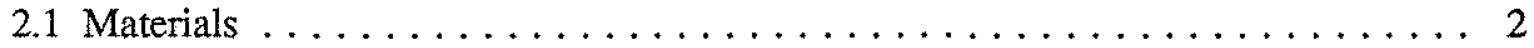

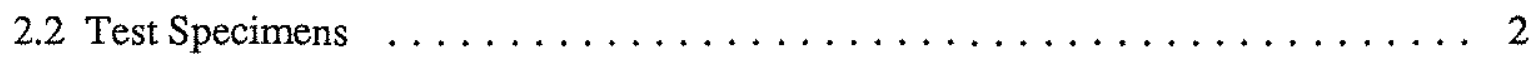

2.3 Loading System $\ldots \ldots \ldots \ldots \ldots \ldots \ldots \ldots \ldots \ldots \ldots \ldots \ldots \ldots$

2.4 Stress and Strain Measurements $\ldots \ldots \ldots \ldots \ldots \ldots \ldots \ldots \ldots \ldots \ldots$

2.5 High-Speed Data Acquisition $\ldots \ldots \ldots \ldots \ldots \ldots \ldots \ldots \ldots \ldots \ldots \ldots$

2.6 SEM Specimen Preparation $\ldots \ldots \ldots \ldots \ldots \ldots \ldots \ldots \ldots \ldots \ldots \ldots \ldots \ldots$

2.7 SEM Imaging and SEM/IAS Calibration $\ldots \ldots \ldots \ldots \ldots$

2.8 Determination of Intensity Ranges for Standard Threshold File . . . . . . . . 11

2.9 Acquiring a Calibrated Cement Paste Image $\ldots \ldots \ldots \ldots \ldots \ldots \ldots$

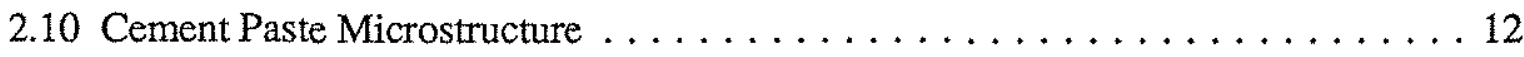

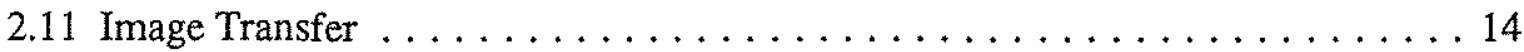

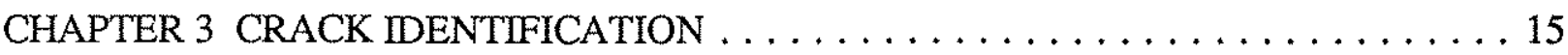

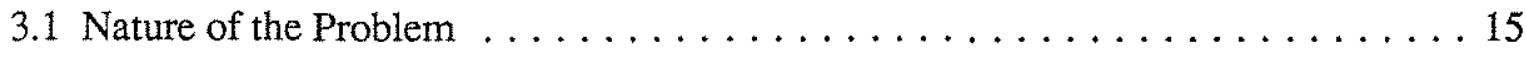

3.2 Graphics Capabilities of Program $\ldots \ldots \ldots \ldots \ldots \ldots \ldots \ldots$

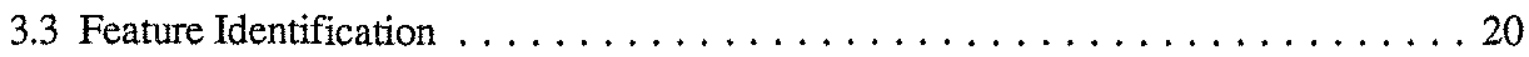

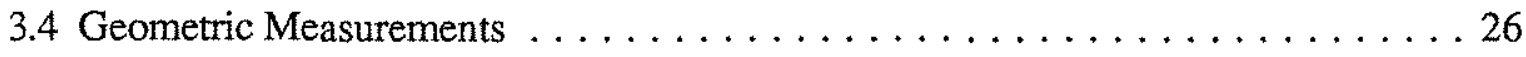

3.5 Differentiation of Crack and Noncrack Features $\ldots \ldots \ldots \ldots$

3.6 Identification of Phases Adjacent to Cracks $\ldots \ldots \ldots \ldots \ldots$ 
TABLE OF CONTENTS (continued)

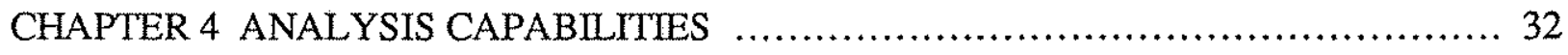

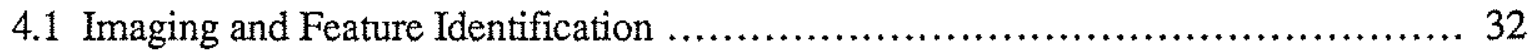

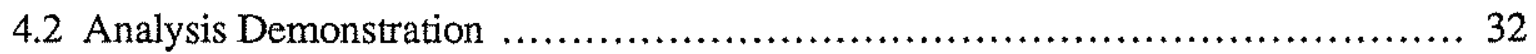

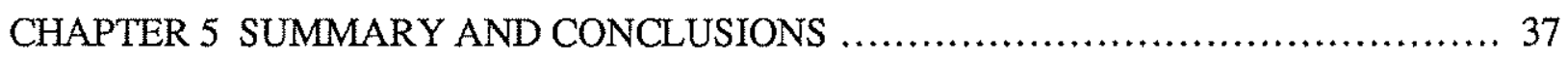

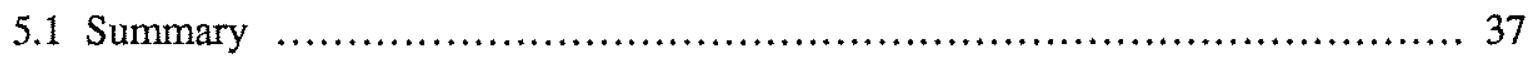

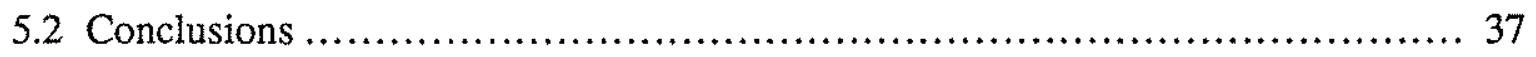

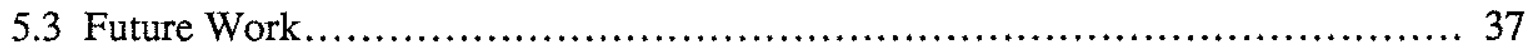

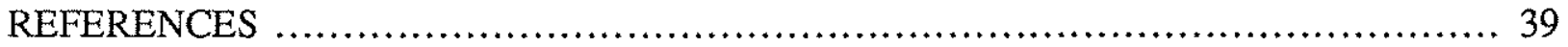

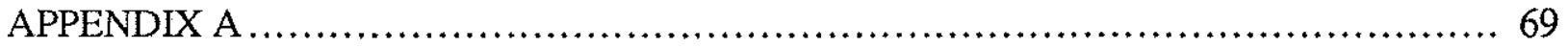




\section{LIST OF TABLES}

Table

2.1 Analysis of cement using $x$-ray analysis

2.2 Silicon ( $\mathrm{Si}$ ) and magnesium ( $\mathrm{Mg}$ ) standard gray level threshold settings (Silicon / Magnesium $=+2 /-10.5$ )

2.3 Cement paste gray level threshold settings of 28 -day old $(w / c=0.5)$ cement paste (Silicon $/$ Magnesium $=+2 /-10.5$ )

3.1 Red, green and blue intensity combinations for phase and crack thresholding

4.1 Area percent analysis of 28 -day old $(w / c=0.5)$ cement paste at 0 and6000 microstrain including the number of frames required for 95 percent confidence that the area percent is within 10 percent of the measured value $-2020 x$ Magnification ...

4.2 Mean crack density (using perimeter divided by 2) for phase and phase boundary cracking of 28-day old (w/c $=0.5)$ cement paste at 0 and 6000 microstrain including the number of frames required for 95 percent confidence that the mean crack density is within 10 percent of the measured value $-2020 x$ Magnification .....

4.3 Percentage of total crack length (using perimeter divided by 2) for different crack orientation and crack size ranges of 28-day old $(\mathrm{w} / \mathrm{c}=0.5)$ cement paste at 0 and 6000 microstrain $-2020 \mathrm{x}$ Magnification

4.4 Percentage of total crack length (using projected length) for different crack orientation and crack size ranges of 28-day old $(w / c=0.5)$ cement paste at 0 and 6000 microstrain $-2020 \times$ Magnification 


\section{LIST OF FIGURES}

Figure

2.1 BSE image of the $\mathrm{Si} / \mathrm{Mg}$ standard at a magnification of $300 \mathrm{x}$

2.2 The artificial scale on the SEM videoscope screen ............................ 47

3.1 Effect on resolution of narrow epoxy filled cracks....................... 48

3.2 Effect on resolution of wide epoxy filled cracks ........................... 49

3.3 Graphical and integer representations of a line scan through a crack ........... 50

3.4 The floor of a feature (crack), the transition and plateau regions along a line scan

3.5 Minimum required value of $I_{\text {dif }}$ as a function of distance away from the edge pixel

3.6 Perimeter squared to area ratio versus projected length for cracks ............. 53

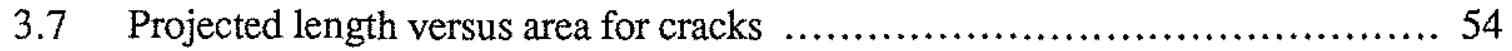

3.8 Requirement for perimeter squared to area ratio versus projected length (Cracks and Noncracks).

3.9 Requirement for projected length versus area (Cracks and Noncracks) .........56

4.1 a Basic BSE gray level image of 28 -day old $(w / c=0.5)$ cement paste at 6000 microstrain .................................................. 57

4.1b Thresheld pseudo-color image of Fig 4.1a .............................. 58

4.1c Cracks identified by computer program for Fig 4.1a ........................ 59

4.2a Basic BSE gray level image of 28-day old $(w / c=0.5)$ cement paste at 6000 microstrain 60

4.2b Thresheld pseudo-color image of Fig 4.2a .............................. 61

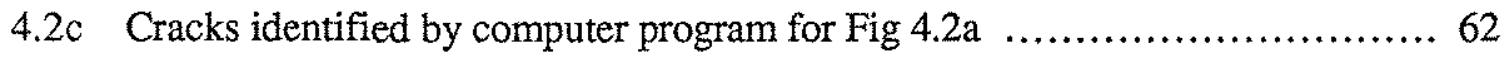

4.3 Schematic of computer display showing gray level image of cement paste with cracks identified based on type of cracking (original magnification $=2020 \mathrm{x}$ )

4.4 Stress-strain curves of 28-day old $(w / c=0.5)$ cement paste loaded to 6000 microstrain and failure

4.5 Cumulative crack density, as measured using perimeter divided by 2 , versus the crack size perimeter divided by 2 of 28 -day old $(w / c=0.5)$ cement paste at 0 and 6000 microstrain $-2020 \times$ Magnification 


\section{LIST OF FIGURES (continued)}

Figure $\quad$ Page

4.6 Cumulative crack density, as measured using projected length, versus the crack size projected length of 28 -day old $(w / c=0.5)$ cement paste at 0 and 6000 microstrain $-2020 x$ Magnification

4.7 Crack distribution by crack orientation ( 20 degree increments) based on perimeter divided by 2 of 28 -day old $(w / c=0.5)$ cement paste at 0 and 6000 microstrain. Scanned area taken perpendicular to the axis of loading - 2020x Magnification

4.8 Crack distribution by crack orientation (20 degree increments) based on projected length of 28 -day old $(w / c=0.5)$ cement paste at 0 and 6000 microstrain. Scanned area taken perpendicular to the axis of loading - 2020x Magnification

A.1 Apparatus for epoxy impregnation of cement paste specimens 



\section{CHAPTER 1 INTRODUCTION}

The purpose of this report is to describe the development of a procedure for automated identification of microcracks in cementitious materials. The degree and nature of microcracking is measured using backscattered electron images obtained with an integrated scanning electron microscope/image analysis system. Multiple images of each specimen are analyzed using a computer program developed to identify and measure microcracks within the individual phases of cement paste. This information can be used to determine the roles played by the phases in cement paste in the formation and propagation of microcracks.

Analysis is carried out using a FORTRAN program that identifies cracks within the cement paste matrix and designates the phases and/or phase boundaries on which the cracks have formed. The program was developed to: 1) eliminate the subjectivity that occurs when cracks are identified by the human eye, especially in cases where the definition of what constitutes a crack is somewhat vague or arbitrary, 2) consistently identify and measure cracks, phases, and other features over any period of time, as long as the input parameters remain unchanged (input parameters are variables used by the program to identify cracks, boundary cracking, etc.), and 3) rapidly analyze the large number of images required to establish a satisfactory statistical level of confidence in the analysis. The program can accomplish these tasks over an indefinite period without suffering from the debilitating effects upon operator judgment caused by fatigue.

Specimen preparation and imaging procedures developed by Zhao and Darwin (1990, 1992) and crack identification techniques developed by Martin (1990) serve as the starting points for the work reported here. Zhao and Darwin $(1990,1992)$ developed procedures for reproducible qualitative backscattered electron analysis of cement paste, Martin (1990) demonstrated that cracks could be isolated in digital images of cement paste based on differences in gray level intensity. The specific procedures are described in this report. 


\section{CHAPTER 2 \\ EXPERIMENTAL PROCEDURES}

To carry out this study and demonstrate the techniques, cement paste specimens with a water-cement ratio, w/c, of 0.5 are studied. No admixtures were used. Twenty-eight day old specimens were loaded in compression at a strain rate of 3 microstrain/sec to 6000 microstrain and compared to a nonloaded specimen. A companion specimen was loaded to failure.

\subsection{Materials}

Cement: Type I Portland cement, Ash Grove brand, with the following composition (based on $x$-ray analysis) was used: tricalcium silicate $=53.0 \%$, dicalcium silicate $=20.0 \%$, tetracalcium aluminoferrite $=10.0 \%$, and tricalcium aluminate $=9.0 \%$ (Table 2.1) .

\subsection{Test Specimens}

As fabricated, the test specimens were 1 in. square $(25.4 \mathrm{~mm})$ in cross section by $5 \mathrm{in}$. (127 mm) in length, as described by Harsh et al. (1989).

Cement paste was mixed according to ASTM C 305, except the final 20 percent of the water was added after the first mixing period, and the mixing time was doubled to obtain a better dispersion of the materials.

Following the procedure used by Cong et al. $(1990,1992)$, the specimens were cast vertically in groups of six. The molds were oiled prior to casting, and the joints were sealed with modeling clay to prevent moisture loss. The molds were filled in three equal layers. Each layer was hand-rodded 25 times using a $1 / 4$ in. $(6 \mathrm{~mm})$ diameter steel rod and then consolidated on a vibrating table at a frequency of $60 \mathrm{cycles} / \mathrm{sec}$ and amplitude of $0.006 \mathrm{in}$. $(150 \mu \mathrm{m})$ for $11 / 2 \mathrm{~min}$. During the first 24 hours, the molds were stored in the laboratory in a horizontal position to minimize the effects of bleeding. Specimens were then removed from the molds and cured in lime-saturated water until the time of testing.

Prior to testing, the specimens were shortened to a length of 3 in. $(76 \mathrm{~mm})$ by removing equal portions from each end using a high-speed masonry saw, taking special care to keep the 
sawed surfaces perpendicular with the length of the specimen. Each specimen was wrapped in plastic, secured by rubber bands on both ends, to avoid the loss of moisture during testing.

\subsection{Loading System}

Specimens were tested in the strain control mode using an Instron (Model No. 1334) 110,000 pound (55 ton) capacity closed-loop servo-hydraulic testing machine, following the procedure used by Harsh et al. (1989). A freshly mixed layer of high-strength gypsum cement (Hydrostone) was placed on both ends of the specimen. The specimen was placed between two flat, nonrotating platens by centering and gently pressing it onto the lower platen. Next, the bottom platen was raised slowly (with the actuator in the stroke control mode), bringing the top layer of Hydrostone in contact with the upper platen. The specimen was twisted gently and continuously by hand while the lower platen was further raised in small increments, allowing the Hydrostone to squeeze out between the specimen ends and the platens. The Hydrostone layers obtained at each end of the test specimen were less than 0.01 in. $(250 \mu \mathrm{m})$ thick and provided flat, uniform bearing surfaces at both platens. The Hydrostone layers were allowed to dry for at least 30 min. prior to conducting the tests. Since Hydrostone expands as it sets, the actuator was operated in load control mode with a load of approximately $50 \mathrm{lb}(220 \mathrm{~N})$. This allows the Hydrostone to expand without subjecting the specimen to higher compressive loads. Once the Hydrostone dries, the actuator was placed in strain control mode so that the overall specimen length, including the thickness of the two Hydrostone layers, could be measured just prior to the test.

\subsection{Stress and Strain Measurements}

The axial (compressive) load on the specimens is measured using an Instron load cell, Model 3156-115. The average axial strain in the test specimens is measured using a pair of Schaevitz linear variable differential transformers (LVDT's), Model No. 050 MP. The LVDT's also serve as the controlling transducers for the closed-loop test machine during strain-controlled loading (Harsh et al. 1989). The LVDT's have a range of $\pm 0.05 \mathrm{in} .( \pm 1.27 \mathrm{~mm})$ and a calibrated scale factor of 119.86 volts/in. (4.7189 volts $/ \mathrm{mm})$. The LVDT's (core and housing) are clamped 
to the lower platen at equal distances from opposing faces of the specimen. The LVDT core rods are fixed to the upper platen, parallel to the specimen's longitudinal axis, so that they will enter the LVDT cores when the lower platen is raised. Since the voltage induced in the LVDT core is related linearly to the position of the LVDT core rod in the core housing, the displacement of the system is measured by recording the induced voltage. The two axial deformations (in terms of voltage) are for the total height of the specimen. These measurements are converted to average axial strain in the specimen by dividing the voltages by the measured specimen height and by the LVDT scale factor.

\subsection{High-Speed Data Acquisition}

A Hewlett-Packard measurement plotting system, Model No. 7090A, was used to acquire the experimental stress-strain data (Harsh et al. 1989). This system can simultaneously scan up to three transducer channels and store up to 1000 readings on each channel over a period that may range from 30 milliseconds to 24 hours. Following a test, the data were transferred to a Hewlett-Packard Vectra ES/12, 286 series personal computer for storage and later transferred to an Apollo 3500 series workstation for further analysis.

\subsection{SEM Specimen Preparation}

After loading, the specimens were sectioned into transverse and longitudinally oriented, wafers ( $1 \mathrm{~mm}$ thick by $1 \mathrm{in.}$ by $1 \mathrm{in}$.) using a Buehler Isomet low speed diamond wafering saw. Specimen wafers were placed in a sonicator bath containing ethanol for two minutes, then placed in an oven at $105^{\circ} \mathrm{C}$ to terminate the hydration process.

After removal from the oven, the specimens were placed in a vacuum desiccator to prevent any additional hydration. Within two days of removal from the oven, the specimens were glued, with the surface to be viewed in the scanning electron microscope (SEM) facing up, onto a prepared epoxy base in preparation for vacuum-impregnation with an ultra-low viscosity epoxy (See Appendix A for details on the epoxy-impregnation procedure and preparation of the epoxy base). Epoxy impregnation prevents damage to the specimen because the epoxy penetrates into the cement 
and, after hardening, supports the cement microstructure and keeps debris out of the cracks and voids during polishing. Because of its low mean atomic number, the epoxy, which fills cracks and voids within the cement paste microstructure, appears black in a backscattered electron (BSE) image of cement paste.

Following polymerization (curing and hardening) of the epoxy, the one square-in. wafers were sectioned into four ( $12.5 \mathrm{~mm}$ by $12.5 \mathrm{~mm}$ ) specimens, small enough so that several specimens could be placed into the SEM chamber at one time. One of the four specimens was polished by hand using progressively finer grades of silicon carbide $(\mathrm{SiC})$ paper and diamond paste; the three remaining ones were retained as backup specimens. Polishing began with 150 grade $\mathrm{SiC}$ paper, proceeding to $320,600,1000$, and 2000 grades; followed by $3.0,1.0$ and 0.5 micron diamond polishes. After each stage of polishing, the specimen surface was carefully cleaned with a dry, lint-free cloth and a commercial compressed gas cleaner (The compressed gas cleaner used does not contain chloro-fluorocarbons, which are harmful to the earth's ozone layer).

A jig was used to insure that the specimens would be the same height as a silicon/magnesium (Si/Mg) standard used to calibrate the BSE image. Because the specimen heights were the same, several specimens could be studied in the SEM chamber at one time without adjusting the height of the specimen stage [The reader is referred to Zhao and Darwin $(1990,1992)$ for information regarding development of the Si/Mg standard]. A piece of teflon was placed at the bottom of the jig to protect the polished specimen surface. The specimens were placed in the jig, viewing surface down, and ground down to the level surface of the jig with 60 and 150 grade SiC papers, after the viewing surface had been polished up to 1000 grade SiC paper. After obtaining the correct specimen height, polishing continued with 2000 grade SiC paper. Since the grain size of the 2000 grade $\mathrm{SiC}$ paper is 3 micron, polishing with 2000 grade paper and finer diamond paste does not cause an appreciable change in specimen height.

It is important that the polishing process allow some epoxy to be left covering the viewing surface of the specimen after polishing with 600 grade paper. Ideally, the thin layer of epoxy remaining on the viewing surface should be removed using the 1000 and 2000 grade $\mathrm{SiC}$ paper. 
This procedure insures that deep scratches, caused by SiC paper coarser than 1000 grade, are not left on the cement paste surfaces.

A dry cloth was used, rather than a solvent, for cleaning the specimen surface to prevent dissolution of any of the cement paste constituents or the epoxy. Also, a different cleaning cloth was used for each stage of polishing to prevent contamination of the surface by larger particles, which cause severe scratching of the specimen surface. When polishing with 0.5 micron diamond paste was complete, all diamond paste residue was removed by wetting a cloth with a few drops of ethanol and quickly wiping the polished surface. Care was necessary, since the epoxy is somewhat soluble in ethanol, and prolonged contact with the ethanol can cause dissolution of the epoxy from the cement paste matrix.

The entire polishing process, beginning with the 150 grade $\mathrm{SiC}$ paper and ending with the 0.5 micron diamond paste, took about two to three hours per specimen.

Between each polishing step (using the $\mathrm{SiC}$ paper up through the use of the 2000 grade paper), a light microscope was used to determine when the specimens were properly polished. Proper polishing is attained when all scratches in the epoxy surface are the same size as the SiC particles on the paper, or smaller. As a final check on surface quality, specimens were coated with $20 \mathrm{~nm}$ of gold-palladium in a sputter coater to increase the visibility of scratches on the cement surface under the light microscope. Specimens were also checked using the SEM with secondary electron imaging to measure the width of any surface scratches. If the quality of the surface preparation was deemed inadequate, the gold-palladium layer and the surface scratches were removed using 2000 grit $\mathrm{SiC}$ paper, followed by progressively finer grades of diamond paste.

Once satisfactory polishing was completed, specimens were mounted on aluminum SEM stubs and coated with $20 \mathrm{~nm}$ of gold-palladium. The specimens were now ready for BSE imaging using the SEM.

\subsection{SEM Imaging and SEM/IAS Calibration}

The cement paste specimens were studied using a Philips 515 scanning electron microscope (SEM) fitted with a backscattered electron detector (BSD) consisting of four tilted solid state 
detectors on a swing-away arm. Images were acquired using a Lemont image analysis system (IAS), and analyzed using an Apollo DN 3500 workstation.

The SEM parameters used in the acquisition of BSE images of the cement paste specimens were: accelerating voltage $=25.0 \mathrm{keV}$, beam current $=5.0 \times 10^{-10} \mathrm{~A}$, free working distance $(\mathrm{FWD})$ $=25.5 \mathrm{~mm}$, stage tilt $=0^{\circ}$, wehnelt bias resistance setting $=1$ (highest setting), wehnelt aperture to filament tip distance $=0.25 \mathrm{~mm}$, and spot size approximately $=100 \mathrm{~nm}$. The FWD is defined as the distance between the final aperture in the electron optical column and the specimen surface. Up to six SEM specimens, a Faraday cup, and a Si/Mg standard can be secured on a multiple specimen stage (MSS) and placed in the SEM chamber for imaging. Once a high vacuum is achieved in the SEM, the high voltage switch is enabled, and current is provided to the tungsten filament. Filament current is increased until the secondary electron (SE) signal picked up by the Everhart-Thornley (SE) detector shows that the filament is saturated. Saturation of the filament insures a stable beam current, since the plot of beam current versus filament current reaches a plateau at saturation. Therefore, a small change in filament current results in no significant increase in electron beam current. This allows for a more stable beam current to be maintained, resulting in a more quantitatively accurate and reproducible process. Once the filament has been saturated, the SEM specimens on the multiple specimen stage are imaged, first using the SE detector.

Initially, the Faraday cup is positioned directly under the pole piece of the SEM and centered. The pole piece is located at the very bottom of the electron optical column, which uses a system of electromagnetic lenses to focus the electron beam. The pole piece contains a small aperture (200 microns in diameter) that separates the optical column from the SEM specimen and detector chamber. The pole piece allows the focused electron beam to enter the chamber, where the beam strikes the specimen perpendicular (in this study) to the specimen surface. Magnification is increased until the entire electron beam enters the aperture centered at the top surface of the Faraday cup. The current in the electron beam is absorbed by the carbon stub that comprises the remainder of the Faraday cup. Using the Faraday cup, the beam current is adjusted to $5.0 \times 10^{-10} \mathrm{~A}$. This beam current corresponds to an electron beam diameter of approximately $100 \mathrm{~nm}$ on the specimen 
surface at a free working distance (FWD) of $25.5 \mathrm{~mm}$. A $100 \mathrm{~nm}$ beam or probe diameter was selected to match the picture element (pixel) size in the digitized image. This insures optimum resolution of the microcracks present in the cement paste microstructure, since clear resolution can be attained with probe diameters up to twice the pixel size (Goldstein et al. 1992).

The beam is kept on for approximately 30 minutes prior to the analysis to allow the wehnelt and filament to reach equilibrium due to the thermal expansion of the two elements. The heated filament will begin to expand towards the wehnelt aperture before the wehnelt can expand forward, causing a higher initial beam current due to the shorter distance between the filament tip and the wehnelt aperture. After approximately 30 minutes, the wehnelt will have heated enough to expand forward to where the distance between the filament tip and wehnelt aperture will remain constant, thereby, insuring a fairly constant beam current during the analysis.

After 30 minutes, the beam current is adjusted back to $5.0 \times 10^{-10} \mathrm{~A}$, and the multiple specimen stage (MSS) is rotated until the $\mathrm{Si} / \mathrm{Mg}$ standard can be imaged at a magnification of $300 \mathrm{X}$. The $\mathrm{Si} / \mathrm{Mg}$ standard is positioned in the MSS so that the interface between the silicon wafer and the polished magnesium surface is vertically oriented within the viewing field, with the silicon on the left-hand side of the SEM image (see Fig. 2.1).

The Si/Mg standard is used to calibrate the BSE signal on the SEM video monitor. A readily identifiable position along the $\mathrm{Si} / \mathrm{Mg}$ interface should be selected to provide a consistent signal. Positioning a horizontal line scan across the same region along this interface eliminates variability in signal amplification due to slight inconsistencies in the Si and $\mathrm{Mg}$ signals at different positions in both materials. This is important, since a quantitative image analysis procedure requires that the image collection conditions, ie., SEM parameters, detector amplification, and IAS amplification, be the same each time that images are collected and analyzed (NOTE: It is a good practice to focus the electron beam on a specimen at a magnification about one order of magnitude higher than the magnification selected for imaging, due to the smaller depth of field at higher magnifications. This insures proper focusing of the electron beam on the specimen surface at the lower, desired magnification. For example, if an image of this specimen is desired at $300 \mathrm{X}$, 
focusing of the image should take place at a magnification between 1000 and $3000 \mathrm{X}$. The resulting beam focus provides a sharp image on the cathode ray tube, or viewing screen, because the electron beam diameter is smallest immediately at the surface of the specimen).

With the image of the Si/Mg interface positioned as in Fig. 2.1, a horizontal line scan, obtained by switching the SEM beam raster to line mode, is centered at the same position along the $\mathrm{Si} / \mathrm{Mg}$ interface.

As described by Zhao and Darwin $(1990,1992)$, an artificial scale superimposed on the SEM videoscope, as shown in Fig. 2.2, is used to quantify the BSE detector amplification. The signal saturation lines lie at +25 and -25 on the artificial scale.

After positioning the horizontal line scan (immediately below the edge fracture in this case), the solid-state BSE detectors are used to measure the magnitude (brightness) and contrast of the BSE signal across the Si/Mg interface. The contrast and brightness of the signal are adjusted using the BSE detector amplifier controls until a signal contrast of 12.5 units on the SEM videoscope is established between the silicon and the magnesium, with the magnitudes of the $\mathrm{Si}$ and $\mathrm{Mg}$ signals at +2.0 and -10.5 , respectively. This calibrated BSE signal, obtained at a beam current of $5.0 \mathrm{x}$ 10-10 A, provides an image with good contrast between the phases and excellent resolution of the microcracks present in the cement paste microstructure.

After adjusting the amplifiers on the SEM, an image of the $\mathrm{Si} / \mathrm{Mg}$ interface is acquired by the IAS, using the calibrated signal from the SEM. During this process, the IAS uses its own scan generator and frame grabber to take control of the electron beam and to acquire an image in 32 seconds (slowest available rate) which represents a picture element (pixel) dwell time of $100 \mu \mathrm{sec}$. The signal is displayed using the maximum setting (gain) for the IAS signal amplifiers. The absolute signal level, or brightness, is adjusted using up or down switches on the IAS, to increase or decrease, respectively, the absolute brightness of the signal. This procedure provides an image with properly calibrated contrast between cement paste phases (The Si and Mg BSE signal calibration settings of +2.0 and -10.5 were determined using the $\mathrm{Si} / \mathrm{Mg}$ standard, after multiple images of cement paste were acquired with the phases properly contrasted on the IAS monitor. Both the 
Si/Mg standard signal level and the cement paste specimen image were obtained with identical BSE amplification).

A threshold file for the Si/Mg standard is used to insure that the IAS signal level is properly adjusted. To use the threshold file, an image of the Si/Mg interface is acquired by the IAS using the calibrated signal from the BSE detectors described previously. During acquisition of the image, the standard threshold file is used to display a pseudo-colored image of the Si/Mg standard on the IAS monitor. The pseudo-colored image, controlled by the ranges specified in a threshold file, assigns the colors red and blue, respectively, to the gray levels associated with the silicon and magnesium portions of the image. The gray level intensity ranges in the threshold file, along with the corresponding area percent for each of the five gray level ranges specified, can be found in Table 2.2. The IAS signal level is properly set only when the imaged $\mathrm{Si} / \mathrm{Mg}$ standard displays the proper pseudo-colors. The signal ranges of the Si/Mg standard on the IAS (on a scale of 0 to 255) were 93 to 143 for silicon and 29 to 53 for magnesium.

A properly pseudo-colored image has a very small number of pink (gray level $=54$ to 92) and yellow (gray level $\geq 144$ ) spots dispersed throughout the pure silicon (red) region (see Table 2.2 for area percentages of each gray level range). At the same time, a very small number of pink spots and a few black (gray level $\leq 28$ ) spots are dispersed throughout the magnesium (blue) region. A band of low intensity signal (black) appears between the silicon and the magnesium as a result of the difference in height of about 100 microns between the silicon wafer and the magnesium base.

Using this threshold file to acquire an image on the IAS, any variation in amplification of a properly calibrated signal of the Si/Mg interface will be noticed immediately. Assuming that the SEM signal is calibrated properly, the only possible way an improperly pseudo-colored image of the Si/Mg interface can be obtained is if the brightness level on the IAS is improperly set. Adjustment of the up/down brightness level switches on the IAS until the image is properly pseudocolored, using the standard threshold file, assures proper signal amplification on the IAS.

Once the proper brightness level is obtained on the IAS, no readjustment of this setting is 
required or recommended, so long as the brightness levels (which are digitally discrete signal levels) remain unchanged. Instead, it is recommended that a calibrated Si/Mg signal from the SEM be "fine-tuned" on the microscope until the threshold image is properly pseudo-colored. This results in a more accurately amplified (calibrated) signal, since the digital amplifiers on the IAS can provide only discrete signal adjustments, while the analog signal produced by the BSE amplifiers on the SEM can be adjusted continuously.

\subsection{Determination of Intensity Ranges for Standard Threshold File}

A properly contrasted cement paste image was used, indirectly, to determine the intensity level ranges used in the standard threshold file. Once several cement paste images acquired by the IAS were deemed to display proper contrast of the phases, the amplification level on the IAS was assumed to be correctly adjusted. Next, an image of the silicon-magnesium standard was acquired without adjusting the signal level on the IAS, using the calibrated BSE amplification levels and SEM parameters described earlier for the Si/Mg standard. A histogram of the gray level intensities displayed in the image was used to help determine the threshold boundaries for silicon and magnesium. The threshold levels were defined, as described earlier, so that even one discrete level change in signal by the IAS could be easily detected.

\subsection{Acquiring a Calibrated Cement Paste Image}

After calibrating both the BSE amplifiers on the SEM and using the standard threshold file on the IAS, a cement paste specimen is positioned beneath the pole piece of the SEM. The specimen surface is focused using SE imaging, with the SEM set up according to the parameters listed at the beginning of the section on SEM imaging and SEM/IAS calibration. The microscope is focused at a magnification of 8000 to $10,000 \mathrm{x}$, several times higher than the magnification used for collecting the image. BSE imaging at a magnification of $2020 \mathrm{x}$ is used to acquire an image on the IAS. Using the specimen stage controls on the SEM, multiple images in different regions of the cement paste specimen are obtained by repositioning the specimen.

Every ten images, the electron beam current and BSE signal amplifiers are checked, using, 
respectively, the Faraday cup and the Si/Mg standard and adjusted as necessary. As noted before, once properly set, the IAS amplifier and brightness level controls need no further adjustment; however, the $\mathrm{Si} / \mathrm{Mg}$ image is reacquired using the color threshold file to verify the accuracy of the signal adjustments made on the SEM. Once all of the desired images are obtained, the cement paste images are stored in data files on the IAS, where they can be accessed for future analysis.

\subsection{Cement Paste Microstructure}

The images obtained by the SEM/IAS system, calibrated as described above, allow five separate phases in the cement paste microstructure to be distinguished on the basis of absolute gray level intensity. From lightest (densest material with highest backscattered electron coefficient) to darkest (least dense material with lowest backscattered electron coefficient), these phases include 1) unhydrated cement particles (UH), 2) calcium hydroxide (CH), 3) calcium silicate hydrate within the original boundaries of the cement grains (inner product, IP), 4) calcium silicate hydrate outside of the original boundaries of the cement grains (CSH), and 5) epoxy-filled voids. Absolute gray level cannot be used as a basis for the identification of cracked regions, as will be described in more detail later. The backscattered electron coefficient, or backscattering coefficient, of a material is the ratio of the number of backscattered electrons emanating from the surface of the specimen to the number of primary (beam) electrons striking the specimen surface, in that same material. For example, if $10^{6}$ primary electrons strike the surface of a pure element specimen and $10^{5}$ electrons are backscattered by the specimen, that element would have a backscatter coefficient of 0.1 . Backscattering coefficients are higher for materials with higher mean atomic numbers. For a specific material, the backscattering coefficient can be calculated based on the mean atomic number of its chemical constituents. A more detailed description of the backscattered electron coefficient will be presented later in the text.

When an image is properly acquired by the IAS, using the settings described earlier, the UH particles, consisting mostly of tricalcium silicate $\left(\mathrm{C}_{3} \mathrm{~S}\right)$, dicalcium silicate $\left(\mathrm{C}_{2} \mathrm{~S}\right)$, tricalcium aluminate $\left(\mathrm{C}_{3} \mathrm{~A}\right)$, and tetracalcium aluminoferrite $\left(\mathrm{C}_{4} \mathrm{AF}\right)$, are almost completely saturated (white). By design, these major constituents of unhydrated cement are poorly contrasted relative to one 
another to provide adequate contrast for the hydration phases. If individual constituents of the unhydrated cement paste are to be properly imaged and contrasted for some other purpose, a different signal level is used to calibrate the BSE amplifiers, as shown by Zhao and Darwin (1990, 1992). If the image is properly contrasted to distinguish between $\mathrm{UH}, \mathrm{CH}, \mathrm{IP}, \mathrm{CSH}$, and voids and cracks, the epoxy-filled voids appear black, with other phases appearing as distinct features with intermediate ranges of gray level intensity.

A threshold file is used to identify the pixel intensity ranges attributed to each phase in the cement paste microstructure. The five separate threshold ranges are set by adjusting the ranges to best match the phases present in cement paste for a large number of images. The pixel intensity range for each phase in the microstructure is pseudo-colored by projecting a uniquely defined combination of intensity levels of red, green, and blue light onto each pixel with an intensity that falls within that phase's particular threshold range. This process results in a unique color assignment for each threshold range representing a particular cement paste phase. A high-resolution RGB (red, green and blue) monitor is used for this purpose.

There are 256 discrete intensity levels of contrast available on an 8-bit graphics card. For the current application, the first 241 are assigned to gray levels available for contrast in the image. The last fifteen are assigned to colors used in the crack identification program, explained later in the text, for determining the phase(s) through which cracks pass. These gray levels and color assignments are explained more fully in the section regarding the development of the crack identification program.

A threshold file is developed to segment the gray level image by phase, based on gray level intensities representative of each individual phase. The gray level thresholds for the five phases are listed in Table 2.3 for the cement paste in this study.

For each image, the threshold file is used to determine the area percent of each cement paste phase. The total number of pixels within the threshold range for a given phase is divided by the total number of pixels in the image (245,760 pixels are contained in the IAS image, since the raster controlled by the IAS scans a region of 512 columns and 480 rows to produce one image). This 
ratio is equivalent to the fraction of the area occupied by that particular phase in the image.

\subsection{Image Transfer}

Once images are obtained and stored on the IAS, several images from the same specimen are concatenated (merged into a single data file) and transferred to an Apollo 3500 series workstation for analysis and storage. System capabilities enable a maximum of 15 images to be transferred in a single, concatenated file. Once transferred to the Apollo, the concatenated files are broken down again into single image data files and stored on a data cartridge to free the computer memory.

After the images are transferred to the Apollo, the crack identification program is used to identify and measure each crack's geometric properties: area, orientation, perimeter, projected length, and projected width. Once these properties are measured, each feature (crack) is then analyzed to determine the phases through which it passes in the cement paste microstructure. The total length of the crack, in each phase or along each phase boundary, is measured and stored for further analysis. 


\section{CHAPTER 3 \\ CRACK IDENTIFICATION}

This section presents the background, derivation and operating philosophy used in the crack identification program. The program can identify and measure cracks (area, orientation, perimeter, projected length, and projected width), identify the five separate phases present in cement paste (UH, CH, IP, CSH, and voids) based on absolute gray level, and identify the phase or phase boundary through which the crack passes within digital BSE images of cement paste.

\subsection{Nature of the Problem}

Digital backscattered electron (BSE) images of epoxy impregnated cement paste provide information that allow the phases within the material (UH, CH, IP, CSH, voids and cracks) to be identified. The information is conveyed by the intensity of the individual picture elements (pixels) in the image. A one-to-one correspondence is established between the area scanned on the specimen and the pixels in the image. High density phases, like $\mathrm{UH}$ and $\mathrm{CH}$, are the brightest, while the low density epoxy-filled cracks and voids are the darkest. This difference in intensity should, presumably, allow cracks to be easily identified. Unfortunately, the intensity of a phase, especially low density phases, depends on the density of adjacent and underlying phases, resulting in significant differences in the intensity of cracked regions. Thus, absolute intensity, as measured by the gray scale of a digital image, is insufficient to consistently identify cracks within cement paste. An understanding of the nature of the problem is helpful in understanding the basis upon which the crack identification program is based.

Backscattered Electron Imaging and Image Resolution.-In a scanning electron microscope, backscattered electrons are the result of incident beam electrons scattering elastically in the target material. Elastic scattering is a process in which the direction of an electron is changed but the energy of the electron is only negligibly changed. Some beam electrons expend their energy and are absorbed within the specimen; however, there is a significant fraction of the incident electrons that reemerge from the specimen due to a series of elastic scattering events in 
which a net change in direction allows the electrons to escape the material. This fraction is called the backscattered electron (or backscattering) coefficient, $\eta$, which is defined as

$$
\eta=\frac{n_{b s}}{n_{b}}
$$

in which $n_{b}$ is the number of beam electrons incident on the target and $n_{b s}$ is the number of backscattered electrons. The backscattering coefficient depends primarily on the atomic number density of the target material. [The reader is referred to Zhao and Darwin $(1990,1992)$, for information regarding the calculated value of $\eta$ for each of the components present in cement paste.]

In a BSE image, features are visible (resolved) on the IAS because of a change in pixel intensity from region to region. The fractional change in $\eta$, which is directly related to the signal intensity, is referred to as contrast, $\mathrm{C}$, and is defined as

$$
\mathrm{C}=\frac{\eta_{1}-\eta_{2}}{\eta_{1}}
$$

in which $\eta_{1}$ and $\eta_{2}$ are, respectively, the backscattering coefficients for the high and low density materials.

To obtain the maximum visible contrast between the phases and for easier identification of cracks, the signal is amplified so that the highest density phase, unhydrated cement grains (UH), and the lowest density phase, epoxy-filled cracks and voids, occupy the high and low ends of the intensity gray level scale, respectively. This is done through signal saturation, the process in which the signal is modified so that the high and low intensities of interest, respectively, match the highest (white) and lowest (black) intensity levels that the computer is able to display.

BSE images obtained by the SEM/IAS have a resolution on the order of 0.5 microns for the solid phases in cement paste. However, resolution of epoxy filled cracks is observed to be on the order of 0.1 microns at a magnification of $2020 \mathrm{X}$, which is much better than that thought to be obtainable with BSE imaging. This is due to the fact that the epoxy absorbs a majority of the 
incident electrons, which minimizes the effects of the information volume (described next) on resolution. Also, the probe diameter (about 0.1 microns) is approximately the same dimension as the pixel $(0.0696 \times 0.0868$ microns at a magnification of $2020 \mathrm{X})$. Features can be resolved with probe diameters up to approximately twice the feature dimension (Goldstein et al. 1992).

The resolution limit of 0.5 microns for solid phases is due to the relatively large region in the vicinity of the electron probe (information volume) from which backscattered electrons exit the specimen. The size of this region is influenced both by the size and the shape of the interaction volume within the specimen (the region within the specimen where primary electrons from the beam interact with the specimen). Both the lateral distribution of the interaction volume and the depth of penetration of the primary electrons are dependent upon the accelerating voltage of the electron beam and the mean atomic number of the specimen. The reader is referred to Goldstein et al. (1992) for a more complete discussion of electron-specimen interaction.

The epoxy, filling cracks and voids, is significantly less dense than any of the cement paste phases; thus, its average atomic number and corresponding backscattering coefficient are lower than those of the cement paste phases. The reason for improved resolution of epoxy filled cracks is that, when the primary electrons strike the epoxy, very few backscattered electrons are produced. Therefore, the large information volume normally associated with BSE imaging is of little concern because the resolution of the softer phase is controlled by the large drop in signal (BSE's). Thus, the diameter of the electron probe (about 0.1 microns in this case) and the pixel spacing are the limiting factors influencing the resolution of epoxy filled cracks. If a crack is of such a size or orientation that a significant amount of backscattered electrons are produced within adjacent or underlying phases, the crack can still be resolved, but the absolute signal intensity will be increased. These factors will be discussed further in the next section.

Drawbacks of Using Gray Level to Identify Cracks.-Incident beam electrons generally penetrate into the material some distance before a net change in the direction of travel, due to elastic scattering, causes the backscattered electrons to escape the material. The emerging electrons, thus, carry information from throughout the depth of the information volume. A large 
change in $\eta$ will improve the resolution possible with BSE's, but it will also make the intensity of the signal of the soft phase (cracks) sensitive to the depth of that phase. The denser the underlying material, the greater the effect that backscattered electrons from that material will have on the intensity of pixels representing the softer phase.

A narrow crack provides a good example of the effect of adjacent and underlying phases on the intensity of the signal. Fig. 3.1a shows that a narrow crack with an orientation significantly less than $90^{\circ}$ to the SEM viewing surface can have a relatively small volume of epoxy, at the point where the beam strikes the specimen, directly over the phase material immediately surrounding the crack. Since the electron beam is not completely absorbed by the epoxy, due to the small volume of epoxy, the electrons interact with the surrounding material. This causes a greater number of electrons to be backscattered. Thus, the pixel intensity of this region, on a gray level image, will be much brighter than if the interaction of the electrons were primarily within the epoxy. Fig. 3.1b shows a narrow crack, approximately a pixel or less in width (in this study the beam width is approximately equal to the width of a pixel) and an orientation approximately equal to $90^{\circ}$ to the SEM viewing surface. Since the beam electrons strike phase material on the surface of the specimen, the number of backscattering electrons will also be significantly greater than if the interaction of the electrons were primarily within epoxy. Therefore, the pixel intensity of this region will also be much brighter. However, the intensity of this region, on the gray level image, will not be as bright as the example given in Fig. 3.1a, due to the increased absorption of electrons by the epoxy directly under the point of incidence of the electron beam. In some instances, a narrow crack lying within a soft material (say CSH) will show up as being extremely black on a gray level image, even though the crack is very narrow (less than a pixel in width).

When the epoxy absorbs a high percentage of electrons, the interaction between the electrons and the surrounding material will be minimal. Figs. $3.2 \mathrm{a}$ and $3.2 \mathrm{~b}$ show that the wider the crack, the lower the likelihood of backscattered electrons from adjacent or underlying phases playing a role in the image intensity at the crack, i.e., the region of the image occupied by the crack will be very dark. 
From this discussion, it is clear that gray level alone cannot be used to identify cracks in images of cement paste, since the density and the proximity of adjacent phases can play a role in the resolution of cracked regions. Therefore, a procedure that uses local differences in gray level, rather than absolute values, is needed to identify cracks.

\subsection{Graphics Capabilities of Program}

As described earlier, eight-bit graphic cards are used on the Lemont IAS and the Apollo computer, allowing 28 , or 256 , discrete gray level intensities to be used for contrasting SEM images acquired by the IAS. The crack analysis program requires the use of 15 colors for performing graphics tasks. These include, identifying phases, phase boundaries, and/or phases surrounding cracks. Therefore, 15 intensity levels are reserved for color graphics needs, which will be explained in more detail, leaving 241 gray levels for contrasting the image of the cement paste microstructure.

Once a gray level image is acquired and analyzed, the program identifies the cracks and colors the crack pixels red. The process of identifying features with a preselected color, known as pseudo-coloring, is a procedure used on standard red-green-blue (RGB) monitors to obtain different colors by proportioning different intensities of red, green, and blue. Equal proportions of red, green, and blue correspond to the gray level scale. For example, a gray level of 0 (black) has red, green, and blue intensity levels of 0,0 , and 0 , and a gray level of 1 (one step brighter than 0 ) has red, green, and blue intensity levels of 1,1 , and 1. This continues up to a gray level of 240 (white), which has red, green, and blue intensity levels of 240,240 , and 240. In the program, intensities above 240 are interpreted as specific pseudo-colors (Table 3.1).

Crack pixels are identified using a intensity level of 255 , which is interpreted as the pseudocolor red (red, green, and blue intensity levels of 255,0 , and 0 , respectively). Red crack pixels are superimposed on the gray level image.

In the next step of the analysis, the remainder of the gray level image (everything except the cracks) is then segmented, using threshold ranges for each of the five cement paste phases (including voids distributed throughout the cement paste). Each phase is pseudo-colored using a different 
combination of RGB intensities. The remaining nine intensity levels are used to identify perimeter pixels along each crack, with the color dependent upon the phase or phase boundary at which the crack is located. A summary of the gray level ranges used to identify cement paste phases is given in Table 2.3. The RGB combinations used for phase and crack identification are given in Table 3.1 .

Since the pixel intensities of the digital image are stored in a FORTRAN matrix, pixel coordinates correspond to the row and column number at which the pixel gray level is stored. Thus, the program can easily access the pixel intensity of any pixel while "scanning" the image during the analysis. The term "scanning" or "scan" means to access the pixel intensities in the FORTRAN matrix, pixel by pixel, in any of the four possible directions (horizontally, vertically and two diagonal directions) to make the appropriate calculations for the analysis.

The graphics capabilities of the program are not used for every image analyzed, but are quite useful for random checks for accuracy of the analysis. Modifications must, of course, be made in the input parameters if the analysis is not found to be accurate. The graphics features allow the operator to adjust the input parameters, as required, and to continuously verify that the decisions made by the program are correct. Once the operator is assured that crack/phase identification is accurate, the graphics capabilities of the program can be bypassed.

It is well known that the microstructure of cement paste can change significantly due to factors such as changes in the constituent materials, water-cement ratio and age of testing. Thus, a satisfactory analysis may require modification of the input parameters to accommodate the specific material being analyzed.

\subsection{Feature Identification}

The general concept behind image analysis of cracks is to identify regions where an abrupt change in intensity takes place. This change in intensity is typically a drop-off followed by a rapid increase over a relatively short distance. Due to the varying size, shape, and intensity of actual cracks, the rules to define a crack are lenient to allow for the identification of cracked regions. This leniency, however, also causes noncrack features to be identified. Procedures to filter out these 
other features have been developed and will be discussed later in the text.

The following sections describe the original (Martin 1990) and current procedures used to identify cracks.

Fixed $\triangle$ and Span Procedure.-The procedure developed by Martin (1990) involves the comparison of the intensity of a pixel in a gray-level image to the intensities of the surrounding pixels. All comparisons are taken along a single line of pixels. The process of accessing pixel intensities along a line of pixels in a digital image is referred to as a line scan.

Figs. 3.3a and 3.3b show graphical and integer representations, respectively, of a line scan through a crack. In general, a line scan perpendicular to a crack will encounter two adjacent phases with pixel intensities greater than the pixel intensity within the crack.

Martin's program performs line scans for a fixed distance, or span, from every pixel in the image. The gray level intensities of the pixels at both ends of the scan are compared with the graylevel intensity of the pixel at which the line scan originates. For the center pixel to be considered part of a crack, both pixel intensities at the end of the scan must be greater than the pixel intensity at the center of the scan by a predetermined amount, $\Delta$. Once a pixel is determined to be part of a crack, its pixel coordinates are stored in another array. Crack pixels with adjoining coordinates are grouped together as distinct features that are separate from other groups of adjoining pixels stored in the array. This process of crack identification is carried out for each pixel, with scans in the horizontal, the vertical, and the two diagonal directions. Martin's procedure demonstrated that cracks could be identified based on differences in gray level rather than on absolute values of gray level alone. However, as explained next, the process does not accurately identify all cracks.

Fig. 3.4 illustrates the variation in pixel intensity across a crack. To aid in the discussion, a few terms must be defined. The floor of the crack (or the floor of the feature) corresponds to the region along a line scan in which the pixel intensity lies within a small range $( \pm \delta)$ of the average pixel intensity, $\mathrm{I}_{\mathrm{avg}}$, within this region. The floor of a crack is bounded on two sides by transition regions of rising intensity. A transition region contains pixels with intensities controlled by the overlapping information obtained from bordering materials. A plateau is a 
region adjacent to a crack, and just outside the transition region, in which the pixel intensity has risen high enough so that the signal represents an adjacent phase.

If Martin's procedure is used with a small span, a wide crack may not be identified and only portions of a medium-width crack will be identified, because the intensity of pixels within the floor of the crack will be compared with other pixels within the crack or pixels within the transition region. In this case, the differences in pixel intensity, or $\Delta$, will not be great enough to exceed the fixed $\Delta$ used to define a crack. As a result, only the center region of medium-width cracks will be identified, while wide cracks will not be identified at all.

If Martin's procedure is used with a large span, comparisons will be made between phases that naturally show large differences in intensity. These differences do not depend on local changes due to the presence of the crack, but are dominated by the heterogeneous nature of cement paste. The use of a span that is too large results in the definition of "cracked features" that exceed the boundaries of the true cracks.

Martin's procedure also encounters specific problems when voids are adjacent to cracks, since the difference in pixel intensity is not great enough for crack identification and the measured $\Delta$ may even be negative. Finally, the procedure results in the identification of a great many voids as cracks.

As these drawbacks to the original procedures were discovered during the course of this study, it became clear that a better understanding of the changes that occur in pixel intensity adjacent to cracks was necessary. This additional information led to modifications in the crack identification procedure. This work is described next.

Current Procedure.-The study of a large number of BSE images of cement paste lead to the conclusion that the sharpness of the boundary of a crack (slope of the transition region) is one of the characteristics that allows cracks to be identified. To quantify the variation in pixel intensity, a series of images were studied using line scans perpendicular (or as close as possible) to known cracks. Each line scan contained the crack floor along with the adjacent transition regions and plateaus. 
The differences in intensity, $\mathrm{I}_{\text {dif }}$, between pixels near a crack and pixels within the floor of the crack (intensity represented by $I_{\text {avg }}$ ) are illustrated in Fig. 3.5. Fig. 3.5 shows both the mean and lower 95 percent confidence limit of $I_{\text {dif }}$ versus the distance from the edge pixel on the floor of the cracks, $d_{\text {edge }}$. A smoothed version of the lower 95 percent confidence limit for $I_{\text {dif }}$ from the edge of the floor of the crack to the end of the transition region (the point at which $\mathrm{I}_{\mathrm{dif}}$ levels off) is used to define the minimum "slope" of a transition region adjacent to a crack. As shown in Fig. 3.5, this locus of points is represented by the bilinear distribution: $I_{\text {dif }}=0$ for $d_{\text {edge }} \leq 0.112 \mu \mathrm{m}$, $\mathrm{I}_{\text {dif }}=158 \mathrm{~d}_{\text {edge }}-17.7$ for $0.112 \mu \mathrm{m} \leq \mathrm{d}_{\text {edge }} \leq 0.27 \mu \mathrm{m}$. In the program, the parameters defining the transition region can be adjusted if the brightness and contrast settings on the image analysis system are altered.

As with the fixed $\Delta$ and span procedure, the procedure used here scans in 4 directions, as it steps from pixel to pixel on the image. For each pixel, the program evaluates adjacent pixels to define the floor of the feature, checks the slope of the transition region and finally, based on gray level, determines if the feature is lying within a void.

To carry out the procedure for each pixel, in each direction, the program scans one pixel at a time until all of the requirements of a crack are met or the edge of the image is reached. As the scan begins, the intensity of the initial pixel is assumed to be the initial running average $I_{\text {avg }}$, which is used to determine which pixels possess intensities within $\pm \delta$ of the running average. If the adjacent pixel is within $\pm \delta$ of the initial pixel intensity, a new running average is obtained and used for comparisons of adjacent pixels. This procedure continues until a pixel is found with an intensity that lies outside the range $\mathrm{I}_{\text {avg }} \pm \delta$. For cement paste, the maximum distance of a scan in one direction is $1.07 \mu \mathrm{m}$ (equal to the sum of the maximum allowable crack width in this study, $0.80 \mu \mathrm{m}$, and the maximum width of a transition zone, $0.27 \mu \mathrm{m}$ ). If the transition zone is not found within $1.07 \mu \mathrm{m}$, the feature is not identified as a crack.

The first pixel that lies outside $I_{\text {avg }} \pm \delta$ is used as the first pixel within the transition region. For the region identified as the floor of a feature to qualify as a crack, the intensity within the transition region must exceed the minimum values illustrated in Fig. 3.5 over the range $0 \leq d_{\text {edge }} \leq$ 
$0.27 \mu \mathrm{m}$. If $I_{\text {dif }}$ for each pixel, starting with $d_{\text {edge }}=0$, exceeds the minimum value, the width of the transition region is defined as the smaller of $0.27 \mu \mathrm{m}$ or the edge distance at which $I_{\text {dif }}$ first exceeds 25 . If $\mathrm{I}_{\mathrm{dif}}$ does not exceed 25 anywhere within $0.27 \mu \mathrm{m}$ of the edge pixel, the feature is not defined as a crack. To insure that the feature does not represent a portion of a void, the absolute intensity at the outside edge of the transition region must exceed a minimum value, taken as the maximum intensity for a void (Table 2.3). In the current study, the maximum intensity for pixels within a void is 19 (Table 2.3 ). Since $I_{\text {dif }} \geq 25$, the need to insure that the crack is not a portion of a void is negated. However, this check has been retained in the program to provide for further requirements.

The scanning and identification procedure is carried out in each of the four directions. The function defining minimum values of $I_{\text {dif }}$ within the transition region (Fig. 3.5) can be modified by the user. If the requirements described above are met for both transition zones in one of the four scanning directions, the pixel is identified as representing a portion of a crack.

To make sure that a crack is not within a void, and thus a portion of the void, the program evaluates the absolute intensity of the pixels adjacent to the crack for up to a distance equal to the minimum resolution of solid phases (currently set at $0.5 \mu \mathrm{m}$ ). Pixels representing solid phases are evaluated based on a smoothed digital gray level image in which the gray level of each pixel is represented by the average of the intensities of that pixel and the eight surrounding pixels. If any of the pixels adjacent to a crack exhibits a gray level within the range defined for voids (Table 2.3), the crack is treated as a portion of the void, not as a separate crack.

Two values of maximum crack width are used in the analysis. The values are based on observations of a large number of images and depend on the intensity of the pixels within the floor of the crack. In cases where at least one pixel within the floor of a crack has an intensity of 0 , a maximum crack width of $0.80 \mu \mathrm{m}$ is used. In all other cases, a maximum crack width of $0.26 \mu \mathrm{m}$ is used. In the study used to select these values, no crack exceeded these criteria. The study also revealed that the variation in intensity within the floor of a crack is higher in cases where some of the pixels have an intensity of 0 than in cases where the minimum intensity is $>0$. To accommo- 
date this, the intensity variation, $\pm \delta$, relative to the running average, $I_{\text {avg }}$, along the floor of a crack is set at \pm 15 if at least one pixel has an intensity of 0 and at \pm 5 otherwise.

If the criteria described above are satisfied, a pixel within the floor of the feature is identified as a crack pixel and its intensity within the image matrix is changed to 255 (255 is reserved for this purpose). Once this operation is complete, the program steps to the next pixel and repeats the entire procedure. The process continues until each pixel in the image (245,760 pixels) is evaluated. This process involves the evaluation of pixels that have already been identified as crack pixels. However, the multiple evaluation is necessary to insure that all cracks are found.

Although the term "crack" has been used to describe the features obtained with this procedure, the relatively lenient criteria on the transition zone (lower 95 percent confidence limit) results in the identification of a number of noncrack features. Therefore, further processing of the image is required.

Connecting Adjacent Features.- In some instances, the crack identification procedure described above results in the incomplete identification of all pixels in a crack, causing a single crack to appear as two or more smaller cracks. A separation of even one pixel causes the program to identify features as separate cracks. In some cases, the features may, in fact, appear to be separate cracks; however, due to the proximity and relative orientation of the two features, the conclusion reached in this study is that the lack of continuity is due to a weakness in imaging techniques rather than the fact that the features represent separate cracks.

The technique of connecting cracks depends on establishing the separation and relative orientation of two adjacent features. The end pixels of a feature are the two pixels within the feature that are the farthest apart (the same two pixels are used to calculate the projected length of the crack). To insure that only cracks were connected to other cracks, features must possess a minimum area of $0.1 \mu \mathrm{m}^{2}$ and minimum projected length-to-projected width ratio of 2.25 . If the distance between end pixels on adjacent features is less than 25 percent of the projected length of the current feature being considered and the angle formed between the features (defined by the end pixels) is less than $45^{\circ}$, the two features are connected by identifying those pixels on a line connect- 
ing the two closest pixels on the adjacent features. The identification is made, as before, by changing the intensity of the pixels on the connecting line to 255 in the gray level image. This modification results in the two features being considered as a single feature for further analysis.

\subsection{Geometric Measurements}

Basic Geometric Definitions.-Some of the features identified using the techniques described above are not cracks. Geometric properties are used to differentiate those features from cracks. Each of the geometric properties is defined below.

A feature is defined as all of the continuous pixels that have been identified as being part of a particular phase. The pixel coordinates for each feature are stored in an array so that geometric calculations can be made.

The area of each feature is the sum of the areas of the pixels found in the feature. The perimeter is obtained by first determining which pixels in the feature are surrounded above, below, left, and right by other pixels in the feature. These pixels are termed "interior" pixels and by default, all other pixels in the feature are considered to be perimeter pixels. The perimeter is equal to the sum of the center-to-center distances between each of the adjoining perimeter pixels in the feature.

The absolute length of a crack is approximated as one-half of the perimeter. The projected length is the distance between the centers of the two pixels that are the farthest apart on the feature (end pixels). The end pixels are found by comparing the distances between all perimeter pixels.

The orientation of the crack is the angle between the axis formed by the end pixels and the horizontal axis of the viewing field. The projected width of the crack is equal to the sum of the perpendicular distances from this axis to each of the two most distant pixels on each side of the axis.

\subsection{Differentiation of Crack and Noncrack Features}

Procedures to differentiate noncrack features from true cracks are described next. Some of 
the noncrack features are small voids (approximately $0.5 \mu \mathrm{m}$ in diameter) within the cement paste matrix or long slender voids, most often adjacent to unhydrated cement grains. Noncrack features also include small regions of softer phases surrounded by denser phases within the cement paste matrix, some small scratches in the surface of the specimens (mostly within the dense UH particles), and other regions that are difficult to define but are identified as cracks by the techniques described above.

To help differentiate between crack and noncrack features, several geometric properties of true cracks were investigated. These included the area of the feature, the projected length, the ratio of the projected length to the projected width, and the ratio of the perimeter squared to the area.

Initially, it was thought that cracks would have higher perimeter squared area ratios than noncrack features. However, it was soon discovered that noncrack features sometimes have high perimeter squared-to-area-ratios.

With study, two combinations of geometric properties were found to separate cracks from noncrack features in the image. These combinations are illustrated in Figs. 3.6 and 3.7, in which the properties of actual cracks are plotted. Fig. 3.6 compares the perimeter squared-to-area ratio to the projected length of the cracks. Fig. 3.7 compares the projected length to the area of the crack. In each figure, the points representing the properties of the cracks lie predominantly on one side of a particular locus of points that may be described by one or two line segments. Most noncrack features (not plotted) appear on the opposite side of these dividing lines.

As illustrated in Fig. 3.6, for a given perimeter squared-to-area ratio, $\mathrm{p}^{2} / \mathrm{A}$, cracks have higher projected lengths, $1_{p}$, than noncracks. Only features lying below the locus of points represented by

$$
\frac{\mathrm{p}^{2}}{\mathrm{~A}}=140.51_{\mathrm{p}}-121.8
$$

for $0.867 \leq 1_{p} \leq 2.085$, and

$$
\frac{p^{2}}{A}=41.251_{p}+85.0
$$

for $2.085 \leq l_{p} \leq 6.0$ 
are accepted as cracks. Since no noncrack features have been observed with a projected length greater than $6 \mu \mathrm{m}$, no restrictions are applied to features with projected lengths greater than $6 \mu \mathrm{m}$.

As illustrated in Fig. 3.7, cracks with cross-sectional areas, A, of $1.5 \mu \mathrm{m}^{2}$ or less exhibit projected lengths above the locus of points represented by

$$
1_{p}=2.33 \mathrm{~A}+0.90
$$

for $0 \leq 1.5 \mu \mathrm{m}$

Features with areas in excess of $1.5 \mu \mathrm{m}^{2}$ are consistently identified correctly based on the transition region requirements and the restrictions illustrated in Fig. 3.6.

The combined of the two criteria illustrated in Figs. 3.6 and 3.7 provide an excellent filtering mechanism to separate cracks from noncrack features that are erroneously identified based on changes in gray level. The two filtering criteria are summarized in Figs. 3.8 and 3.9 .

\subsection{Identification of Phases Adjacent to Cracks}

To understand the role of microcracking in the strength and deformation of cement paste, it is important to determine what phases or phase boundaries undergo cracking. To do this, a procedure is needed to identify the portions of cracks that pass through phases and along phase boundaries. The proximity of a crack to a phase and the density of the surrounding phases relative to one another are used to determine whether a crack is formed within a single phase or lies on the boundary between two phases.

Phase identification procedures are carried out simultaneously with the initial crack perimeter measurements. The length of the crack perimeter is measured moving around each feature in a clockwise direction. As the program progresses from one pixel to another around the perimeter of a crack, it scans in a direction perpendicular to the crack boundary at each pixel location to obtain information on the phases adjacent to that pixel. Individual phases are identified based on the gray level intensity ranges previously assigned (Table 2.3). Phases surrounding the crack are identified and their distances from the perimeter pixels are recorded.

Phases are identified using a "smoothed" image, which is obtained by assigning to each 
pixel the average of its intensity with the intensity of the 8 surrounding pixels. This procedure reduces the effects of noise in the acquired image. A reduction in noise is especially important to prevent the erroneous identification of phase boundaries that are, in fact, just adjacent pixels of the same phase that have different intensities due to random variations in the signal. Smoothing is performed only after the cracks have been identified and after the area percent attributed to each phase has been determined. The average intensity assigned to each pixel during this process is based on the original pixel intensities found in the image. A total scan distance of $3.0 \mu \mathrm{m}$ perpendicular to the crack perimeter is used. The scan is carried out in both directions from the crack, perpendicular to the crack boundary at the perimeter pixel location of interest.

Boundary Cracks.-The nature of cracking in hydrated cement paste prevents the direct assignment of a phase to each crack pixel based on the phases immediately in contact with the pixel. Rules must be devised to establish whether a crack pixel is surrounded by a single phase or whether it lies along a phase boundary. The reason for the difficulty is that a crack, totally immersed in a single phase, may closely border a denser phase that may have influenced the orientation of the crack in the softer material. This is evidenced by the observation that many cracks found in the softer cement paste phases tend to deflect around denser particles, rather than propagate directly through them or pass immediately along the boundary of the denser particles. Therefore, boundary cracks are defined, in this study, not only as cracks that lie immediately on a boundary between two cement paste phases, but also as cracks in a softer material whose orientation is influenced by a denser cement paste phase.

The definition used for a boundary crack requires that an upper limit be established on the proximity of the crack to denser phases. Based on an evaluation of a large number of images, it was observed that denser phases generally influence cracking out to a distance of $1.5 \mu \mathrm{m}$. Therefore, phases are evaluated, perpendicular to perimeter pixels, out to a maximum of $1.5 \mu \mathrm{m}$ on each side of the crack.

Phase Identification Procedure.-Scanning in a direction perpendicular to the perimeter of a crack requires that the orientation of the perimeter be established at that location. In the 
current program, the orientation is established by an imaginary line drawn between the centers of the two perimeter pixels adjacent to the pixel of interest. Phases are evaluated over a distance of $3.0 \mu \mathrm{m}$ on a line directly perpendicular to this imaginary line and passing through the center of the current pixel of interest. For example, in the case of vertical pixels, scanning is carried out horizontally away from the perimeter in one direction and horizontally on the far side of the crack in the opposite direction. In the case of 3 adjacent pixels on a diagonal, phases are scanned in diagonal directions perpendicular to the axis upon which the pixels lie.

As phase information is gathered along the scan lines perpendicular to each perimeter pixel, a decision is needed to establish the nature of the adjacent phase and to determine whether the crack passes through a single phase or along a phase boundary. The determination of the primary adjacent phase is based on a "phase length," equal to the number of pixels encountered times the distance between adjacent pixels. The primary phase is the phase closest to the perimeter pixel with a phase length $\geq 0.5 \mu \mathrm{m}$, the resolution limit for a solid phase in cement paste with BSE imaging. If the scan produces a phase length $<0.5 \mu \mathrm{m}$, the next phase encountered that has a phase length $\geq 0.5 \mu \mathrm{m}$ is considered to be the primary phase. Scanning continues until a primary phase is found or until 4 phases have been encountered, at which point the routine uses the phase with the largest phase length as the primary phase. The only time a void is considered to border a crack is when the void is immediately adjacent to the crack with a phase length $\geq 0.5 \mu \mathrm{m}$. Otherwise, only solid phases are considered to be primary phases. [Note: Although criteria given earlier prevent a pixel from being defined on a single line scan as a crack pixel if the scan crosses a void, each pixel is evaluated using four independent line scans, any one of which can identify the pixel as a crack pixel. Thus, a pixel near a void can be identified as part of a crack if at least one line scan through the pixel does not intersect the void.]

Once the primary phases are established, then the nature of the phases through which the crack passes can be determined (it is emphasized that this is done one perimeter pixel at a time).

Based on the evaluation of a large number of cracks, specific rules have been established to identify the phases: If a primary phase is encountered on both sides of the crack and the length of 
this phase is greater than a required minimum (taken equal to $1.5 \mu \mathrm{m}$ in the current study), the perimeter pixel in that crack is identified as lying wholly within a single phase. If one primary phase is present on one side of the crack and a different primary phase is present on the other and at least one of these phases has a phase length $\geq 1.5 \mu \mathrm{m}$, the pixel is identified as lying on the boundary between the two phases. If the same primary phase is identified on both sides of the crack, but a second, denser phase is encountered within $1.5 \mu \mathrm{m}$ of the perimeter pixel, the pixel is again identified as lying on the boundary between two phases. The only time that this rule is not used is when denser phases are encountered within $1.5 \mu \mathrm{m}$ on both sides of the crack. This situation occurs when a soft phase separates two denser phases, with the crack passing through the softer phase. In this case, the perimeter pixel is assigned solely to the softer material.

As the phase or phase boundary corresponding to each perimeter pixel is established, the total perimeter length assigned to each phase or phase boundary is calculated. Since this summation occurs along the total perimeter of a crack (and the perimeter is equal approximately to two times the total crack length), the actual crack length attributed to each phase or phase boundary is obtained by dividing the total perimeter assigned to each by 2 .

After this analysis is performed for all identified cracks, pixels within the image can be pseudo-colored to provide a graphic representation of the analysis. Each of the 5 phases in cement paste, including voids, is distinctly pseudo-colored, while the pixels along the perimeter of each crack are pseudo-colored based on the appropriate phase or phase boundary (Table 3.1). 


\section{CHAPTER 4}

\section{ANALYSIS CAPABILITIES}

This chapter demonstrates the capabilities of the automatic crack identification program described in Chapter 3.

\subsection{Imaging and Feature Identification}

As described in Chapters 2 and 3, individual regions of cement paste are imaged and then analyzed. Figs. 4.1a and 4.2a provide examples of images as they are acquired. Both images represent cement paste with a water-cement ratio of 0.5 .

Following the procedures described in Chapter 3, the individual phases (Figs. $4.1 \mathrm{~b}$ and 4.2b) and cracks (Figs. 4.1c and 4.2c) are identified. The cracks are characterized by area, perimeter, projected length, projected width, orientation (measured based on the two points used to establish the projected length), and the phases through which the cracks pass. Crack length is characterized by both one-half of the perimeter and the projected length. Crack pixel locations, as illustrated in Figs. 4.1c and 4.2c, and the individual data for each crack are stored along with the initial image, allowing further analysis and/or reanalysis as required. Information related to feature identification can be displayed on the computer, as shown in Fig. 4.3. The computer display highlights the individual phases within cement paste using selected pseudocolors, identifies the crack locations, and identifies the individual perimeter pixels based on the adjacent phases in cement paste. The following section provides an example of the analysis capabilities of the program.

\subsection{Analysis Demonstration}

To demonstrate the capabilities of the automated crack identification program, cement paste with a water-cement ratio of 0.5 was evaluated at 28 days. One sample was loaded to failure, producing the stress-strain curve shown in Fig. 4.4. A second sample was loaded to a strain of $6000 \mu \varepsilon$ and then unloaded. A third, companion specimen was not loaded. Using the procedures described in Chapter 2,1 mm thick slices were obtained from the nonloaded and $6000 \mu \varepsilon$ samples. 
Following preparation, 80 digitized backscattered electron images were obtained from each slice. As described earlier, the images were obtained at a nominal magnification of $2020 \mathrm{x}$ at a beam current of $5 \times 10^{-10}$ amps, with a $512 \times 480$ pixel raster and a pixel dwell time of $100 \mu \mathrm{sec}$.

The result of the phase analysis for each specimen is presented in Table 4.1. The table shows that there is a close agreement in the area percent for the phases for the nonloaded and loaded specimens. Table 4.1 also shows the standard deviation in area percent for each phase, as obtained for the 80 images, and the number of frames required for 95 percent confidence that the true area percent is within 10 percent of the measured value. For example, if the area percent of a phase is 14.57 , as it is for calcium hydroxide $(\mathrm{CH})$ in the nonloaded specimen, 96 frames are required to provide 95 percent confidence that the average area percent is within 1.457 percent of the true average area of $\mathrm{CH}$.

The number of frames, $\mathrm{n}$, is calculated using Eq. 4.1.

$$
\mathrm{n}=\left(\frac{1.96 \sigma}{\varepsilon}\right)^{2}
$$

in which $\sigma$ is the estimated population standard deviation of the area percent for a single phase and $\varepsilon$ is the acceptable error or half of the maximum acceptable confidence interval (Ostle and Malone 1988). For Table 4.1, $\varepsilon$ is 10 percent of the measured area percent. As observed earlier by Zhao and Darwin $(1990,1992)$, the number of frames for the desired level of confidence differs for each phase, with the greatest number of frames required for unhydrated particles, followed next by cracks. Also, as observed by Zhao and Darwin, the highest confidence is obtained for the inner product $[\mathrm{IP}(\mathrm{CSH})]$ and the calcium silicate hydrate outside the initial boundary of the cement grain (CSH).

Table 4.2 presents the results of the crack analysis based on one-half of the crack perimeter (phase identification and total crack density) and the projected length (total crack density only). A comparison of the mean crack densities illustrates that $\mathrm{p} / 2$ provides an estimate of crack length equal to nearly twice that provided by $l_{\mathrm{p}}$. 
Further analysis of the percentage distribution of cracking by phase illustrates that cracks which are solely within unhydrated particles or within calcium hydroxide represent only a small percentage of total cracking (about 2.5 percent in each phase). These small percentages compare to area percents (Table 4.1) of about 10 percent for unhydrated particles and about 14 percent for calcium hydroxide. In contrast, cracking within CSH dominates.

CSH represents about 42 percent of the area percent of the material, and 36 to 38 percent of the total cracking lies solely within CSH. However, an additional 35 percent lies on the boundary between $\mathrm{CSH}$ and the harder phases [UH, $\mathrm{CH}, \mathrm{IP}(\mathrm{CSH})]$, and over 9 percent occurs within $\mathrm{CSH}$ adjacent to a void. Thus, nearly 80 percent of the cracks lie within CSH. An additional 4 to 5 percent of the cracks occur in the CSH portion of the inner product, $\mathrm{IP}(\mathrm{CSH})$. This analysis demonstrates the overwhelming importance of calcium silicate hydrate as the location and controller of microcracking in these samples. Another important observation is that inner product, unhydrated particles, and calcium hydroxide tend to act as hard "aggregates" in a CSH matrix, much the same as fine and coarse aggregates act within the cement paste matrix in concrete. It should be emphasized that most of the boundary cracking recorded Table 4.2 actually occurs solely within CSH (but adjacent to the harder phases).

The relatively large percentage of cracks at void boundaries results from the procedures described in Chapter 3 for both identifying cracks and establishing the phases through which the cracks pass. The initial analysis of an image identifies crack pixels. The subsequent step of identifying adjacent phases uses rules that depend on an approximation of the direction perpendicular to the crack. That perpendicular direction is not necessarily the direction in which the scan was taken that identified the pixel as being part of a crack. Therefore, the "perpendicular" direction might be directed towards a void instead of into a surrounding phase. The phase identification procedures for cracks also use the minimum phase resolution of $0.5 \mu \mathrm{m}$. An increase in this value might minimize the effects of small voids on the results.

In addition to the mean percentage crack density and mean density in $\mathrm{mm} / \mathrm{mm}^{2}$, Table 4.2 also lists information on the standard deviation (based on individual frames) and the number of 
frames required for 95 percent confidence that the mean crack densities is within 10 percent of the measured values. The corresponding area for the required number of frames is also shown.

The results indicate that the scatter for individual crack types (based on phases and phase boundaries) is quite high from image to image, leading to very high frame requirements for cracks that appear in small percentages, such as 1611 frames for cracks in unhydrated (UH) material, which represent only 2.69 percent of the total cracks (Table 4.2). The number of frames required to provide the desired level of accuracy is significantly smaller when based on total cracking, but is still in excess of the 80 frames used for this example. Strategies for obtaining the increased number of frames include using a larger number of pixels per image at a lower magnification. For example, changing from a $512 \times 480$ raster to a $1024 \times 960$ raster while reducing the magnification by one-half would reduce the required number of frames required by 75 percent, providing a manageable number of images when based on the desired accuracy for total crack density.

Cumulative crack density based on crack length is presented in Fig. 4.5 and 4.6 for crack lengths approximated by $\mathrm{p} / 2$ and $\mathrm{l}_{\mathrm{p}}$, respectively. These figures indicate that, for cracks with lengths up to about $12 \mu \mathrm{m}$ based on $\mathrm{p} / 2$ and about $7 \mu \mathrm{m}$ based on $1_{\mathrm{p}}$, the nonloaded and loaded specimens produce virtually identical crack densities. Beginning at 12 and $7 \mu \mathrm{m}$, respectively, the crack distributions begin to deviate significantly. Based on $\mathrm{p} / 2$, that deviation continues to increase for cracks with lengths up to $40 \mu \mathrm{m}$. Based on $1_{p}$, the increase is approximately complete at a projected length of $20 \mu \mathrm{m}$. These differences are consistent, considering the fact that $\mathrm{p} / 2$ provides an estimate of crack length equal to about twice that of $1_{p}$. The results illustrated in Figs. 4.5 and 4.6, however, may have much greater import, since they indicate that the effects of loading can be established based on cracks larger than a specific size and that cracks below that size represent cracks that either existed prior to loading or crack that were caused by preparation procedures.

Tables 4.3 and 4.4 provide a summary of crack orientation based on cracks that lie within $20^{\circ}$ ranges between 0 and $180^{\circ}$. The percentage of cracking within each orientation range is identified based on the percentage of total crack length for cracks lengths $<2 \mu \mathrm{m}$, between 2 and 3 $\mu \mathrm{m}, 3$ and $4 \mu \mathrm{m}, 4$ and $6 \mu \mathrm{m}, 6$ and $12 \mu \mathrm{m}$, and $>12 \mu \mathrm{m}$ for crack lengths based on $\mathrm{p} / 2$, and 
$<2 \mu \mathrm{m}$ between 2 and $3 \mu \mathrm{m}, 3$ and $4 \mu \mathrm{m}, 4$ and $5 \mu \mathrm{m}$, and $>5 \mu \mathrm{m}$ for crack lengths based on $1_{\mathrm{p} .}$ The results are further illustrated for $\mathrm{p} / 2$ and $\mathrm{l}_{\mathrm{p}}$, respectively, in Figs. 4.7 and 4.8, which diagram percentage total crack length for each $20^{\circ}$ range in the form of a crack rose.

For a transverse surface (SEM specimen surface perpendicular to the direction of loading), it is expected that all crack angles should be represented in an approximately equal manner. While Figs. 4.7 and 4.8 would support this in the most general sense, there is clearly less cracking for angles near $90^{\circ}$ than there is for angles closer to 0 and $180^{\circ}$. All of the reasons for this deviation from a uniform distribution are not completely clear. A portion of the deviation, at least for short cracks, results from the use of rectangular rather than square pixels. However, the deviation from a square pixel does not explain the tendency toward horizontal cracking observed for any but the smallest cracks. A plausible reason for the observed deviation for larger cracks is the fact that cracks truncated by the boundaries of the image are more likely not to be identified as cracks, due to not meeting the geometric requirements, than cracks not truncated by the boundaries. Since the image is wider than it is high, the likelihood of intercepting vertical cracks is greater than the likelihood of intercepting horizontal cracks. Thus, cracks oriented between $80^{\circ}$ and $100^{\circ}$ would be expected to be affected the most. This trend appears to hold for the results shown in Table 4.3 and 4.4. Based on this analysis, the distortion in crack orientation can be reduced by converting to a system with square pixels and increasing the size of the raster on the specimen to reduce the percentage of the image that is adjacent to a boundary. 


\section{CHAPTER 5 \\ SUMMARY AND CONCLUSIONS}

\subsection{Summary}

The development of an automated procedure for the identification of microcracks in cementitious materials is described. The degree and nature of microcracking is measured using backscattered electron images obtained with an integrated scanning electron microscope/image analysis system. Multiple images for specimens are analyzed using a computer program developed to identify and measure microcracks within the individual phases of cement paste. The procedure is developed to assist in the determination of the roles played by individual phases in cement paste in the formation and propagation of microcracks. Procedures for specimen testing, preparation, imaging, and crack analysis are described, along with a description of the development of the analysis program. The analysis capabilities of the program are demonstrated.

\subsection{Conclusions}

The following conclusions are based on the work described in this report.

1. The gray level of epoxy-filled cracks in polished cement paste specimens is affected by the atomic number density of underlying and adjacent phases. Therefore, cracks cannot be identified based on gray level alone.

2. Epoxy-filled cracks in polished cement paste specimens can be identified based on local changes in gray level and the application of geometric requirements.

3. Combined procedures that establish the floor of a crack, minimum gradient and gray level adjacent to cracks, and minimum differences in gray level between the floor of a crack and adjacent solid phases provide a reproducible and consistent technique for crack identification in cement paste.

\subsection{Future Work}

The work reported here represents the first major effort to establish automated techniques for identifying microcracks in cementitious materials. A number of improvements can be made in 
the technique through changes in image acquisition methods. Principal among these improvements is conversion of the scan raster to produce square pixels, rather than rectangular pixels, and an increase in the region scanned to reduce the percentage of the image that is adjacent to a boundary. These procedures will reduce the potential for distortions in crack orientations.

The procedures described in this report also will be strengthened by conversion to an image acquisition system that will allow an increase in the pixel dwell time. This change will increase the signal-to-noise ratio of the image, with a resulting increase in the measureable contrast between phases. The images will be clearer, and the individual phases will be more sharply delineated.

The procedures developed in this study have been demonstrated using cement paste with a water-cement ratio of 0.5 . The general applicability of the procedure should be demonstrated at other water-cement ratios, as well as with materials containing mineral admixtures, such as silica fume. Application of the techniques to mortar and concrete should also follow. 


\section{REFERENCES}

Cong, X., Gong, S., Darwin, D., and McCabe, S. L. (1990). "Role of Silica Fume in Compressive Strength of Cement Paste, Mortar, and Concrete," SL Report 90-2, University of Kansas Center for Research, Lawrence, April, 35 pp.

Cong, X., Gong, S., Darwin, D., and McCabe, S. L. (1992). "Role of Silica Fume in Compressive Strength of Cement Paste, Mortar and Concrete," ACI Materials Journal, Vol. 89, No. 4, JulyAugust, pp. 375-387.

Goldstein, J. I., Newbury, D. E., Echlin, P., Joy, D. C., Romig, A. D., Lyman, C. E., Fiori, C., and Lifshin, E. (1992). Scanning Electron Microscopy and X-Ray Microanalysis, Plenum Press, New York and London, $820 \mathrm{pp}$.

Harsh, S., Shen, Z., and Darwin, D. (1989). "Strain-Rate Sensitive Deformation of Cement Paste and Mortar in Compression," SM Report No. 22, University of Kansas Center for Research, Lawrence, March, 289 pp.

Martin, J. L. (1990). "Image Analysis of Cracks in Cement Paste," Project, Department of Electrical and Computer Engineering, University of Kansas, Lawrence, December, 55 pp.

Ostle, B. and Malone, L. C. (1988). Statistics in Research, Iowa State University Press, Fourth Edition, $649 \mathrm{pp}$.

Zhao, H. and Darwin, D. (1990). "Quantitative Backscattered Electron Analysis Techniques for Cement-Based Materials," SM Report No. 24, University of Kansas Center for Research, Lawrence, $55 \mathrm{pp}$.

Zhao, H. and Darwin, D. (1992). "Quantitative Backscattered Electron Analysis of Cement Paste," Cement and Concrete Research, Vol. 22, No. 4, July, pp. 695-706. 
Table 2.1: Analysis of cement using x-ray analysis

\begin{tabular}{cc}
\hline Chemical Compounds & Weight Percent \\
\hline $\mathrm{SiO}_{2}$ & 21.10 \\
$\mathrm{Al}_{2} \mathrm{O}_{3}$ & 4.76 \\
$\mathrm{Fe}_{2} \mathrm{O}_{3}$ & 3.24 \\
$\mathrm{CaO}^{\mathrm{MgO}}$ & 64.31 \\
$\mathrm{SO}_{3}$ & 2.54 \\
$\mathrm{Na}_{2} \mathrm{O}$ & 2.52 \\
$\mathrm{~K}_{2} \mathrm{O}$ & 0.30 \\
Loss $\mathrm{on}_{\mathrm{Ignition}}$ & 0.17 \\
$\mathrm{P}_{2} \mathrm{O}_{5}$ & 1.08 \\
$\mathrm{TiO}_{2}$ & 0.24 \\
$\mathrm{Cr}_{2} \mathrm{O}_{3}$ & 0.40 \\
$\mathrm{MnO}$ & 0.03 \\
$\mathrm{ZnO}$ & 0.11 \\
$\mathrm{SrO}$ & 0.03 \\
& 0.22 \\
\hline Bogue $\mathrm{Compounds}$ & \\
\hline & Weight Percent \\
$\mathrm{C}_{3} \mathrm{~S}$ & 53 \\
$\mathrm{C}_{2} \mathrm{~S}$ & 20 \\
$\mathrm{C}_{4} \mathrm{AF}$ & 9 \\
\hline
\end{tabular}

Table 2.2: Silicon (Si) and magnesium $(\mathrm{Mg})$ standard gray level threshold settings (Silicon / Magnesium $=+2 /-10.5$ )

\begin{tabular}{ccccc}
\hline Level No. & Phases & $\begin{array}{c}\text { Gray Level } \\
\text { (Minimum) }\end{array}$ & $\begin{array}{c}\text { Gray Level } \\
\text { (Maximum) }\end{array}$ & $\begin{array}{c}\text { Area } \\
\text { Percent (\%) }\end{array}$ \\
\hline 1 & & 144 & 240 & 1.22 \\
2 & $\mathrm{Si}$ & 93 & 143 & 42.48 \\
3 & $\mathrm{Mg}$ & 29 & 92 & 1.89 \\
4 & 0 & 28 & 13.99 \\
5 & & 0 & & 40.14 \\
\hline
\end{tabular}


Table 2.3: Cement paste gray level threshold settings of 28-day old $(w / c=0.5)$ cement paste (Silicon / Magnesium $=+2 /-10.5$ )

\begin{tabular}{cccc}
\hline Level No. & Phases & $\begin{array}{c}\text { Gray Level } \\
\text { (Minimum) }\end{array}$ & $\begin{array}{r}\text { Gray Level } \\
\text { (Maximum) }\end{array}$ \\
\hline & & 210 & 240 \\
1 & UH & 158 & 209 \\
2 & CH & 110 & 157 \\
4 & IP(CSH) & 20 & 109 \\
5 & CSH & 0 & 19 \\
\hline
\end{tabular}

Table 3.1: Red, green and blue intensity combinations for phase and crack thresholding

\begin{tabular}{crrrc}
\hline Phases & Red & Green & Blue & $\begin{array}{c}\text { Corresponding Intensity } \\
\text { Level }\end{array}$ \\
& & & & \\
& & & & 241 \\
UH & 255 & 211 & 132 & 242 \\
CH & 243 & 140 & 70 & 243 \\
IP & 204 & 84 & 36 & 244 \\
CSH & 136 & 58 & 29 & 245 \\
VOID & 0 & 0 & 0 & \\
& & & & \\
& & & & \\
Cracks & Red & Green & Blue & Corresponding Intensity \\
& & & & 246 \\
& & & & 247 \\
UH & 255 & 0 & 255 & 248 \\
CH & 100 & 100 & 100 & 250 \\
IP & 0 & 0 & 255 & 251 \\
CSH & 87 & 174 & 87 & 252 \\
UH/IP & 150 & 0 & 255 & 246 \\
UH/CH & 0 & 255 & 0 & 253 \\
UH/CSH & 110 & 174 & 255 & 254 \\
IP/CH & 255 & 0 & 255 & \\
IP/CSH & 255 & 255 & 255 & 0 \\
CH/CSH & 255 & 255 & 0 & \\
& & & & \\
\hline
\end{tabular}


Table 4.1: Area percent analysis of 28-day old $(w / c=0.5)$ cement paste at 0 and 6000 microstrain including the number of frames required for 95 percent confidence that the area percent is within 10 percent of the measured value - 2020x Magnification

\begin{tabular}{|c|c|c|c|c|}
\hline Phases & $\begin{array}{c}\text { Area } \\
\text { Percent } \\
\%\end{array}$ & $\begin{array}{c}\text { Standard } \\
\text { Deviation } \\
\sigma\end{array}$ & $\begin{array}{c}\text { Number of } \\
\text { Frames Required } \\
n\end{array}$ & $\begin{array}{c}\text { Corresponding } \\
\text { Area Required } \\
\qquad\left(\mu^{2}\right)\end{array}$ \\
\hline \multicolumn{5}{|c|}{0 Microstrain } \\
\hline $\begin{array}{c}\text { UH } \\
\text { CH } \\
\text { IP(CSH) } \\
\text { CSH } \\
\text { VOIDS } \\
\text { CRACKS }\end{array}$ & $\begin{array}{r}10.26 \\
14.57 \\
20.59 \\
41.42 \\
12.55 \\
0.61\end{array}$ & $\begin{array}{r}10.48 \\
7.29 \\
4.28 \\
8.61 \\
5.14 \\
0.40\end{array}$ & $\begin{array}{r}401 \\
96 \\
16 \\
16 \\
64 \\
167\end{array}$ & $\begin{array}{l}5.97 \times 10^{5} \\
1.43 \times 10^{5} \\
2.38 \times 10^{4} \\
2.38 \times 10^{4} \\
9.52 \times 10^{4} \\
2.49 \times 10^{5}\end{array}$ \\
\hline \multicolumn{5}{|c|}{6000 Microstrain } \\
\hline $\begin{array}{c}\mathrm{UH} \\
\text { CH } \\
\mathrm{IP}(\mathrm{CSH}) \\
\text { CSH } \\
\text { VOIDS } \\
\text { CRACKS }\end{array}$ & $\begin{array}{r}9.91 \\
13.03 \\
20.22 \\
42.79 \\
13.36 \\
0.70\end{array}$ & $\begin{array}{l}9.94 \\
6.05 \\
3.66 \\
7.95 \\
5.61 \\
0.53\end{array}$ & $\begin{array}{r}386 \\
82 \\
12 \\
13 \\
67 \\
226\end{array}$ & $\begin{array}{l}5.74 \times 10^{5} \\
1.22 \times 10^{5} \\
1.79 \times 10^{4} \\
1.94 \times 10^{4} \\
9.97 \times 10^{4} \\
3.36 \times 10^{5}\end{array}$ \\
\hline
\end{tabular}


Table 4.2: Mean crack density (using perimeter divided by 2) for phase and phase boundary cracking of 28 -day old $(\mathrm{w} / \mathrm{c}=0.5)$ cement paste at 0 and 6000 microstrain including the number of frames required for 95 percent confidence that the mean crack density is within 10 percent of the measured value - 2020x Magnification

\begin{tabular}{|c|c|c|c|c|c|}
\hline $\begin{array}{l}\text { Type of } \\
\text { Cracking }\end{array}$ & $\begin{array}{c}\text { Mean \% } \\
\text { Crack } \\
\text { Density }\end{array}$ & $\begin{array}{l}\text { Mean Crack } \\
\text { Density } \\
\left(\mathrm{mm} / \mathrm{mm}^{2}\right)\end{array}$ & $\begin{array}{c}\text { Standard } \\
\text { Deviation } \\
\sigma\end{array}$ & $\begin{array}{c}\text { Number of } \\
\text { Frames Required } \\
n\end{array}$ & $\begin{array}{l}\text { Corresponding } \\
\text { Area Required } \\
\left(\mu \mathrm{m}^{2}\right)\end{array}$ \\
\hline \multicolumn{6}{|c|}{0 Microstrain } \\
\hline UH & 2.69 & 0.84 & 1.72 & 1611 & $2.40 \times 10^{6}$ \\
\hline $\mathrm{CH}$ & 2.33 & 0.90 & 1.61 & 1223 & $1.82 \times 10^{6}$ \\
\hline $\mathrm{IP}(\mathrm{CSH})$ & 5.52 & 1.97 & 2.36 & 551 & $8.20 \times 10^{5}$ \\
\hline $\mathrm{CSH}$ & 35.74 & 12.14 & 8.76 & 200 & $2.98 \times 10^{5}$ \\
\hline $\mathrm{UH} / \mathrm{CH}$ & 1.59 & 0.44 & 0.57 & 660 & $9.82 \times 10^{5}$ \\
\hline $\mathrm{UH} / \mathrm{IP}$ & 1.71 & 0.50 & 1.09 & 1825 & $2.72 \times 10^{6}$ \\
\hline UH/CSH & 5.73 & 1.52 & 1.35 & 302 & $4.49 \times 10^{5}$ \\
\hline $\mathrm{IP} / \mathrm{CH}$ & 3.21 & 1.10 & 1.31 & 551 & $8.20 \times 10^{5}$ \\
\hline $\mathrm{IP} / \mathrm{CSH}$ & 21.99 & 7.25 & 4.92 & 176 & $2.62 \times 10^{5}$ \\
\hline $\mathrm{CH} / \mathrm{CSH}$ & 7.01 & 2.36 & 2.10 & 304 & $4.52 \times 10^{5}$ \\
\hline UH/VOID & 0.43 & 0.15 & 0.24 & 915 & $1.36 \times 10^{6}$ \\
\hline $\mathrm{CH} / \mathrm{VOM}$ & 0.42 & 0.16 & 0.23 & 802 & $1.19 \times 10^{6}$ \\
\hline IP/NOID & 0.91 & 0.35 & 0.46 & 678 & $1.01 \times 10^{6}$ \\
\hline CSH/VOID & 9.62 & 3.40 & 3.04 & 305 & $4.54 \times 10^{5}$ \\
\hline VOID/VOID & 1.10 & 0.39 & 0.51 & 671 & $9.99 \times 10^{5}$ \\
\hline TOTAL & & 33.47 & 20.84 & 148 & $2.20 \times 10^{5}$ \\
\hline TOTAL FOR & & 19.11 & & & \\
\hline \multicolumn{6}{|c|}{6000 Microstrain } \\
\hline UH & 2.45 & 0.99 & 2.02 & 1608 & $2.39 \times 10^{6}$ \\
\hline $\mathrm{CH}$ & 2.67 & 1.08 & 1.87 & 1154 & $1.72 \times 10^{6}$ \\
\hline $\mathrm{IP}(\mathrm{CSH})$ & 4.50 & 1.93 & 2.30 & 549 & $8.17 \times 10^{5}$ \\
\hline $\mathrm{CSH}$ & 37.51 & 14.15 & 11.12 & 237 & $3.53 \times 10^{5}$ \\
\hline $\mathrm{UH} / \mathrm{CH}$ & 1.34 & 0.53 & 0.76 & 773 & $1.15 \times 10^{5}$ \\
\hline $\mathrm{UH} / \mathrm{IP}$ & 1.64 & 0.60 & 1.30 & 1807 & $2.69 \times 10^{6}$ \\
\hline $\mathrm{UH} / \mathrm{CSH}$ & 4.84 & 1.67 & 1.67 & 382 & $5.69 \times 10^{5}$ \\
\hline $\mathrm{IP} / \mathrm{CH}$ & 3.25 & 1.31 & 2.04 & 928 & $1.38 \times 10^{6}$ \\
\hline IP/CSH & 23.12 & 7.93 & 6.24 & 237 & $3.53 \times 10^{5}$ \\
\hline $\mathrm{CH} / \mathrm{CSH}$ & 7.03 & 2.84 & 2.71 & 349 & $5.19 \times 10^{5}$ \\
\hline UH/VOID & 0.29 & 0.12 & 0.22 & 1400 & $2.08 \times 10^{6}$ \\
\hline CH/VOID & 0.43 & 0.20 & 0.31 & 928 & $1.38 \times 10^{6}$ \\
\hline IP/VOID & 0.83 & 0.38 & 0.45 & 529 & $7.87 \times 10^{5}$ \\
\hline CSH/VOID & 9.25 & 3.77 & 3.56 & 344 & $5.12 \times 10^{5}$ \\
\hline VOID/VOID & 0.97 & 0.38 & 0.43 & 474 & $7.05 \times 10^{5}$ \\
\hline \multirow{2}{*}{\multicolumn{2}{|c|}{$\begin{array}{l}\text { TOTAL } \\
\text { TOTAL FOR } 1_{\mathrm{p}}^{*}\end{array}$}} & 37.87 & 27.68 & 205 & $3.05 \times 10^{5}$ \\
\hline & & 20.99 & & & \\
\hline
\end{tabular}

* Projected Length 
Table 4.3: Percentage of total crack length (using perimeter divided by 2) for different crack orientation and crack size ranges of 28 -day old $(w / c=0.5)$ cement paste at 0 and 6000 microstrain - 2020x Magnification

\begin{tabular}{|c|c|c|c|c|c|c|c|c|c|}
\hline & \multicolumn{9}{|c|}{0 Microstrain } \\
\hline & \multicolumn{9}{|c|}{ Percentage of Total Crack Length } \\
\hline Size Ranges & \multicolumn{9}{|c|}{ Crack Orientation Ranges (deg.) } \\
\hline$(\mu \mathrm{m})$ & $0-20$ & $20-40$ & $40-60$ & $60-80$ & $80-100$ & $100-120$ & $120-140$ & $140-160$ & $160-180$ \\
\hline$<2$ & 0.26 & 0.00 & 0.21 & 0.18 & 0.14 & 0.04 & 0.09 & 0.17 & 0.08 \\
\hline $2-3$ & 1.03 & 0.93 & 0.67 & 0.89 & 0.81 & 0.65 & 1.07 & 1.64 & 1.39 \\
\hline $3-4$ & 0.77 & 1.41 & 0.66 & 0.92 & 0.62 & 1.16 & 1.28 & 1.24 & 1.43 \\
\hline $4-6$ & 1.71 & 1.29 & 1.23 & 0.79 & 2.17 & 1.29 & 2.25 & 2.58 & 2.01 \\
\hline $6-12$ & 5.72 & 5.90 & 5.13 & 5.52 & 4.21 & 4.62 & 4.09 & 4.93 & 5.53 \\
\hline$>12$ & 2.47 & 2.40 & 1.38 & 2.39 & 0.39 & 1.68 & 2.90 & 2.94 & 2.73 \\
\hline \multirow[t]{3}{*}{ TOTAL } & 11.96 & 11.93 & 9.28 & 10.69 & 8.34 & 9.44 & 11.68 & 13.50 & 13.17 \\
\hline & \multicolumn{9}{|c|}{6000 Microstrain } \\
\hline & \multicolumn{9}{|c|}{ Percentage of Total Crack Length } \\
\hline Size Ranges & \multicolumn{9}{|c|}{ Crack Orientation Ranges (deg.) } \\
\hline$(\mu \mathrm{m})$ & $0-20$ & $20-40$ & $40-60$ & $60-80$ & $80-100$ & $100-120$ & $120-140$ & $140-160$ & $160-180$ \\
\hline$<2$ & 0.27 & 0.07 & 0.11 & 0.00 & 0.04 & 0.00 & 0.04 & 0.19 & 0.30 \\
\hline $2-3$ & 1.14 & 1.22 & 0.88 & 1.13 & 0.65 & 0.67 & 0.96 & 1.35 & 0.84 \\
\hline $3-4$ & 0.90 & 0.77 & 0.80 & 1.10 & 0.97 & 1.37 & 1.31 & 0.73 & 0.78 \\
\hline $4-6$ & 1.02 & 0.93 & 1.54 & 0.89 & 1.01 & 1.84 & 1.17 & 1.60 & 1.59 \\
\hline $6-12$ & 4.36 & 4.10 & 4.42 & 3.41 & 3.71 & 2.29 & 5.25 & 4.85 & 5.48 \\
\hline$>12$ & 4.42 & 1.49 & 4.28 & 3.14 & 2.69 & 2.95 & 3.44 & 4.03 & 5.55 \\
\hline TOTAL & 12.11 & 8.58 & 12.03 & 9.67 & 9.07 & 9.12 & 12.17 & 12.75 & 14.54 \\
\hline
\end{tabular}


Table 4.4: Percentage of total crack length (using projected length) for different crack orientation and crack size ranges of 28 -day old $(w / c=0.5)$ cement paste at 0 and 6000 microstrain $-2020 x$ Magnification

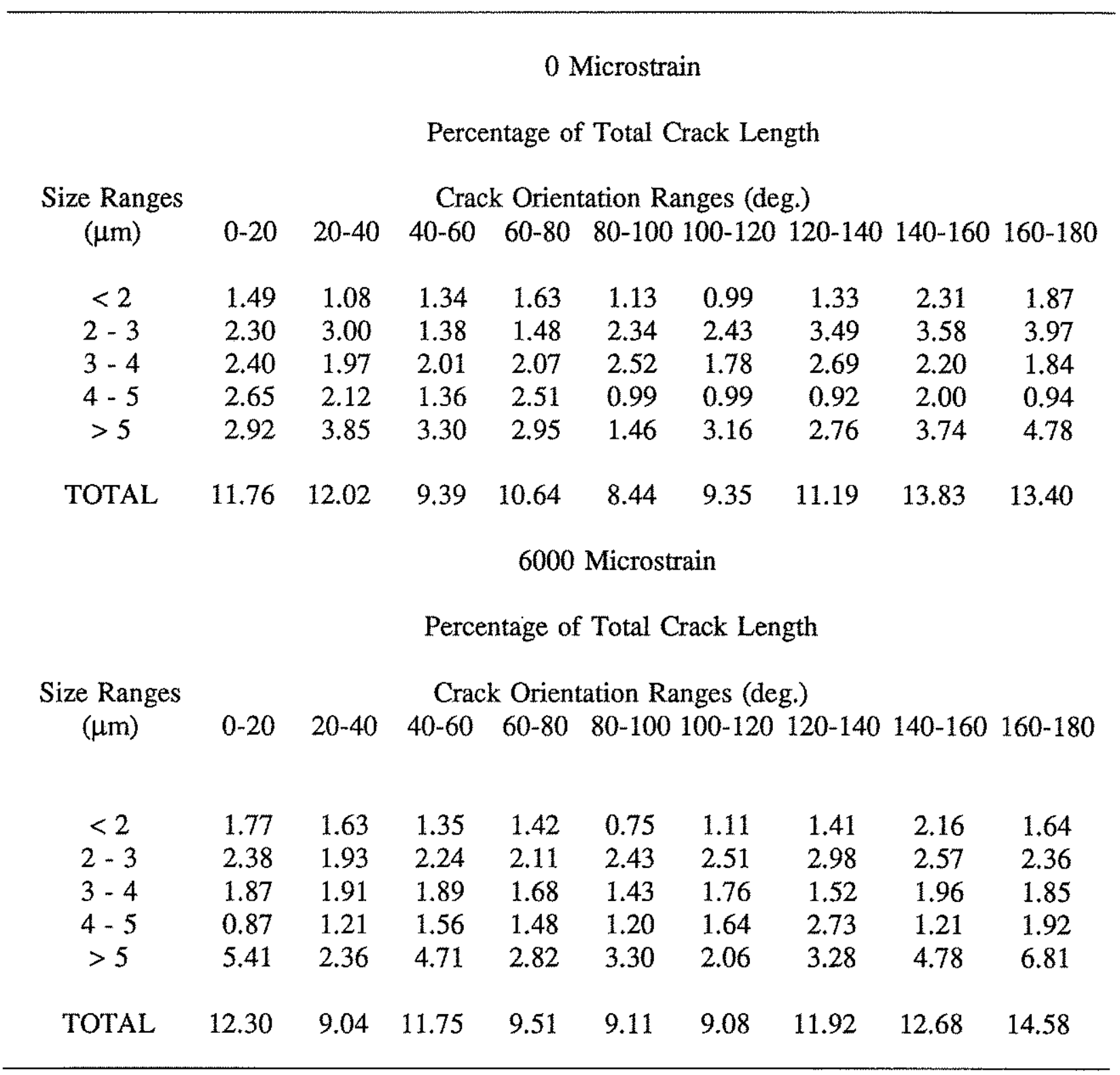




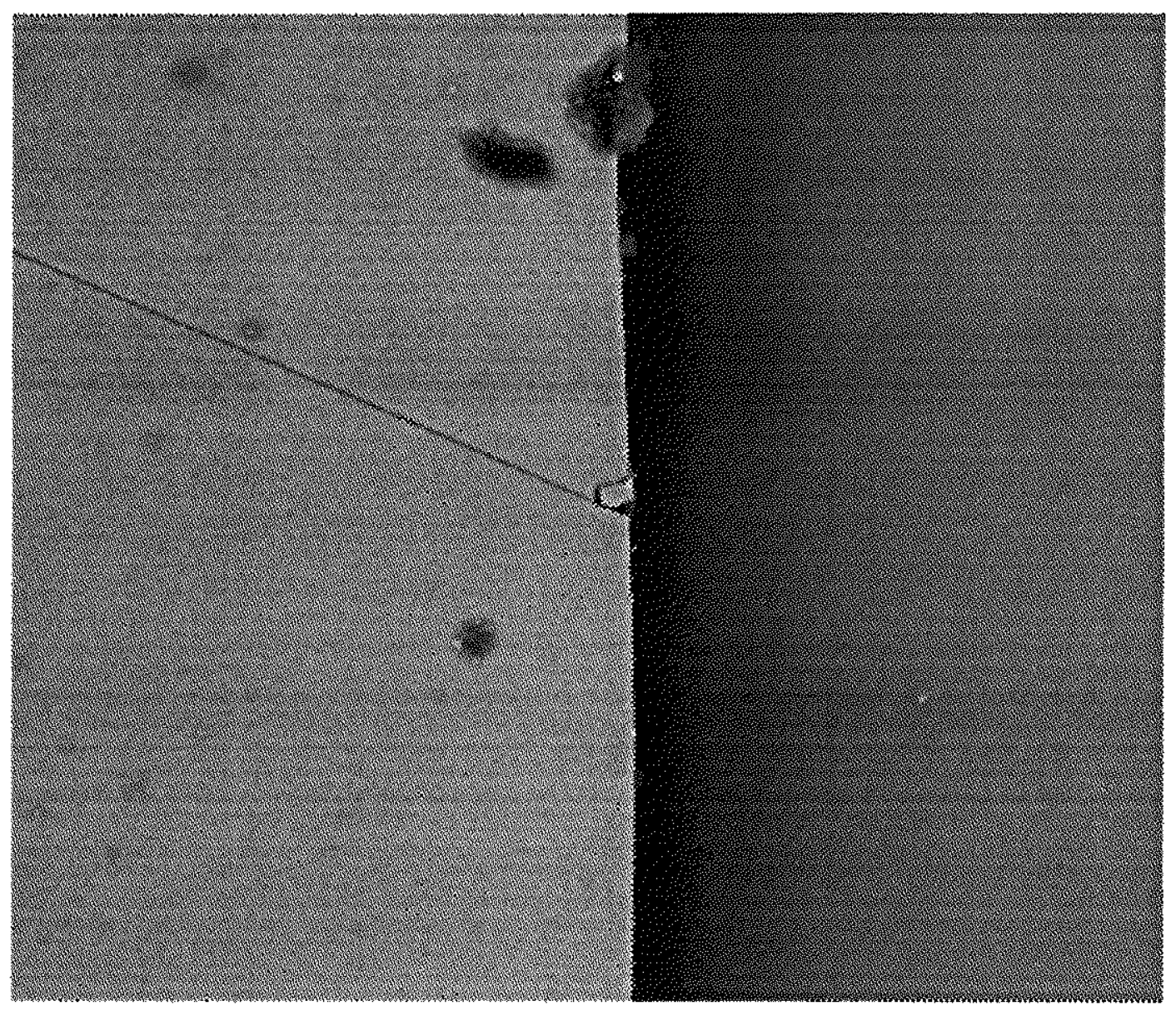

Fig. 2.1: BSE image of the $\mathrm{Si} / \mathrm{Mg}$ standard at a magnification of $300 \mathrm{x}$ 


\section{Videoscope Screen}

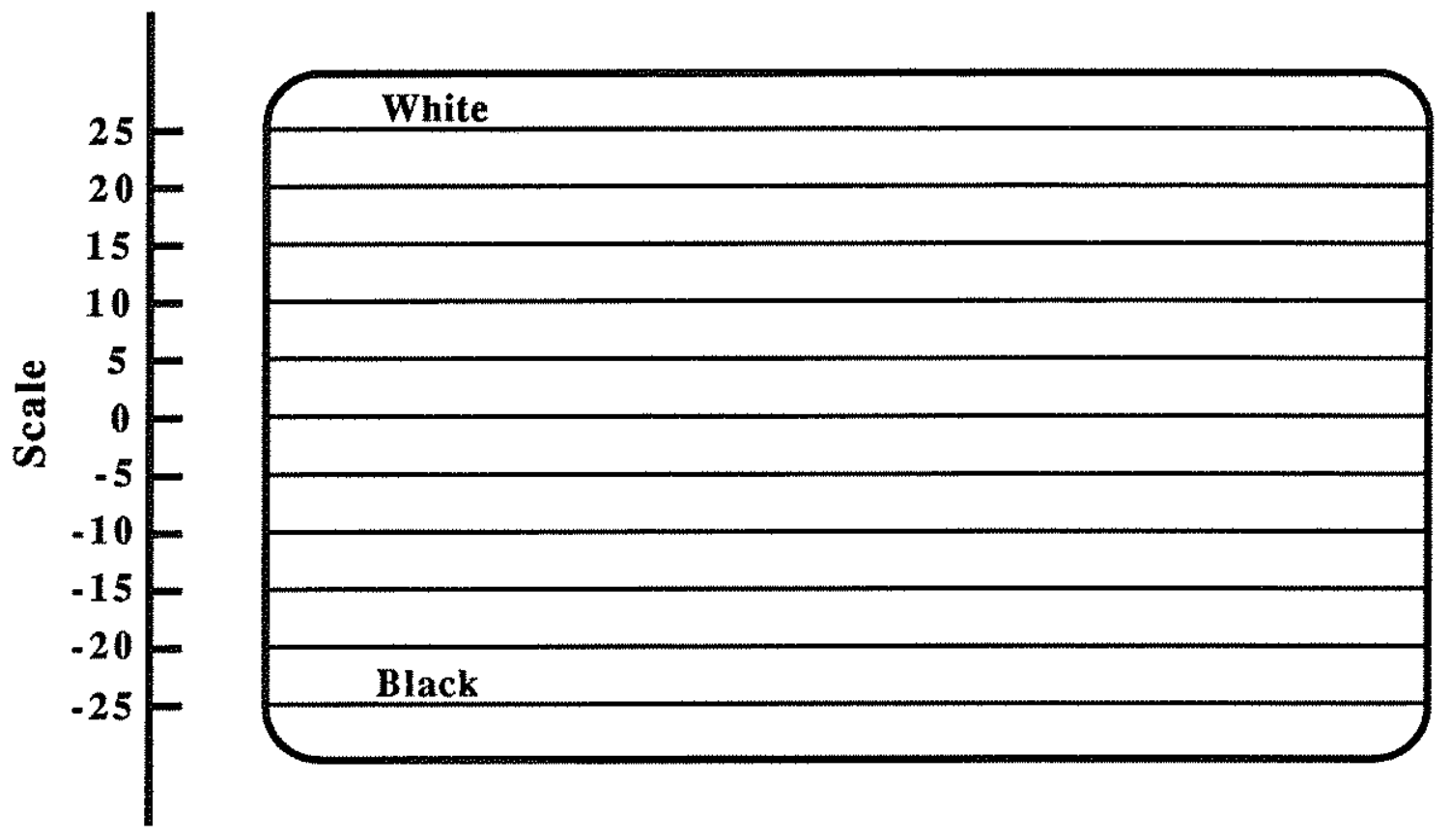

Fig. 2.2: The artificial scale on the SEM videoscope screen 


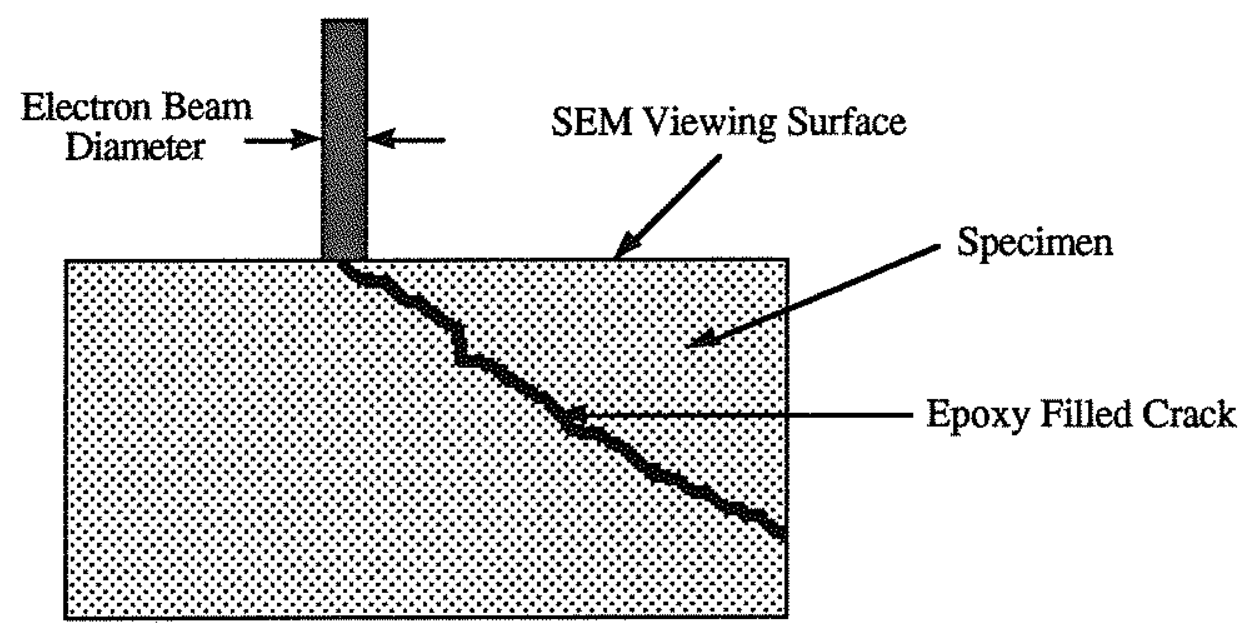

Narrow epoxy filled crack with orientation less than

90 degrees (relative to the horizontal)

(a)

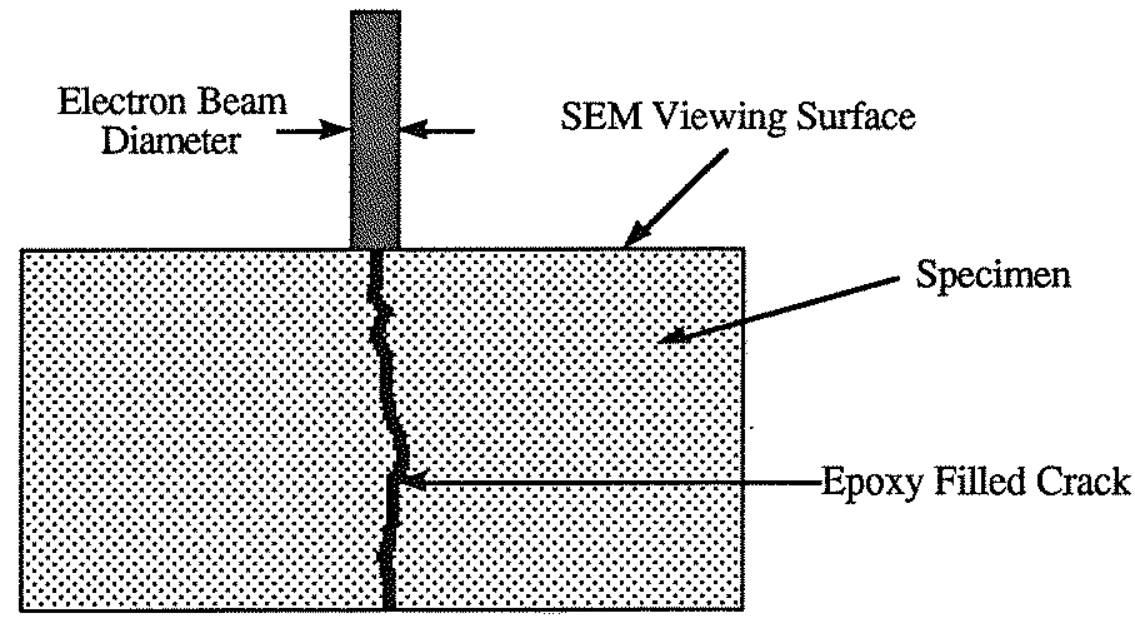

Narrow epoxy filled crack with orientation approximately

90 degrees (relative to the horizontal)

(b)

Fig. 3.1: Effect on resolution of narrow epoxy filled cracks 


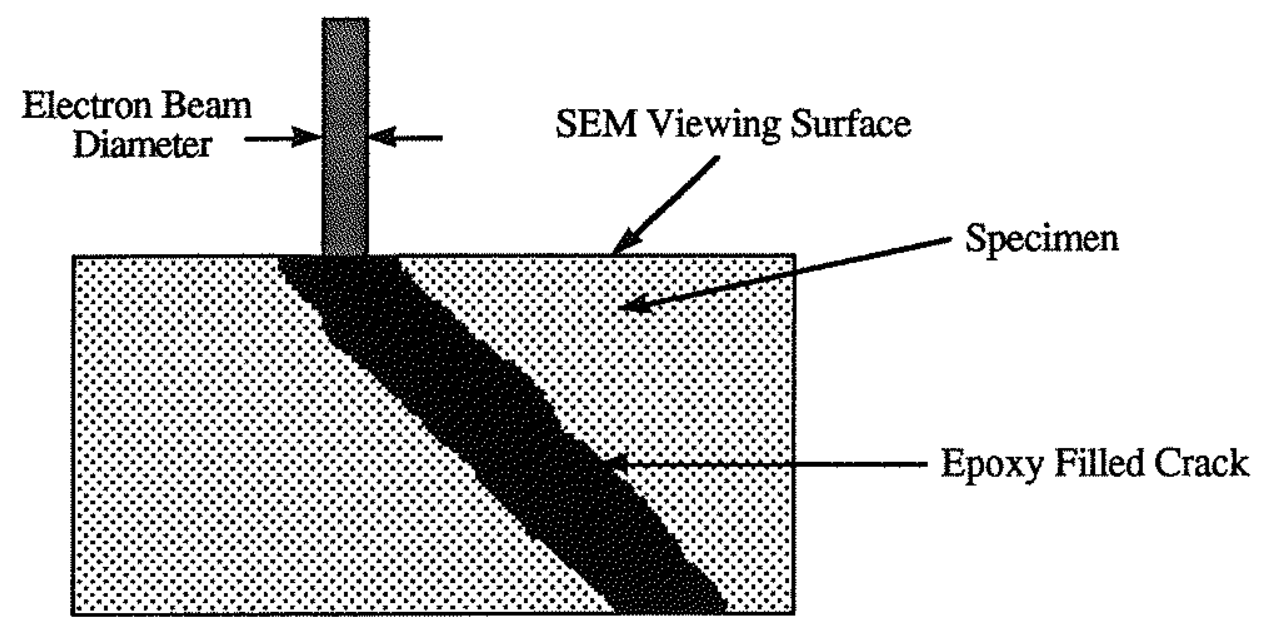

Wide epoxy filled crack with orientation less than 90 degrees (relative to the horizontal)

(a)

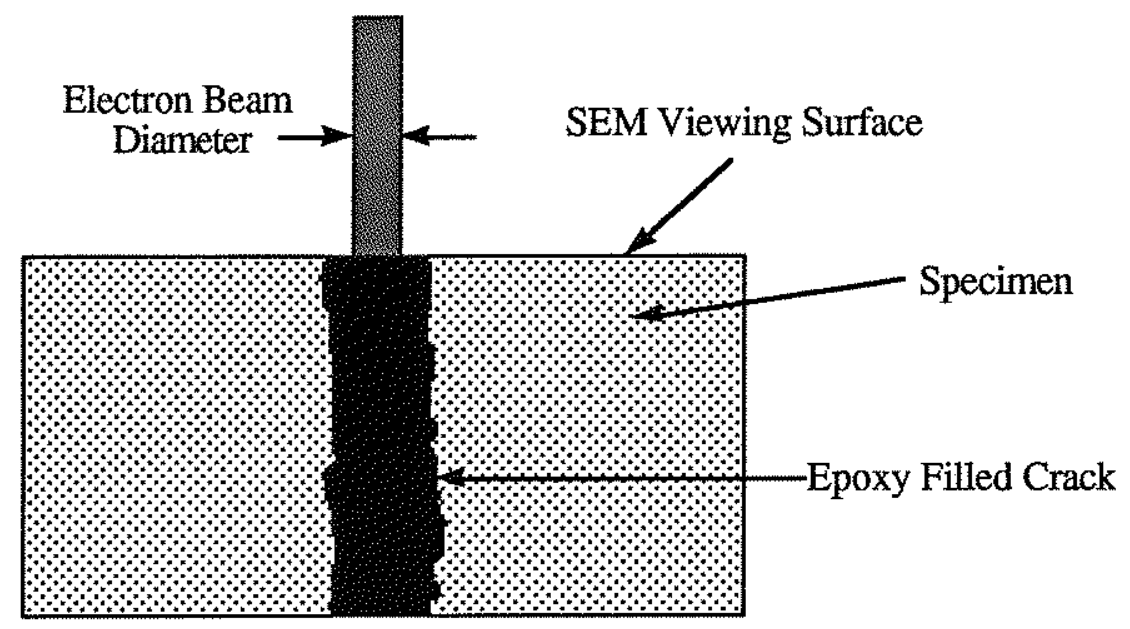

Wide epoxy filled crack with orientation approximately

90 degrees (relative to the horizontal)

(b)

Fig. 3.2: Effect on resolution of wide epoxy filled cracks 


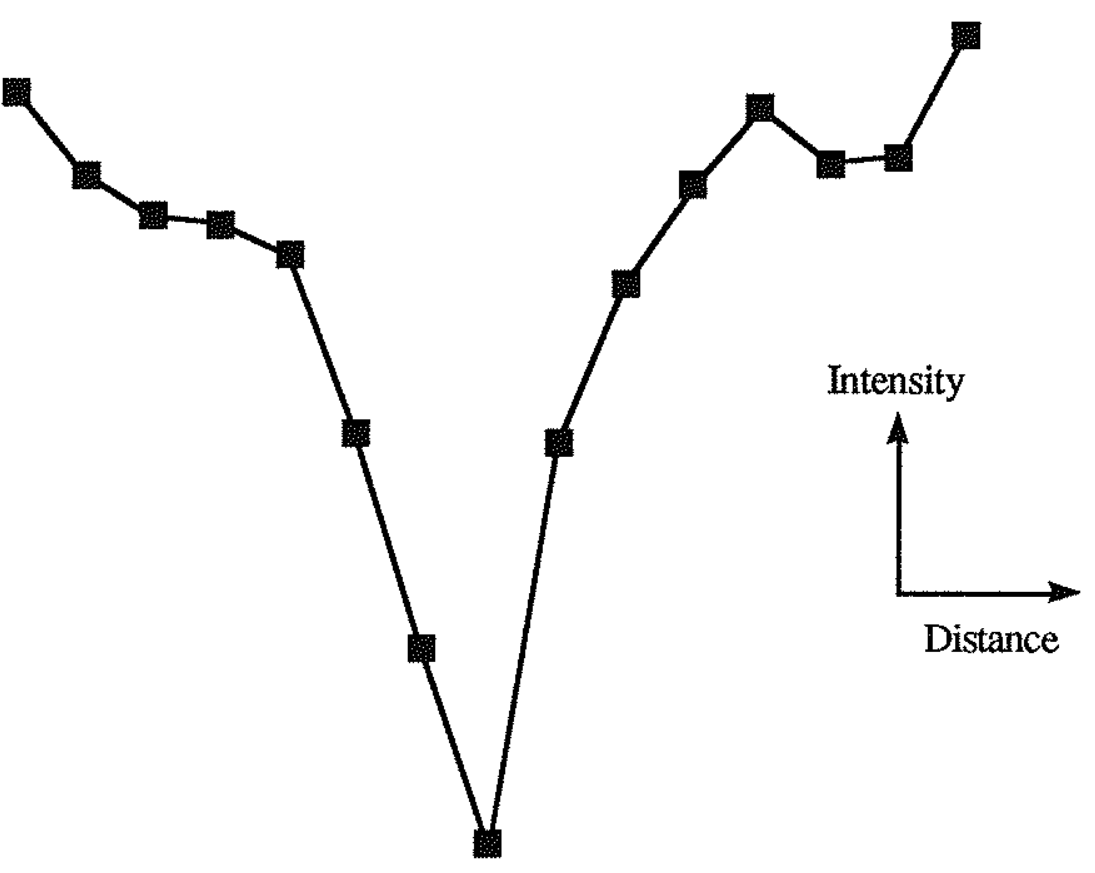

Graphical representation of a line scan

(a)

1601441361341289249990122142157146141172

Integer representation of a line scan

(b)

Fig. 3.3: Graphical and integer representations of a line scan through a crack 


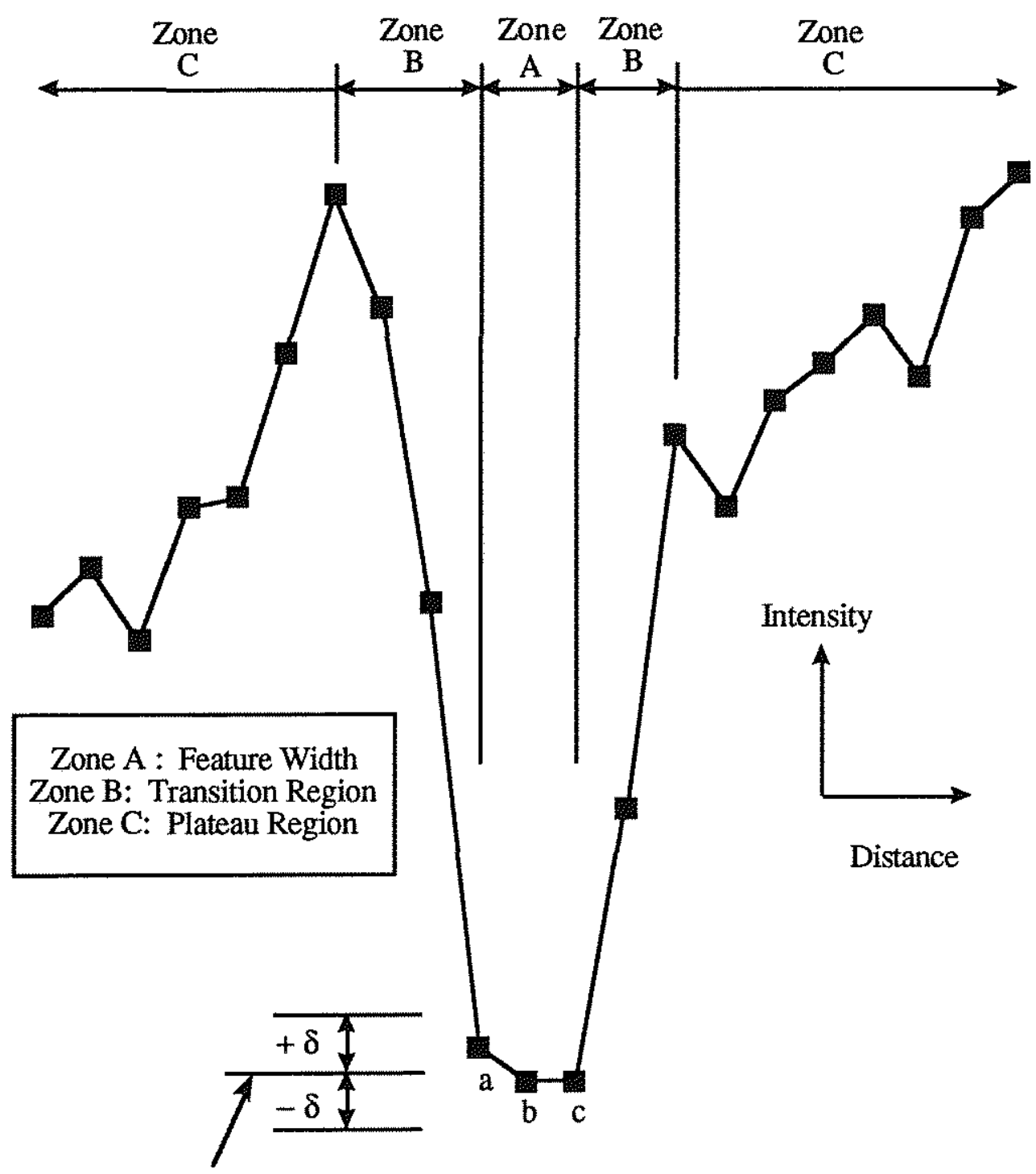

Average pixel intensity, lavg, of $a, b$, and $c$

Pixel intensities $a, b$, and c correspond to the "floor of the feature". Pixel intensities $a$ and $c$ are the "edge pixels".

The $\pm \delta$ corresponds to the maximum intensity variation allowed of any pixel relative to the average intensity, Iavg, within the "floor of the feature".

Fig. 3.4: The floor of a feature (crack), the transition and plateau regions along a line scan 


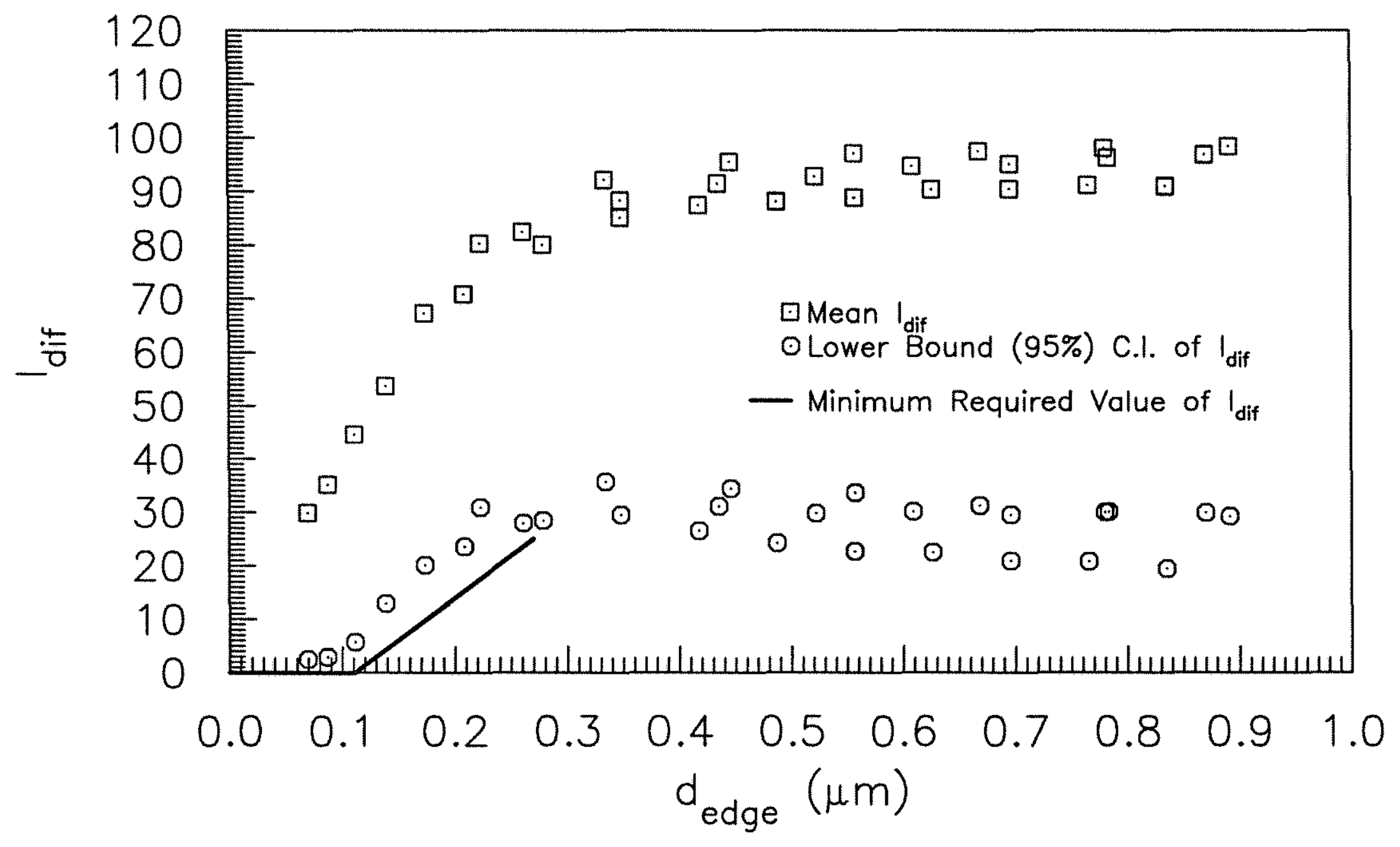

Fig. 3.5: Minimum required value of $I_{\text {dif }}$ as a function of distance away from the edge pixel 


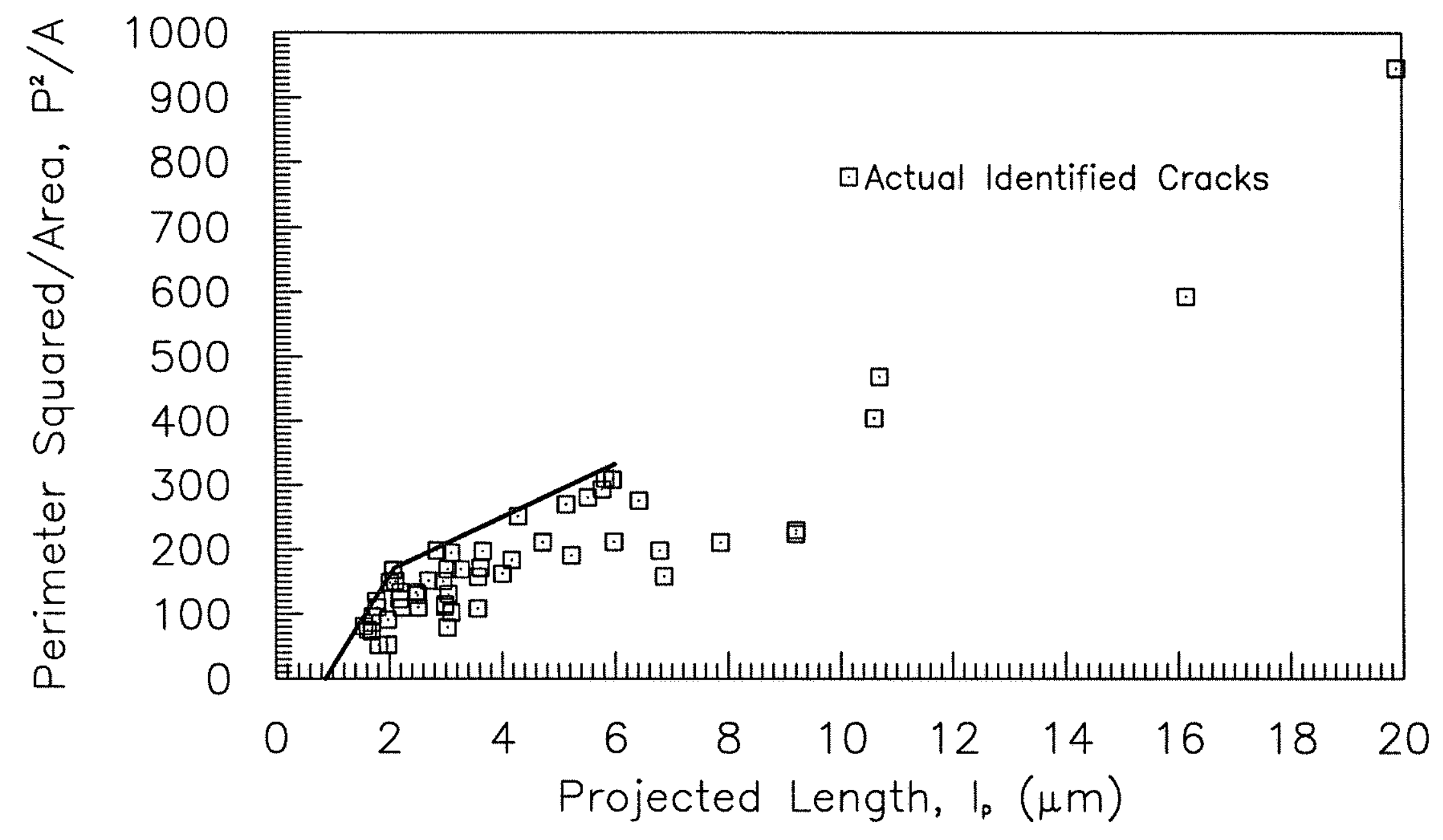




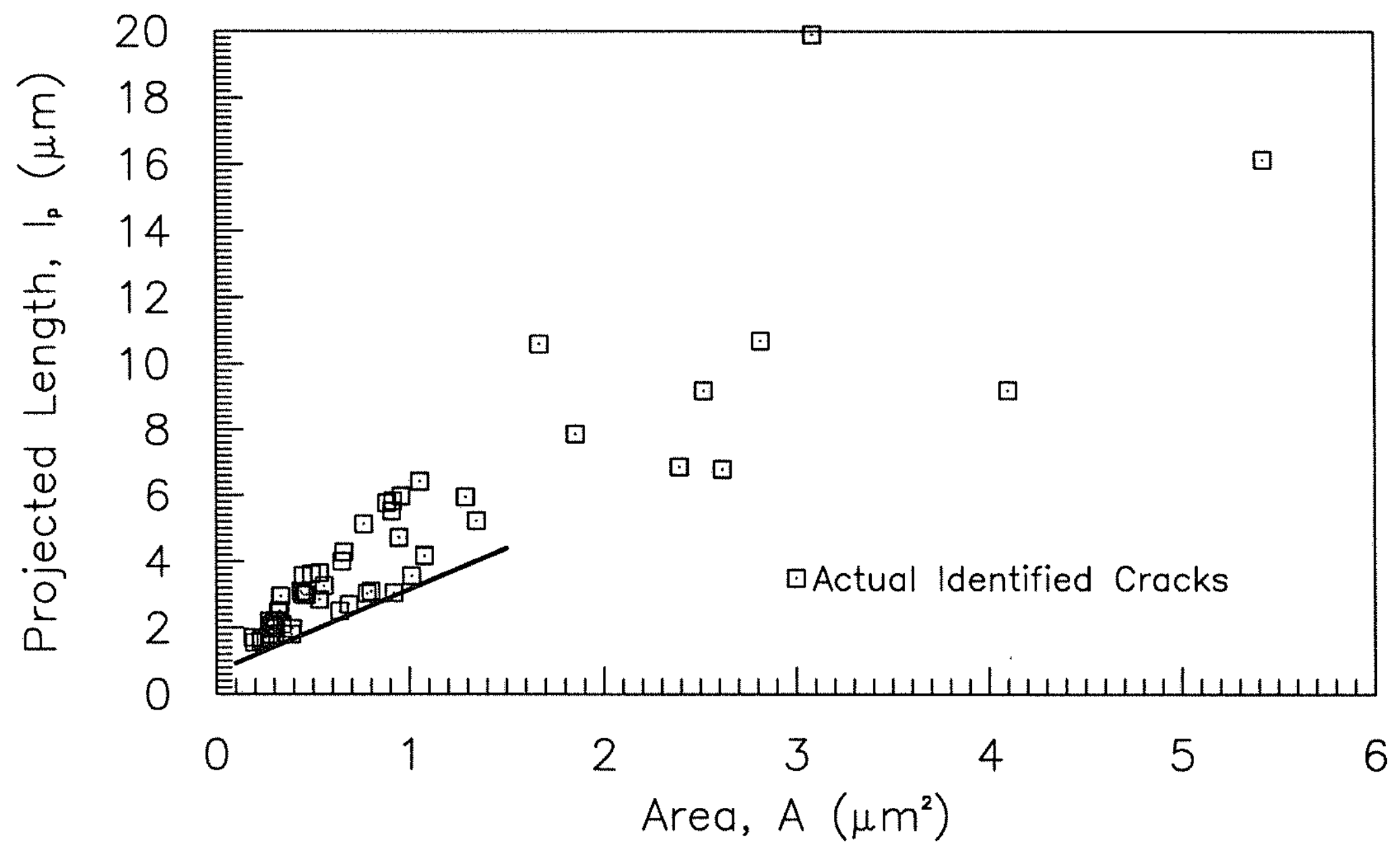




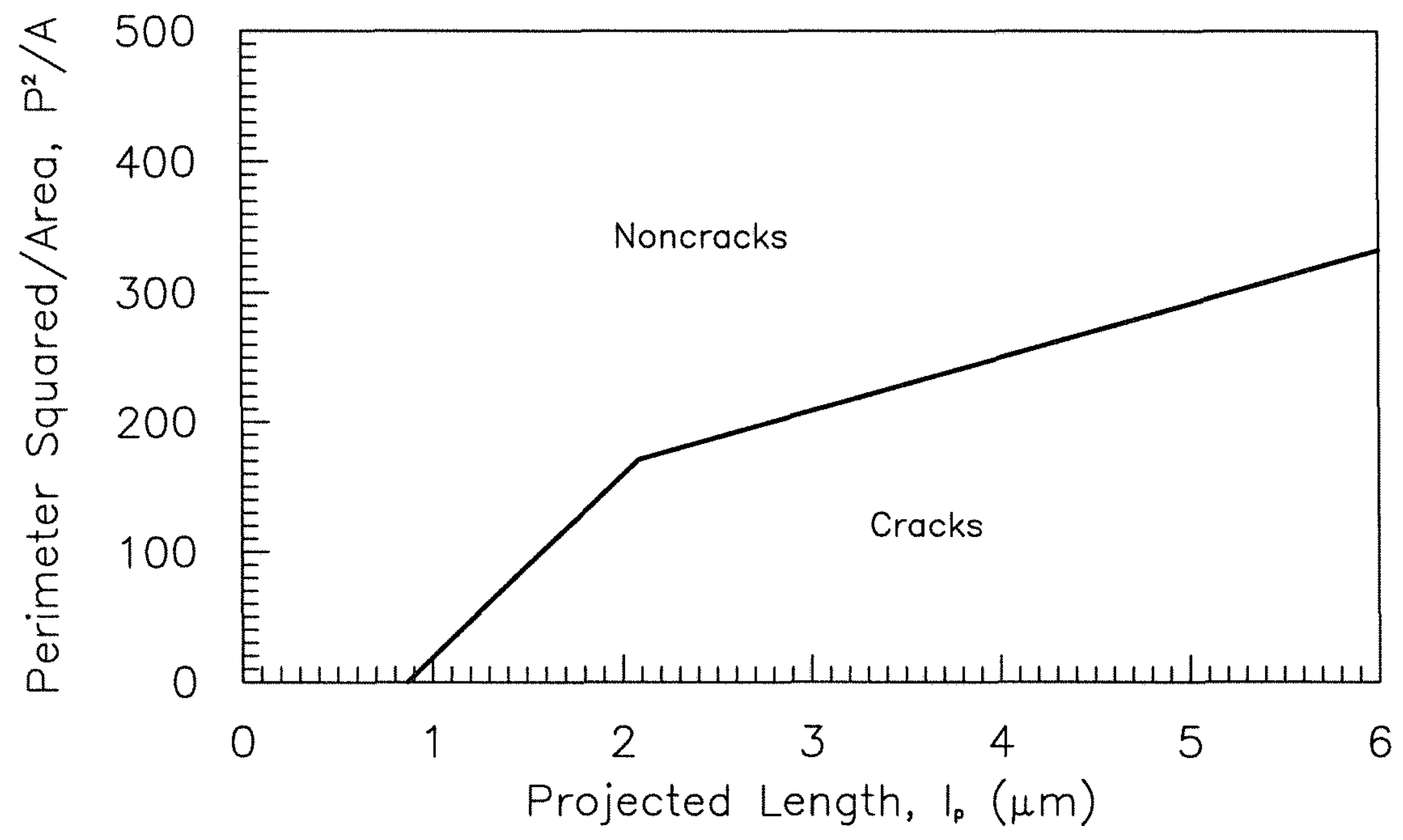

Fig. 3.8: Requirement for perimeter squared to area ratio versus projected length (Cracks and Noncracks) 


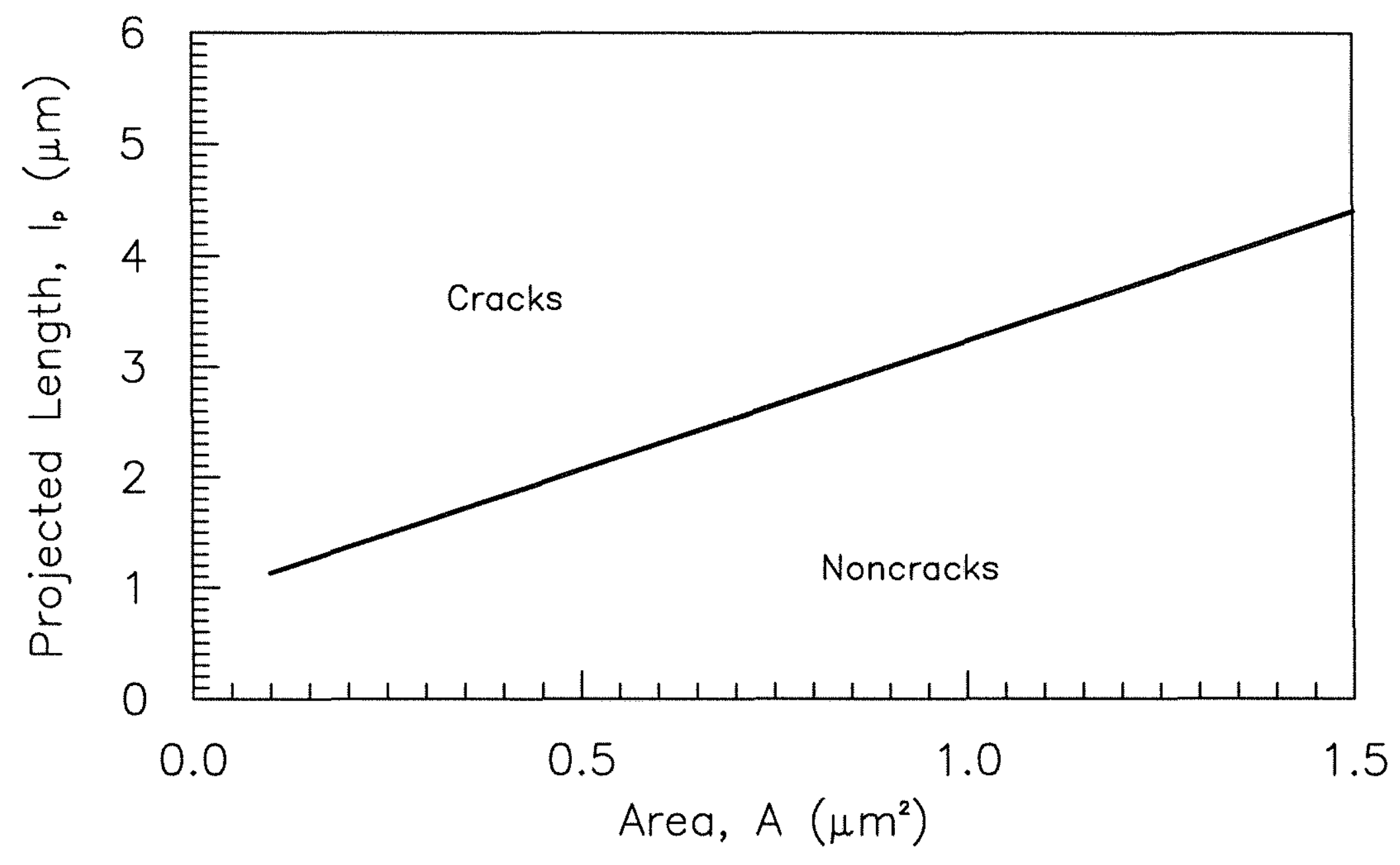

Fig. 3.9: Requirement for projected length versus area (Cracks and Noncracks) 


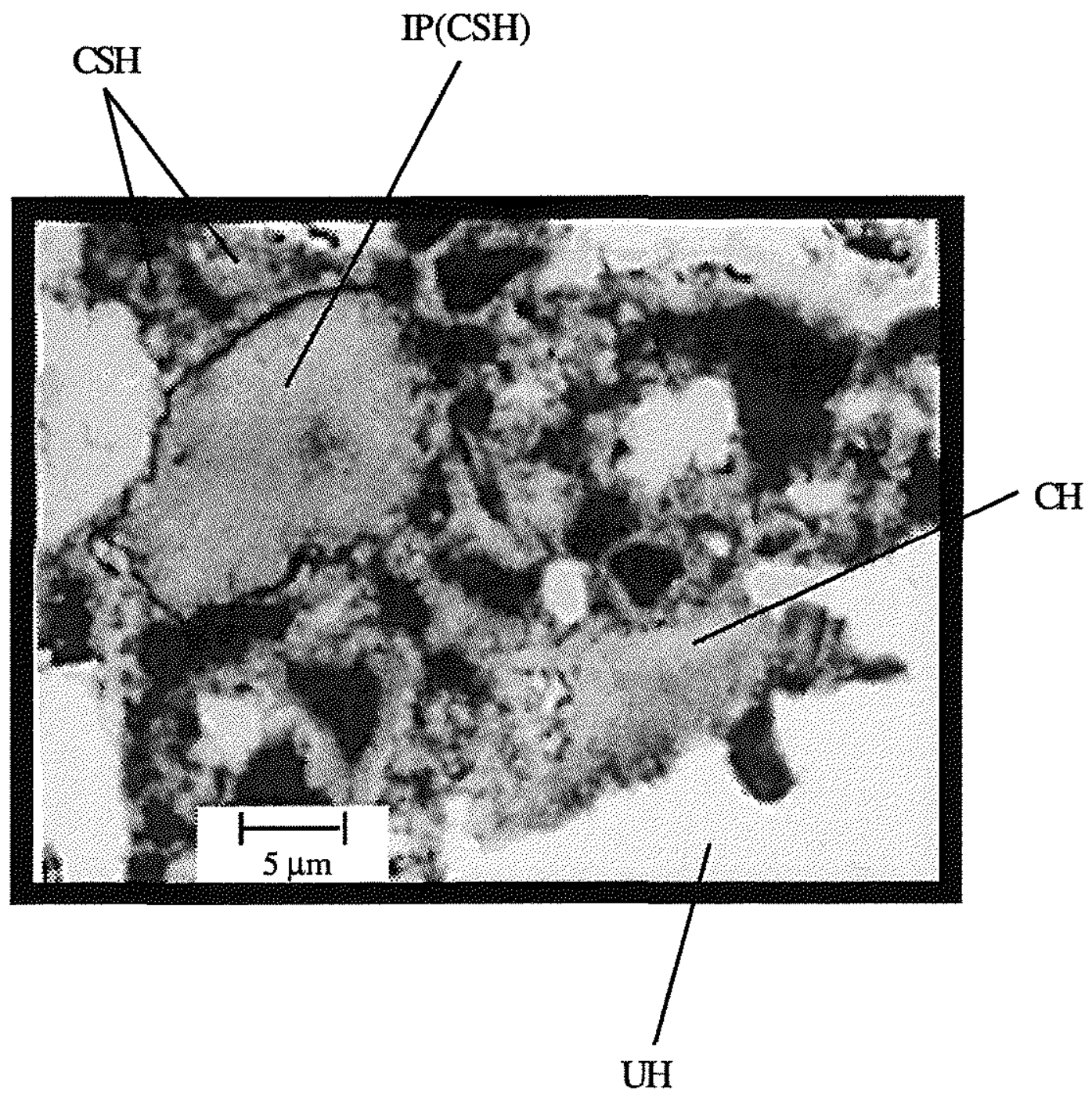

Fig. 4.1a: Basic BSE gray level image of 28 -day old $(w / c=0.5)$ cement paste at 6000 microstrain 


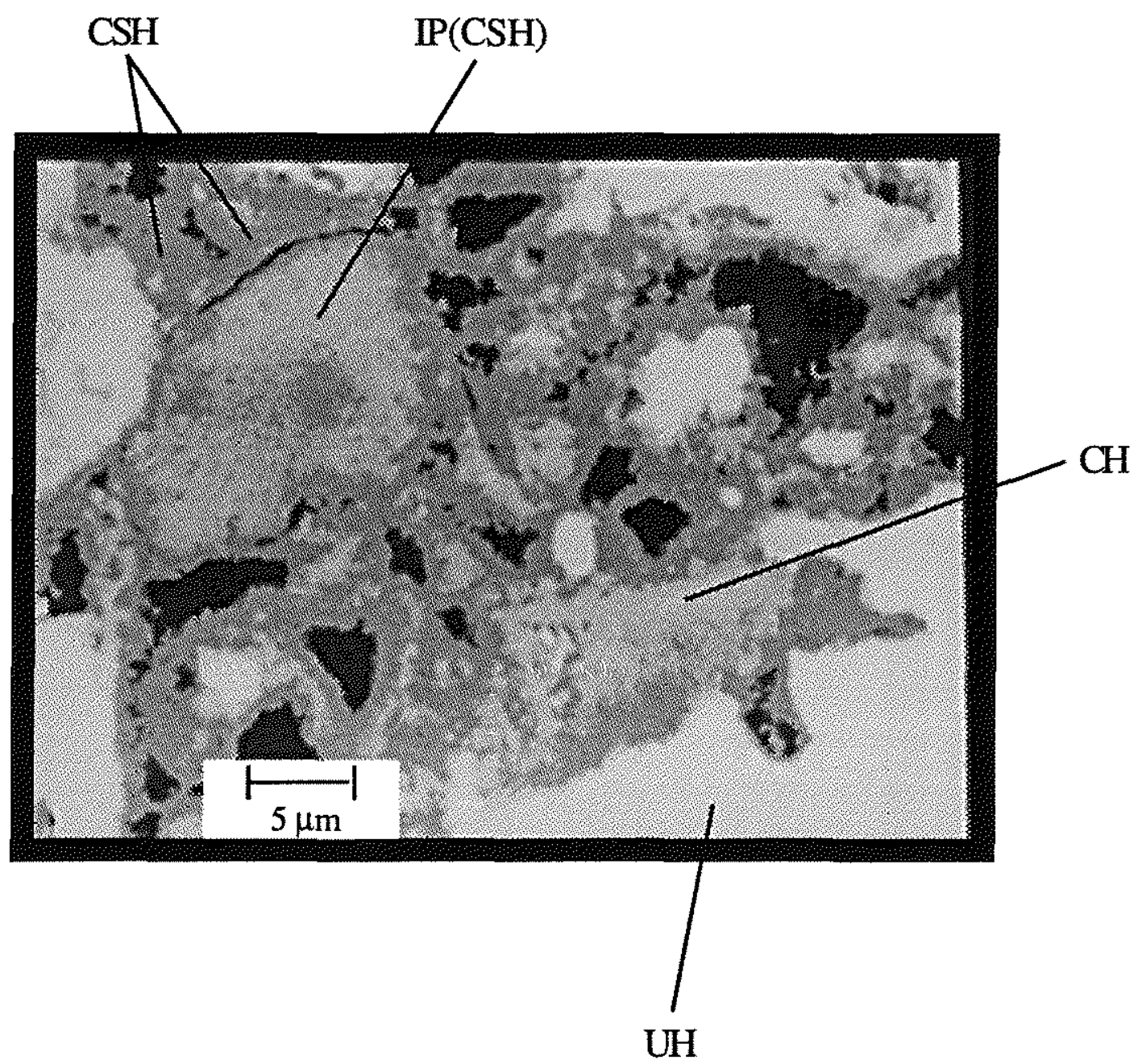

Fig. 4.1b: Thresheld pseudo-color image of Fig. 4.1a 


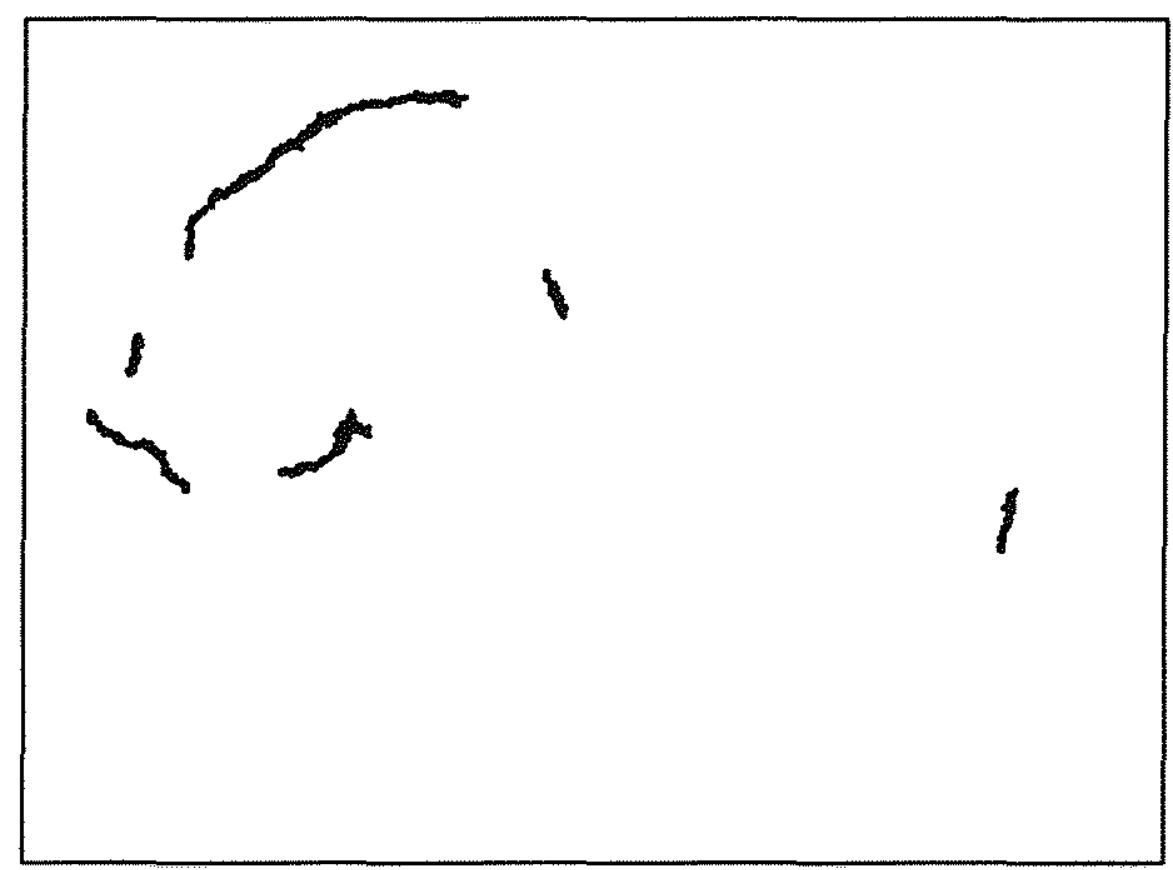

Fig. 4.1c: Cracks identified by computer program for Fig. 4.1a 


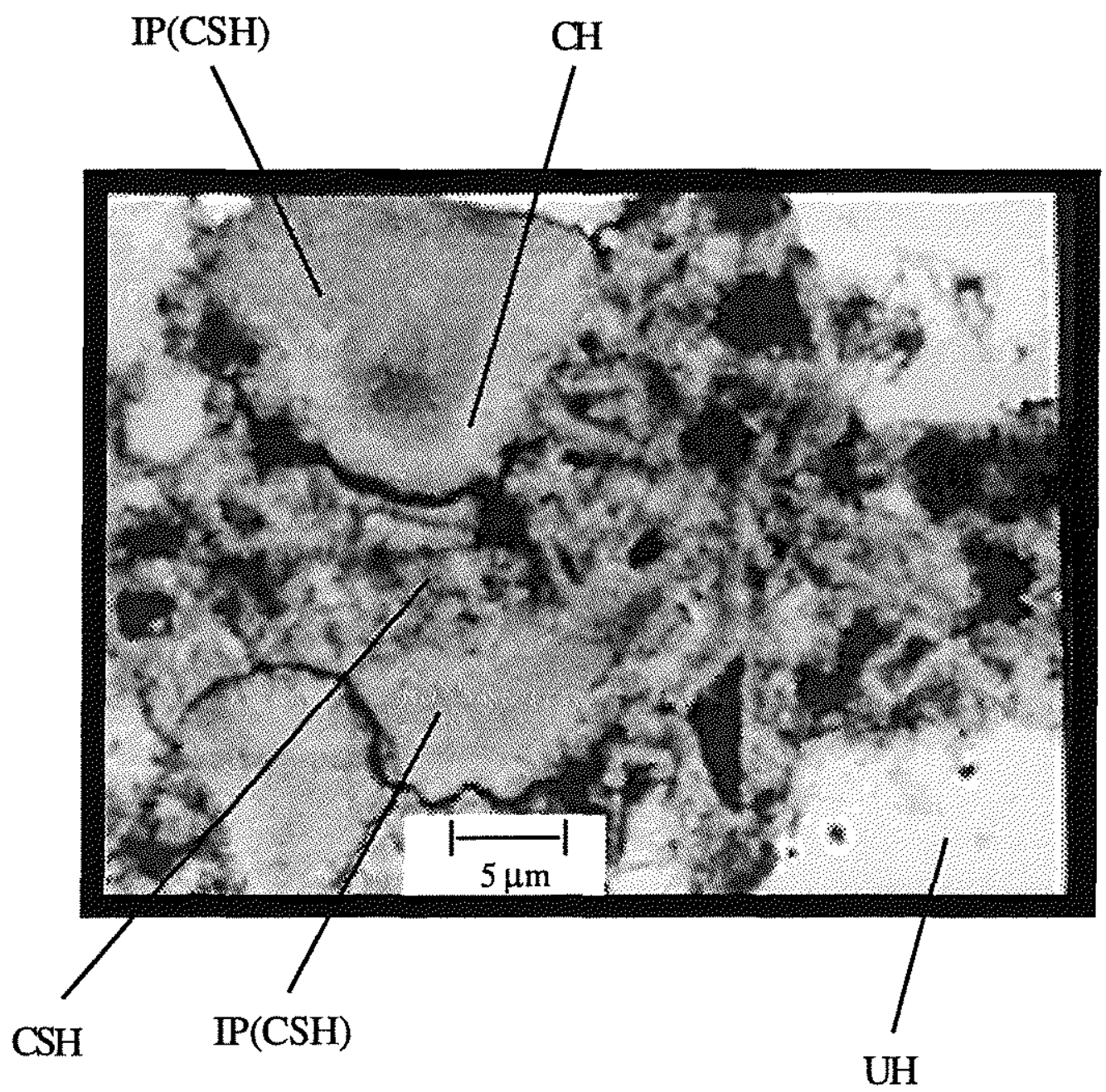

Fig. 4.2a: Basic BSE gray level image of 28 -day old $(\mathrm{w} / \mathrm{c}=0.5)$ cement paste at 6000 microstrain 


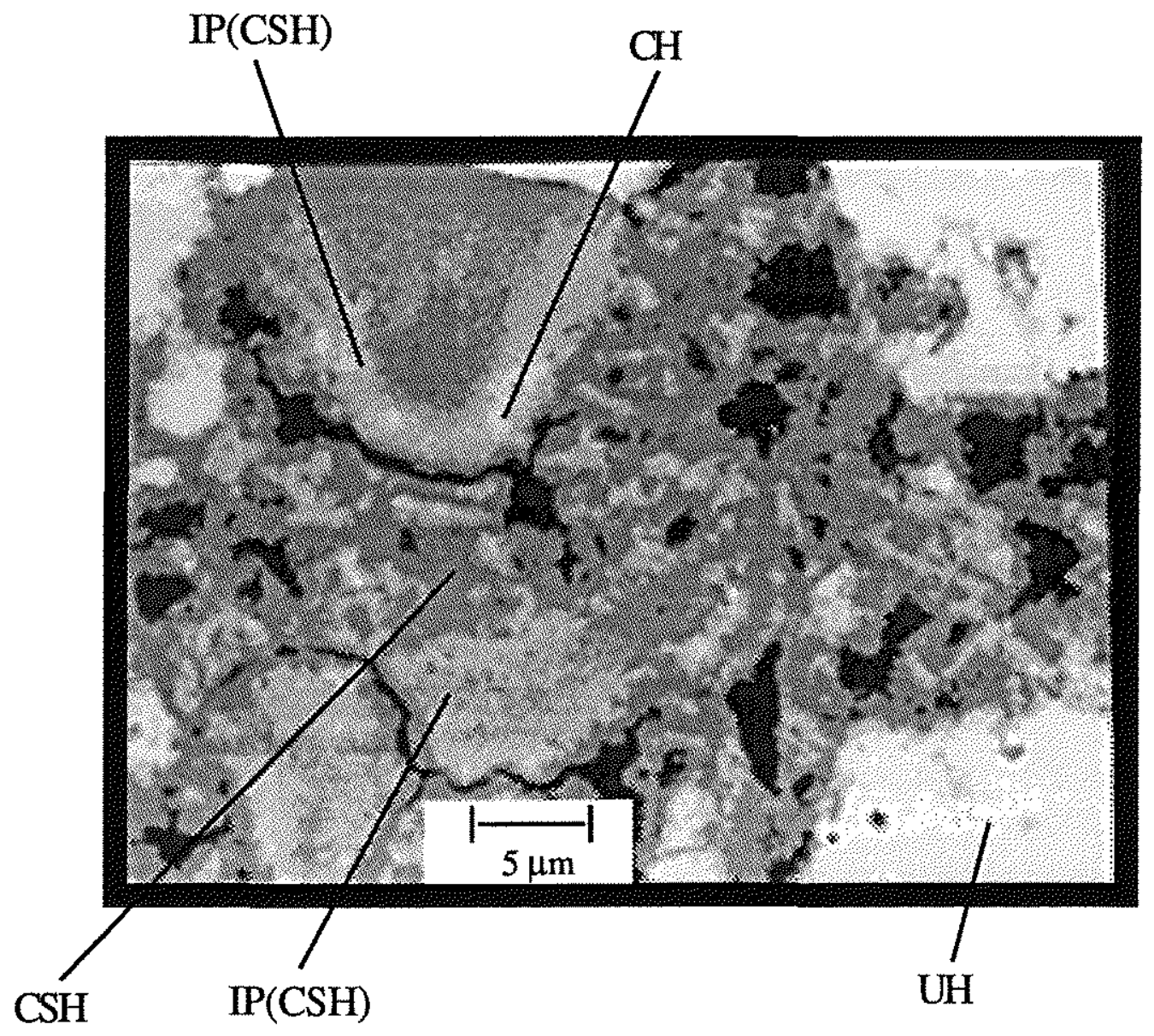

Fig. 4.2b: Thresheld pseudo-color image of Fig. 4.2a 


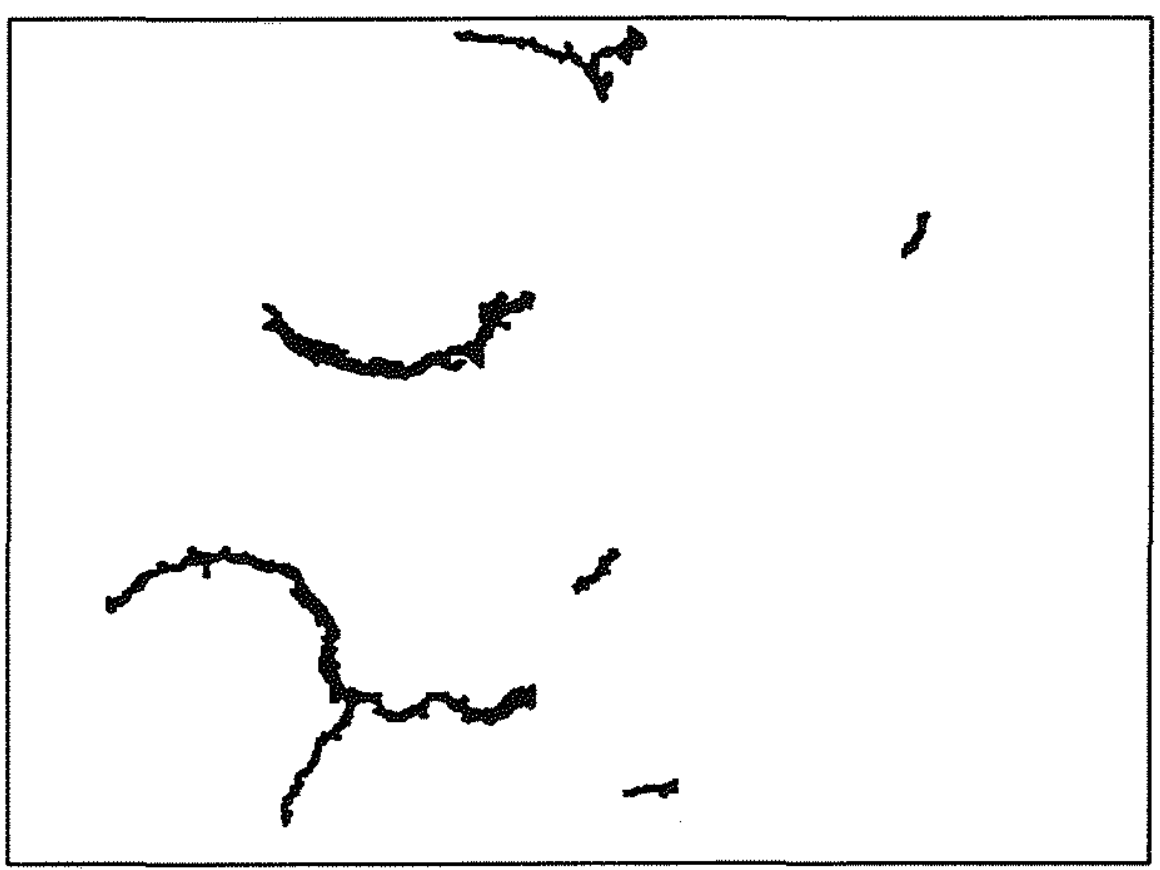

Fig. 4.2c: Cracks identified by computer program for Fig. 4.2a 


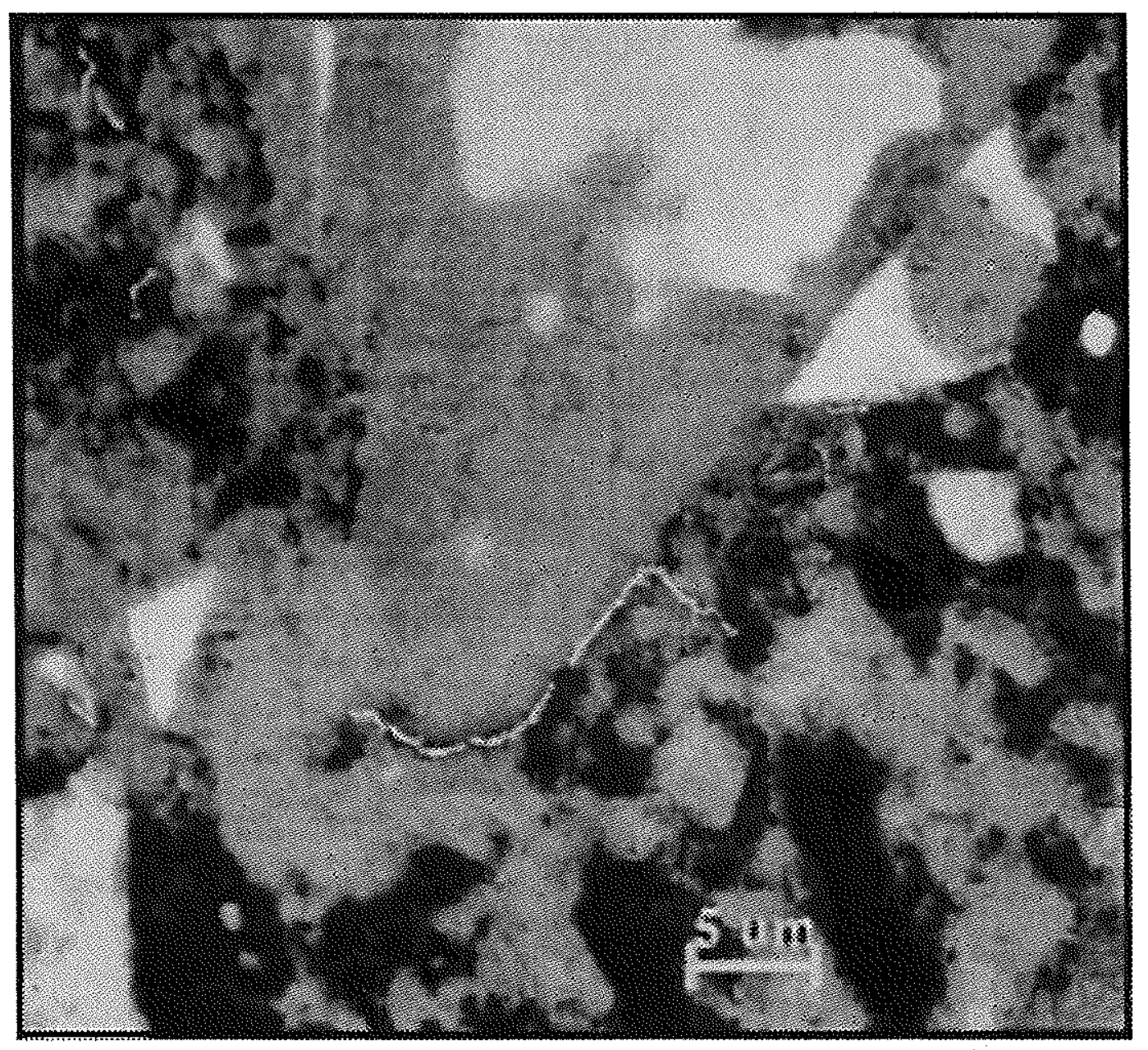

PHASE
COLORS

$\square \mathrm{UH}$

$\mathrm{OCH}$

IP

$\mathrm{CSH}$

VOID
CRACK COLORS

맘

$\mathrm{CH}$

IP

$\mathrm{CSH}$

UHIP

$\mathrm{UH} / \mathrm{CH}$

UHICSH

IPICH

$\square$ IPICSH

$\square \mathrm{CH} / \mathrm{CSH}$

INTERIOR PIXEL

Fig. 4.3: Schematic of computer display showing gray level image of cement paste with cracks identified based on type of cracking (original magnification $=2020 \mathrm{x}$ ) 


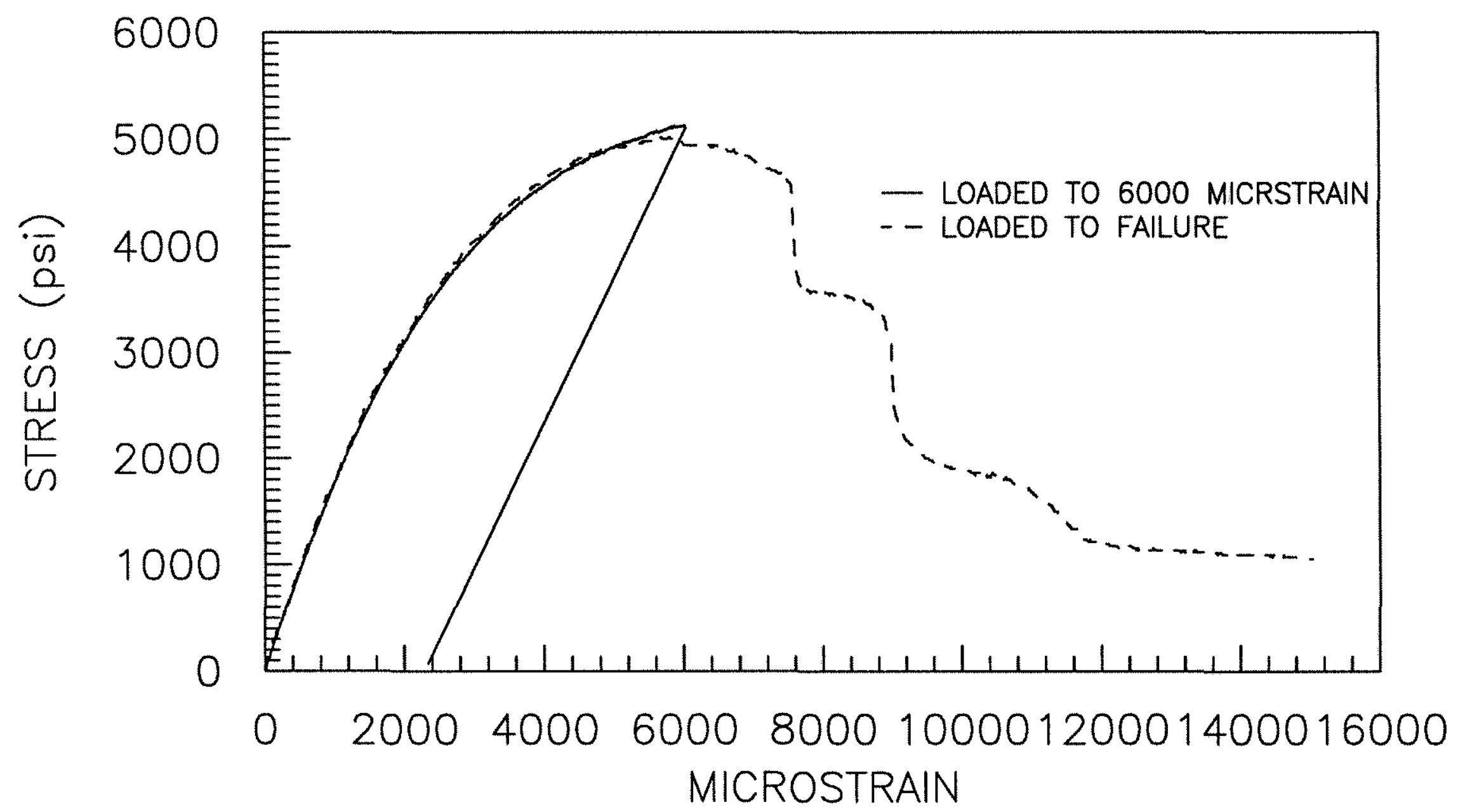

Fig. 4.4: Stress-strain curves of 28-day old $(w / c=0.5)$ cement paste loaded to 6000 microstrain and failure 


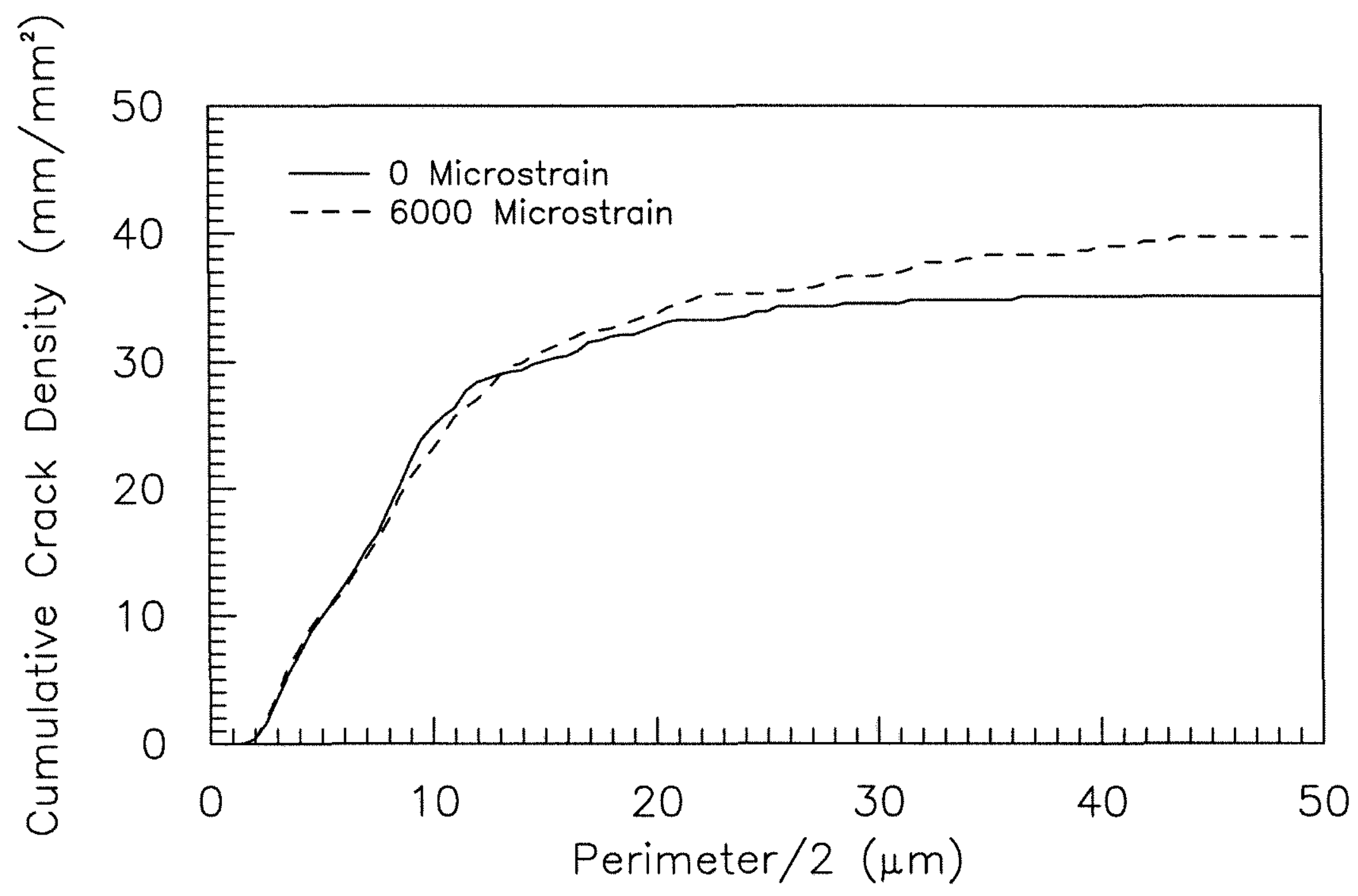

Fig. 4.5: Cumulative crack density, as measured using perimeter divided by 2 , versus the crack size perimeter divided by 2 of 28 -day old $(\mathrm{w} / \mathrm{c}=0.5)$ cement paste at 0 and 6000 microstrain

$$
\text { - 2020x Magnification }
$$




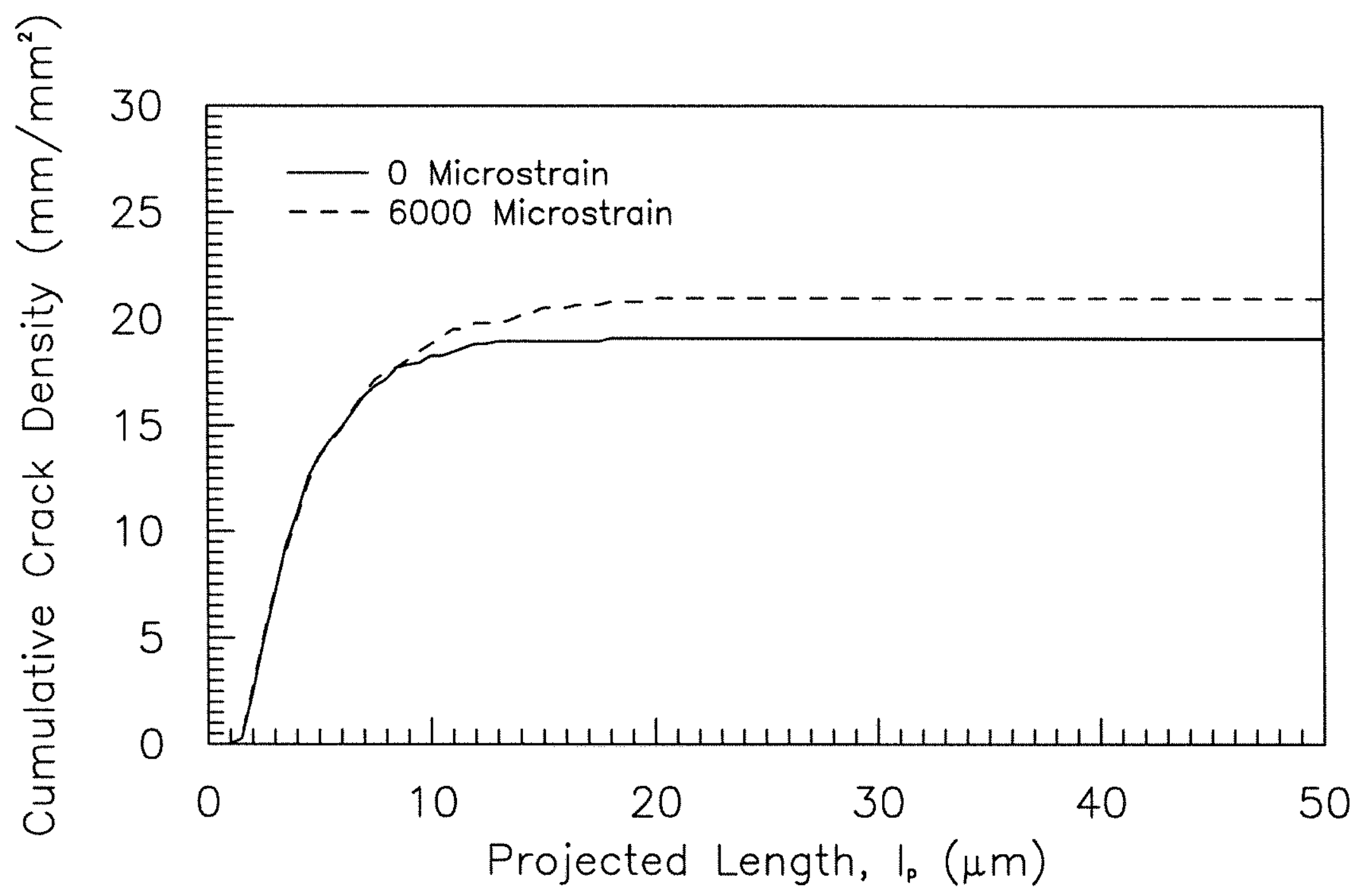

Fig. 4.6: Cumulative crack density, as measured using projected length, versus the crack size projected length of 28 -day old $(\mathrm{w} / \mathrm{c}=0.5)$ cement paste at 0 and 6000 microstrain

$$
-2020 x \text { Magnification }
$$




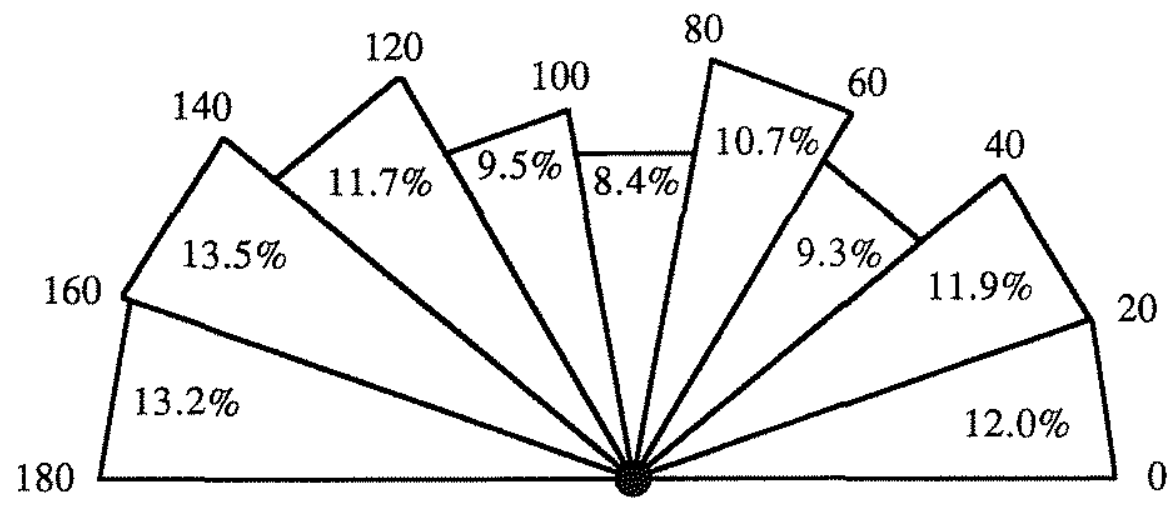

0 Microstrain

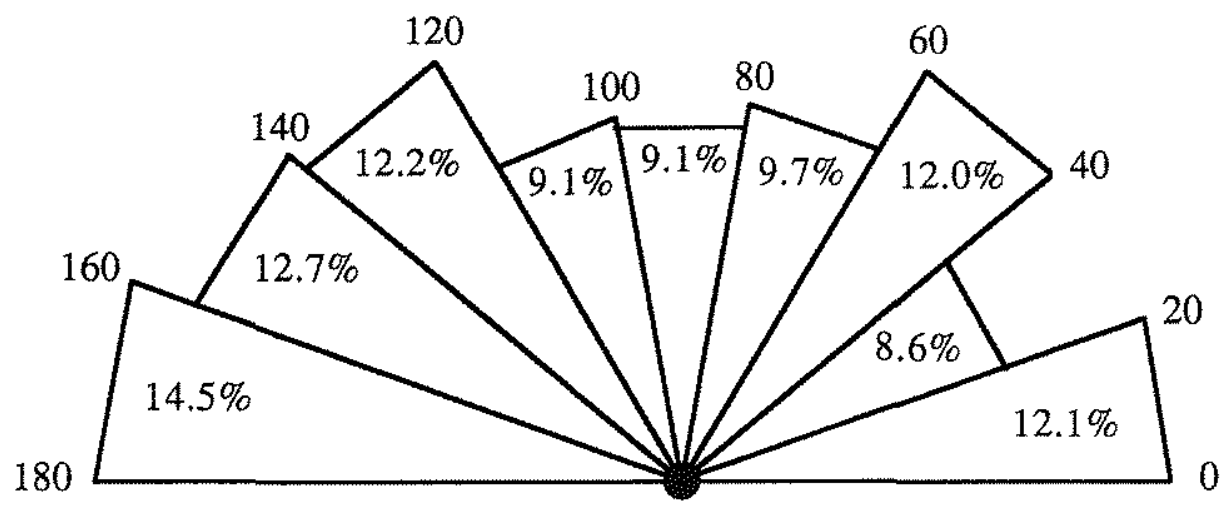

6000 Microstrain

Fig. 4.7: Crack distribution by crack orientation ( 20 degree increments) based on perimeter divided by 2 of 28 -day old $(w / c=0.5)$ cement paste at 0 and 6000 microstrain. Scanned area taken perpendicular to the axis of loading - 2020x Magnification 


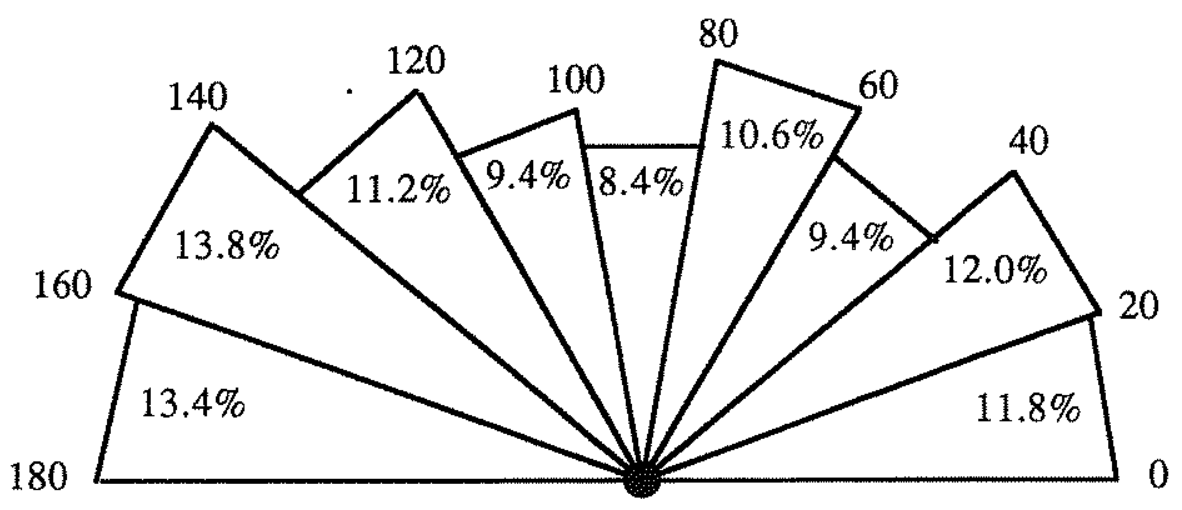

0 Microstrain

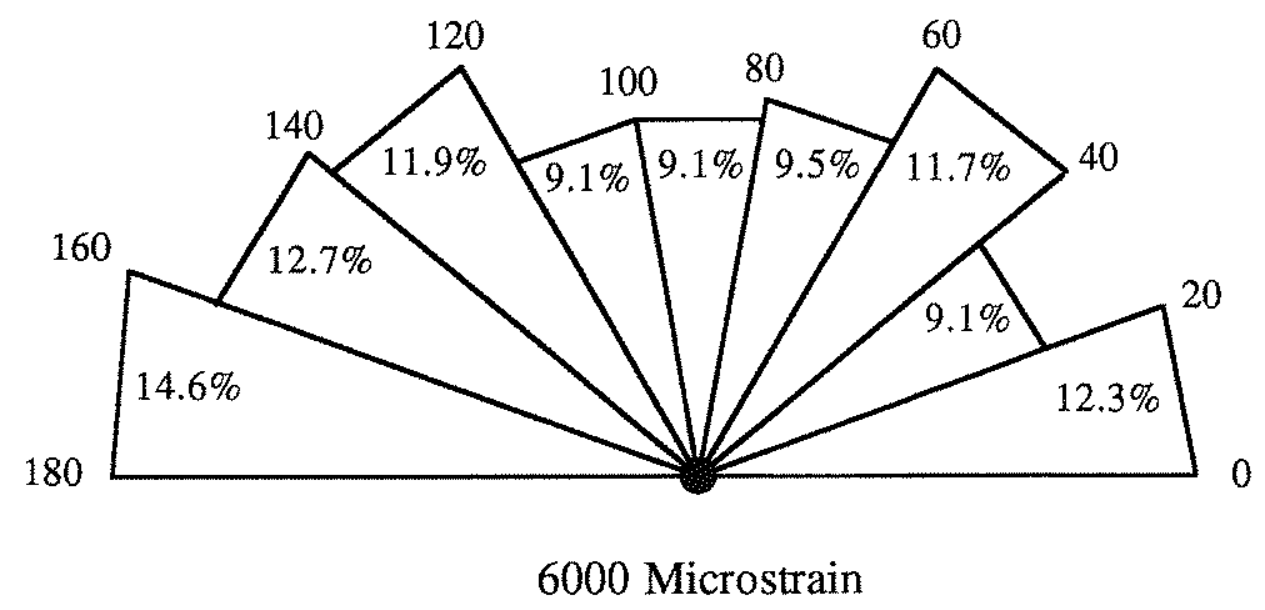

Fig. 4.8: Crack distribution by crack orientation (20 degree increments) based on projected length of 28 -day old $(w / c=0.5)$ cement paste at 0 and 6000 microstrain. Scanned area taken perpendicular to the axis of loading - 2020x Magnification 


\section{APPENDIX A \\ PROCEDURE FOR EPOXY IMPREGNATION OF CEMENT PASTE}

\section{A.1 Chemicals}

The ultra-low viscosity epoxy resin mixture used in this investigation consists of four chemical components: 4-vinylcyclohexene dioxide (VCD), n-octenyl succinic anhydride (OSA), ether of polypropylene glycol (DER-736), and 2-dimethylaminoethanol (DMAE). The VCD makes up the epoxy resin, the OSA is the hardener, the DER-736 is an epoxy modifier, and the DMAE is used as an accelerator for the curing process. The proportions of each of the components may be altered to achieve an epoxy block with the desired polishing characteristics and hardness. Increasing the relative proportion of OSA will increase the hardness of the epoxy block; but it may also cause the epoxy to become brittle, and pieces of epoxy broken off from the mass of an epoxy block can cause scratches in the specimen while polishing the cement paste surface. The epoxy may also become brittle if the relative proportion of the epoxy modifier, DER-736, is decreased. Converse1y, an increase in the epoxy modifier will tend to soften the epoxy block when cured. The epoxy mixture proportions used in this study, by weight ratio are: VCD, 1.0; OSA, 2.45; DER-736, 0.15; DMAE, 0.04. CAUTION: These chemicals must be handled under a fume hood, with proper protection using rubber gloves, goggles, and a proper chemical respirator, since the chemicals are either known or suspected carcinogens and/or dehydrating agents.

The VCD, DER-736, and DMAE can be obtained commercially from several chemical supply houses that sell epoxy embedding media and other SEM preparation supplies. Most often, OSA that is obtained commercially has chemical additives that improve the optical clarity of the cured epoxy, an advantage when using light microscopes. Unfortunately, these chemical additives reduce the vapor pressure of the mixture, causing an increase in the foaming tendency of the OSA, which is undesirable during vacuum impregnation of cement paste specimens. To obtain a low foaming epoxy, the OSA used in this investigation was made to specification by the Humphrey Chemical Co, Inc., P. O. Box 325, Devine Street, North Haven, CT 06473, (203) 281-0012. 


\section{A.2 Equipment}

Glass desiccator (vacuum container) with large opening -- no stems

1 rubber stopper (size 8) with 3 holes for glass tubing

1 rubber stopper (size 8) with no holes

1 straight glass tube, 4 in.

1 straight glass tube, 3 in.

1 bent glass tube $\left(90^{\circ}\right), 6$ in.

1 section Tygon tubing, 2 in.

1 section Tygon tubing, 6 in.

2 sections Tygon tubing, 4 in.

2 tubing clamps

1 hemostat

1 plastic funnel

1 small mixing jar

4 disposable pasteur pipets

1 rubber bulb

1 Rubbermaid (trademark) Servin-Saver® 6 in. $\times 3.5$ in. polyethylene container, $355 \mathrm{ml}$ with lid

vacuum pump

ring stand with clamp

fume hood

scale accurate to $0.001 \mathrm{~g}$

disposable gloves

goggles

respirators

container for hazardous waste 


\section{A.3 Specimen Preparation and Preparation of Epoxy Base}

Before specimens can be vacuum impregnated with epoxy, an epoxy base must be prepared. The Rubbermaid container is used as a non-stick mold for casting the epoxy base, approximately $7 \mathrm{~mm}$ in thickness, used to support the cement paste specimen wafers. The epoxy base can be made without the use of the epoxy impregnation apparatus, since the vacuum is used only for evacuating the air from the cement paste wafers to improve penetration of the epoxy into the specimen when the vacuum is released.

First, enough epoxy ( $94.83 \mathrm{~g}$ total: $26.05 \mathrm{~g}$ VCD, $63.83 \mathrm{~g}$ OSA, $3.91 \mathrm{~g}$ DER-736, and $1.04 \mathrm{~g} \mathrm{DMAE}$ ) is mixed so that the Rubbermaid container will contain at least $7 \mathrm{~mm}$ of liquid epoxy. The Rubbermaid container must be level in the oven so that the epoxy used to make the base has a constant thickness. This is important since the specimen jig, used to insure that each specimen remains the same thickness, cannot be used unless all specimens (with their attached epoxy base) are over $6 \mathrm{~mm}$ thick. The extra millimeter thickness of the epoxy base provides an additional margin of epoxy so that all specimens can be ground down in the jig to the same height as the silicon/magnesium standard. A temperature of $50^{\circ} \mathrm{C}$ is maintained for 24 hours to achieve partial setting of the epoxy mixture. [Note: The epoxy suppliers recommended using total mixture volumes less than $50 \mathrm{~g}$, since excessive heat tends to build up with larger volumes during mixing. Manufacturer recommended curing temperatures range from $60^{\circ}$ to $70^{\circ} \mathrm{C}$. In the current study, it was found that rapid curing at temperatures higher than $50^{\circ} \mathrm{C}$, with the volume of epoxy needed for casting the base, causes the base to cure with a rippled, distorted surface. This type of surface is unacceptable for mounting specimen wafers, since some or part of the wafers would become exposed to air after vacuum impregnation with the epoxy. The lower curing temperature alleviated this problem.] The epoxy base is cooled to room temperature so that it will be ready for mounting the cement paste.

The cement paste wafers are attached to the epoxy base with the SEM viewing face upward, using cyanoacrylate adhesive (super glue). This secures the specimen wafers so that they do not move as the epoxy is injected. Placing the specimens viewing face upward insures that air 
trapped underneath the wafers will not interfere with the final, polished surface. This is especially important since the OSA in the epoxy mixture tends to cause the mixture to foam at low (vacuum) pressure.

\section{A.4 Assembly of Apparatus}

The apparatus used for epoxy impregnation is shown in Fig. A.1. Assembly of the apparatus proceeds as follows: A 3-inch piece of straight glass tubing is inserted into the rubber stopper. Next, a 2-inch piece of Tygon (trademark) rubber tubing and a plastic funnel are attached to the top side of the 3-inch glass tube. The hemostat is clamped onto the Tygon tubing between the funnel and the glass tubing, and the lower portion of the glass tube is inserted through a three-hole rubber stopper that fits into the top of the vacuum container. A straight, 6-inch piece of Tygon tubing is attached to the bottom end of the glass tube. This 6-inch section of tubing can be straightened by clamping it vertically in an oven at $100^{\circ} \mathrm{C}$ for 15 to 20 minutes; it must be straight since it will be used to inject epoxy directly onto the specimen wafers.

Next, a 4-inch piece of Tygon tubing is attached to the 4-inch piece of straight glass tubing and the glass tubing is inserted through the top of another hole in the rubber stopper. This 4-inch piece of tubing will be clamped off and used to bleed air into the vacuum container once the epoxy has been properly injected.

Finally, the glass tubing with the $90^{\circ}$ bend is inserted into the last hole in the top of the rubber stopper. The vacuum pump is connected to the other end of the glass tubing with the $90^{\circ}$ bend using the rubber vacuum hose, secured by a hose clamp. Now the vacuum system is ready for operation.

The Rubbermaid container is placed onto the platform inside the foil-lined glass desiccator (vacuum container). The container, with its level epoxy base and cement paste specimen wafers,

should be levelled so that the $3 \mathrm{~mm}$ layer of injected epoxy will effectively cover the top surfaces of all the specimens. The desiccator lid is placed on top of the vacuum container (moistened with a small amount of vacuum grease on the seal), making certain that the 6-inch rubber tubing is 
centered over the specimens in the Rubbermaid container. It is important to make sure that the rubber tubing is between 5 and $10 \mathrm{~mm}$ higher than the top of the specimen wafers. This will insure that the injected epoxy will cover the specimens without splashing all over the inside of the vacuum container.

Once the rubber stopper and the desiccator lid have been secured on the vacuum container, the funnel should be placed in the clamp on the ringstand so that it stands erect above the rest of the vacuum impregnation apparatus. The apparatus should be evacuated for 5 minutes to achieve a vacuum of approximately $28 \mathrm{in}$. of mercury (a pressure of $6.42 \times 10^{-2}$ torr). While vacuum is being achieved, the epoxy chemicals should be transferred into a suitable glass container for mixing using the disposable pasteur pipets. A typical batch for adequately covering the specimens will total 40.66 grams (11.17 g VCD, $27.36 \mathrm{~g}$ OSA, $1.68 \mathrm{~g}$ DER-736, and $0.45 \mathrm{~g}$ DMAE.) The solution should be stirred vigorously for at least two minutes with one of the pipets to insure complete mixing. The solution is then transferred to the funnel above the vacuum desiccator.

Once the proper vacuum pressure has been achieved, the vacuum pump is shut off and the hemostat which is clamping the tubing attached to the funnel is slowly released. The epoxy is injected over the specimen wafers; care should be taken to monitor the epoxy fluid level as it leaves the funnel. Epoxy injection should take no more than 30 seconds. The hemostat should be clamped onto the tubing before any air is allowed to enter the desiccator. After 5 minutes, the vacuum is released by releasing the clamp to slowly (approximately 3 minutes) bring the vacuum container back to atmospheric pressure. Strict adherence to this procedure will insure adequate epoxy penetration, even into specimens with low permeability, such as cement paste containing silica fume.

\section{A.5 Disassembly of Apparatus and Curing of Epoxy-Impregnated Wafers}

The vacuum pump is detached from the epoxy impregnation apparatus. The funnel is then unclamped from the ringstand and the stopper is carefully removed from the desiccator lid. The apparatus should be set aside so as not to spill the residual epoxy solution. The desiccator lid is 
removed, taking care not to jar the contents inside the vacuum desiccator. The Rubbermaid container is next lifted out of the desiccator, and the lid is secured, insuring a tight seal. The container should be kept as level as possible so as not to expose the specimens. The container must remain sealed while polymerization of the epoxy takes place in the oven, since the OSA (a dehydrating agent) will draw in water vapor from the atmosphere and prevent the epoxy from curing properly.

The stopper, tubing, and funnel apparatus are placed inside of the foil-lined glass desiccator so that no residual epoxy comes in contact with the glass. This will prevent the epoxy from causing the apparatus to stick to the inside of the glass desiccator. The desiccator lid is replaced, and the solid stopper is placed in the top of the lid. The pipets, mixing jars, and towels used for cleaning residual or spilled epoxy should be collected; dispose in a suitable, hazardous waste container.

The sealed desiccator and the specimen container are placed in an oven at $50^{\circ} \mathrm{C}$ for 24 hours, then at $70^{\circ} \mathrm{C}$ for 48 hours. The lower initial temperature is used to allow the epoxy to harden slowly and uniformly, while the higher temperature is used to allow for a harder epoxy block adequate for polishing (soft blocks are difficult to polish). The Rubbermaid container should be placed in an plastic bag so that any epoxy that might have been spilled on the outside of the container will polymerize in the oven. NOTE: Again, the Rubbermaid container with the specimens should be placed on a level surface inside the oven for proper curing.

After curing the impregnated specimens, the entire block of specimens is removed by sacrificing the Rubbermaid mold and tearing out the block of specimens. Specimens can be individually sectioned from the epoxy block, using a band saw, in preparation for the polishing process described earlier in this report. 


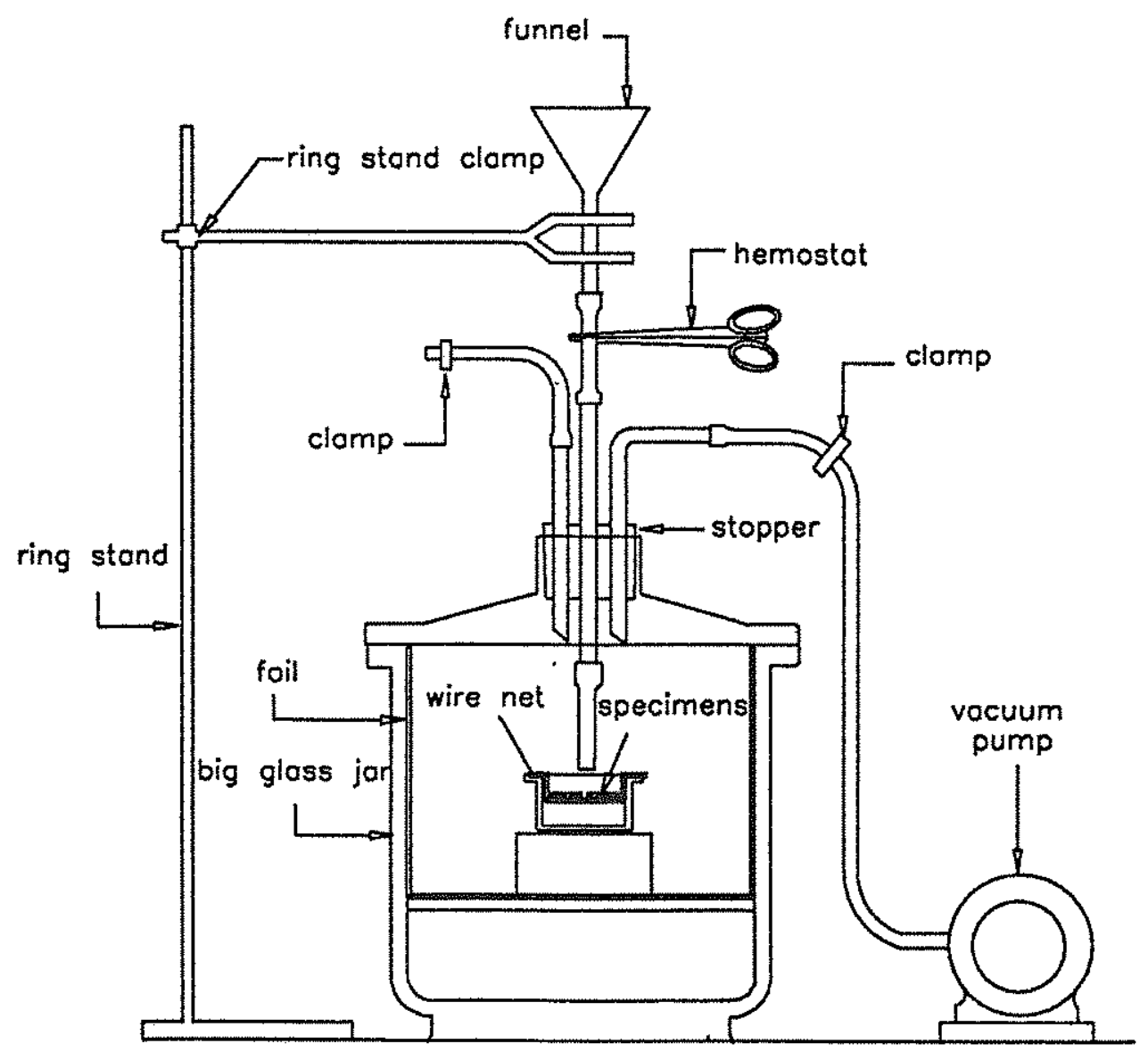

Fig. A.1: Apparatus for epoxy impregnation of cement paste specimens 